\title{
Долговечность \\ полимерных композитов
}

А.Я. Башкарев, В.И. Веттегрень,

М.А. Суслов 


\section{Оглавление}

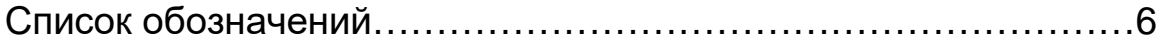

Переводные множители..........................................

Введение......................................................

1. Механизм разрушения полимерных материалов и композитов

1.1. Роль термических фрлуктуаций в механизме разрушения полимеров и композитов...................................... 15

1.2. Возбужденные («перенапряженные») химические связи...19

1.3. Разрывы полимерных молекул.................................25

1.4. Трещины и механизм их укрупнения........................27

2. Кинетика разрушения полимеров и композитов на их основе в широком диапазоне температур................................28 2.1. Температурные зависимости прочности полимеров .

2.2. Энергия активации разрушения композитов в диапазоне

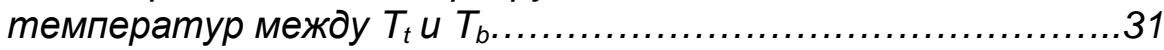
2.3. Влияние статистики молекулярных колебаний на кинетику разрушения полимеров и композитов..................34 2.4. Временная зависимость прочности при $T<T_{t} \ldots \ldots \ldots \ldots . . . . .39$ 2.5. Описание температурно-временной зависимости

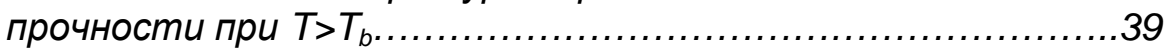
2.6. Температурная зависимость прочности трехмерно армированного углерод-углеродного композита.................43 2.7. К вопросу о величине параметров $U_{0}$ и $ү \ldots \ldots \ldots \ldots \ldots \ldots . . . . . . .49$ Заключение.......................................................5 3. Граничные слои и их влияние на прочность композитов..51 Введение

3.1. Внутренние напряжения в граничных слоях и их влияние на прочность композитов....................................51 3.1.1. Напряжения, вызванные адгезионной связью полимеров с металлами..................................................... 51 3.1.2. Внутренние напряжения, обусловленные различием КТР полимера и металла............................................... 61 3.2. Динамика прочности адгезионных соединений между полимерами и металлами. 
3.3. Влияние формы и концентрации частиц наполнителя на прочность композитов............................................69

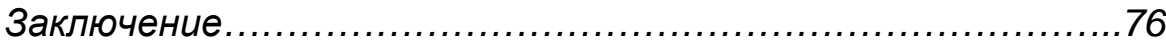

4. Механизм и кинетика трения полимеров и полимерных композитов.......................................................... 75

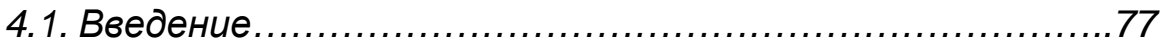

4.2. Кинетика изнашивания.................................. 77

4.2.1. Определение температуры в зоне трения....................78

4.2.2. Кинетика разогрева при трении............................. 81

4.2.3. Зависимость фррикционных параметров от давления......85

4.2.4. Кинетика изнашивания наполненных композитов...........86

4.2.5. Зависимость силы трения между композиционным

материалом и металлическим контртелом от температуры.....91

4.2.6. Кинетика разогрева в области температур, превышающих

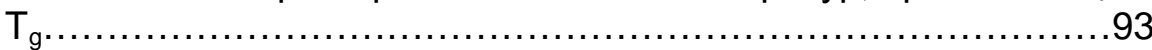

4.3. Деструкция полимеров и полимерных композитов при

трении........................................................ 95

4.4. Определение допустимого давления в узле трения........97

4.5. Динамика разрушения при трении волокнистого

композита....................................................99

4.6. Зависимость коэфрфициента трения композита от свойств матрицы 101

Заключение...................................................107

5. Влияние окружающей атмосферы на кинетику разрушения106 5.1. Влияние воды на кинетику разрушения под действием растягивающих напряжений....................................108 5.2. Напряжения в граничных слоях с воздушной атмосфрерой и их влияние на кинетику разрушения...........................118 5.3. Влияние окружающей среды на трибологические свойства композитов.....................................................123

Заключение.................................................. 125

6. Влияние формы и концентрации частиц наполнителя на теплофизические свойства композитов........................126

Введение.................................................. 126

6.1.1. Температуропроводность композитов...................126

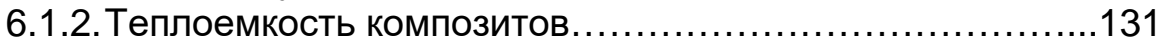


6.2. Коэфрфициент теплового расиирения композитов.......133 Заключение................................................. 137 Список использованных источников ........................... 138 


\section{Список обозначений}

ИК - инфракрасная;

износ - изменение размеров образца при трении;

К-300 - кремнийорганическая смола, отвержденная низкомолекулярным полимером;

КВС-31 -блоксополимер эпоксидной диановой смолы и низкомолекулярного бутадиеннитрильного каучука с концевыми карбоксильными группами;

КГ-1М - блок-сополимер эпоксидной диановой смолы, бутадиеннитрильного карбоксилированного каучука и кремнийсодержащий олигомера;

КДС-19 - блок-сополимер эпоксидной диановой смолы, бутадиеннитрильного карбоксилированного каучука и мета - изомера три(карборан - себацинат)глицида;

Криосил - Эпоксикремнийорганический клей;

КТР - коэффициент теплового расширения;

МЛ - механолюминесценция;

НПВО - нарушенное полное внутреннее отражение;

ПА 6 - полиамид 6;

ПА 6,6 - сополимер полиамидов 6;

ПА 66/6 - сополимер полиамидов 66 и 6 ;

ПА 5,4 - сополимер полиамидов 5 и 4;

ПАБИ - полиамидбензиимидазол;

ПАИС - поли-бис-малеимид на основе 4,4' - диаминодифенилметана и 4,4'-(N, N' - бис-малеимида) дифенилметана.

ПАН - полиакрилонитрил;

ПВХ - поливинилхлорид;

ПММА - полиметилметакрилат;

ПМ - полипромеллитимид;

ПМ-67 - полиимид на основе диангидрида дифенилоксида тетракарбоновой кислоты и диаминдифенилового эфира;

ПМ-69 - полиимид на основе ангидрида бензофенонтетракарбоновой кислоты и диаминдифенилового эфира;

ПОМ - полиоксиметилен;

ПП - полипропилен; 
ПС - полистирол;

ПТФЭ - политетрафторэтилен;

ПФО - полифениленоксид;

ПФС - Полифениленсульфид;

ПФХ-3А - Полифенилхиноксалин на основе 3,3' и 4,4' тетрааминодифенилоксида и 1,4'-бис - (фенилоксил) бензола.

ПЭ - полиэтилен;

ПЭТФ - полиэтилентерефталат;

ПЭ - Полиэтилен.

ЭПР - электронный парамагнитный резонанс;

$\mathrm{Ar}^{2+}$ - дважды ионизированный атом аргона

$a-$ коэффициент температуропроводности;

$a_{c}$ - коэффициент температуропроводности композита;

$a_{f}-$ коэффициент температуропроводности наполнителя;

$a_{m}-$ коэффициент температуропроводности матрицы;

$\mathrm{B}=\gamma / \mathrm{kT}$

C-C - связь между атомами углерода;

$\mathrm{C}_{\mathrm{cr}}$ - концентрация трещин;

$\mathrm{C}_{\text {об }}$ - объемная концентрация.

$\mathrm{C}_{\mathrm{V}}$ - теплоемкость;

$\mathrm{C}_{\mathrm{V}}(\mathrm{T})$ - теплоемкость при температуре $\mathrm{T}$;

$\mathrm{C}_{\mathrm{Vcl}}-$ классическое значение теплоемкости;

$\mathrm{C}_{\mathrm{vol}}$ - концентрация.

C* - «разорванная» углерод - углеродная химическая связь - свободный радикал;

$\dot{\mathrm{C}}_{0}$ - эмпирическая постоянная;

$\tilde{\mathrm{N}}_{\mathrm{d}}$ - скорость накопления возбужденных связей после нагружения полимера или скачкообразного увеличения температуры;

$\dot{\mathrm{C}}_{\mathrm{f}}$ - скорость разрушения;

$\left\langle\mathrm{D}_{\mathrm{cr}}>\right.$ - средний размер трещины;

d - диаметр поры;

$\mathrm{d}_{\mathrm{f}}$ - диаметр частиц наполнителя;

$\mathrm{d} \sigma / \mathrm{dt}$ - скорость увеличения адгезионной прочности покрытия;

$\mathrm{d} \Delta \sigma / \mathrm{dt}$ - скорость уменьшения адгезионной прочности покрытия;

Е - энергия электронного перехода; 
$\mathrm{E}_{\mathrm{c}}$ - модуль упругости полимерной молекулы;

$\mathrm{F}_{\mathrm{f}}$ - сила трения;

$\mathrm{E}_{\mathrm{g}}$ - энергия активации процесса гидролиза в напряженном полимеpe;

$\mathrm{F}_{\mathrm{s}}$ - квазистационароное значение силы трения;

$\mathrm{E}_{\mathrm{p}}$ - модуль упругости полимера;

$\mathrm{E}_{0 \mathrm{~g}}$ - энергия активации процесса гидролиза в ненапряженном полимере;

$\mathrm{F}_{\mathrm{q}}(\mathrm{T})$ - квантовая функция;

$\mathrm{F}(\mathrm{x})$ - плотность теплового источника;

$\mathrm{F}_{\mathrm{q}}(0)$ - значение квантовой функции при $\mathrm{T}<\mathrm{T}_{\mathrm{t}}$;

$\mathrm{F}_{0 \mathrm{f}}$ - максимальное значение силы трения;

$\mathrm{f}_{\mathrm{t}}$ - коэффициент трения

$\mathrm{f}\left(\mathrm{v}_{\mathrm{m}}\right)$ - распределение частот максимумов $v_{\mathrm{m}}$ элементарных полос;

G - параметр Грюнайзена;

h - постоянная Планка;

k - константа Больцмана;

$\mathrm{k}_{\mathrm{f}}$ - константа скорости разрушения;

$\mathrm{k}_{\mathrm{g}}$ - константа скорости гидролиза;

$\mathrm{k}_{\mathrm{r}}$ - константа скорости накопления разрывов химических связей;

$\mathrm{k}_{\mathrm{s}}$ - константа скорости упрочнения, вызванного отвердеванием образца;

$\mathrm{k}_{\gamma}$ - константа скорости разупрочнения, связанная с изменением параметра $\gamma$ под влиянием температуры;

$\mathrm{k}_{\mathrm{og}}$ - предэкспоненциальный множитель в уравнении для скорости гидролиза;

$\mathrm{L}_{\mathrm{fr}}-$ путь трения;

L - расстояние между поверхностями частиц наполнителя;

$\dot{\mathrm{N}}$ - скорость накопления разрывов химических связей;

$\dot{\mathrm{N}}{ }_{0}-$ скорость разрушения полимера при $\mathrm{T} \rightarrow \infty$;

P - сила нормального давления;

R- часть молекулы, примыкающая к разорванной связи;

$\mathrm{R}^{2}$ - величина вероятности интерполяции опытных данных;

$\mathrm{S}$ - скорость звука; 
$\mathrm{S}^{*}$ - свободный радикал, образовавшийся после разрыва связи между атомами серы и углерода;

Т - температура;

$\mathrm{T}(\mathrm{x})$ - значение температуры на расстоянии х от источника;

$\mathrm{T}_{\mathrm{b}}$ - температура размораживания изгибных колебаний;

$\mathrm{T}_{\mathrm{fr}}$ - температура в зоне трения;

$\mathrm{T}_{\mathrm{g}}$ - температура стеклования;

$\mathrm{T}_{\mathrm{K}}$ - температура, выше которой сила трения начинает увеличиваться;

$\mathrm{T}_{\max }$ - температура, связанная с максимальной частотой колебаний атомов;

$\mathrm{T}_{\text {exp }}$ - температура, измеренная на некотором расстоянии от зоны трения;

$\mathrm{T}_{\mathrm{b}}$ - температура размораживания деформационных колебаний

$\mathrm{T}_{\mathrm{f}}$ - время до разрушения при постоянной скорости нагружения;

$\mathrm{T}_{\mathrm{t}}$ - температура размораживания торсионных колебаний;

$\mathrm{T}_{*}$ - температура, при которой прочность равна нулю;

$\dot{\mathrm{T}}$ - "начальная" скорость разогрева покрытия;

$\dot{\mathrm{T}}_{0} \approx 10^{13} * \mathrm{~K} / \zeta_{\mathrm{c}}$

$\mathrm{t}_{\mathrm{i}}$ - время, отсчитанное от момента изменения температуры;

$\mathrm{t}_{\mathrm{m}}$ - время, при котором прочность адгезионного покрытия имеет максимальное значение $\sigma_{\mathrm{m}}$;

q - коэффициент перенапряжений;

$\mathrm{V}_{\mathrm{r}}$ - объем повторяющегося звена молекулы матрицы;

$\mathrm{U}=\mathrm{U}_{0}-\gamma \sigma$;

$\mathrm{U}_{\mathrm{c}}$ - энергия активации разупрочнения;

$\mathrm{U}_{\mathrm{s}}$ - энергия активации затвердевания;

$\mathrm{U}_{0}$ - энергия активации разрыва межатомных связей в ненагруженном теле;

$\mathrm{U}_{0 \mathrm{~d}}-$ энергия активации возбуждения связей;

$\mathrm{U}_{0 \mathrm{t}}-$ значение энергии активации разрыва межатомных связей в ненагруженном теле, найденное при использовании уравнения Журкова в интервале температур $\mathrm{T}_{\mathrm{t}}>\mathrm{T}>\mathrm{T}_{\mathrm{b}}$.

$\mathrm{X}$ - расстояние от источника нагрева;

$\alpha=-\left(v(0) / \mathrm{E}_{\mathrm{c}}\right) \mathrm{G}$ - тензовибрационный коэффициент;

$\beta$ - коэффициент теплового расширения композита; 
$\beta_{\mathrm{f}}$ - коэффициент теплового расширения наполнителя;

$\beta_{\mathrm{m}}$ - коэффициент теплового расширения матрицы;

$(\partial v / \partial \mathrm{T})_{\mathrm{T}>\mathrm{T}_{\mathrm{b}}}$ - наклон зависимости $v(\mathrm{~T})$ при $\mathrm{T}>\mathrm{T}_{\mathrm{b}}$;

$\gamma$ - опытный параметр, имеющий размерность объема;

$\gamma_{0}$ - величина параметра $\gamma$ для неориентированного полимера;

$\Delta a_{c}$ - изменение коэффициент температуропроводности композита;

$\Delta a_{0}$ - значение прироста коэффициента температуропроводности композита при $\mathrm{L} \rightarrow 0$;

$\Delta \mathrm{T}$ - изменение температуры;

$\Delta \mathrm{V}_{\mathrm{a}}$ - активационный объем разрушения;

$\Delta v$ - смещение частоты колебаний при деформации полимерной молекулы;

$\Delta \sigma_{\mathrm{f}}-$ уменьшение прочности покрытия;

$\Delta \sigma_{\mathrm{f}} / \Delta \mathrm{T}$ - тангенс угла наклона зависимости прочности от квантовой функции;

$\varepsilon$ - деформация участка молекулы полимера;

$\varepsilon_{\mathrm{d}}$ - деформация возбужденных связей;

$\varepsilon_{\mathrm{f}}$ - разрывное удлинение полимера;

$\varepsilon_{*} \approx 0,1$ - разрывное удлинение химических связей;

$\zeta$ - коэффициент пропорциональности между Тं и $\dot{\mathrm{N}}$

$\kappa$ - коэффициент поглощения;

$\Lambda$ - длина свободного пробега квантов колебаний молекул - фононов;

$\lambda_{\text {w }}$ - длина волны ИК излучения в вакууме

$\lambda$ - длина волны ИК излучения в вакууме

$\mu_{\mathrm{c}}-$ коэффициент трения композита;

$\mu_{\mathrm{S}}$ - коэффициент трения скольжения матрицы

$\mu_{\mathrm{Sc}}$ - коэффициент трения скольжения композита;

$\mu_{0}$ - коэффициент трения покоя матрицы;

$\mu_{0 c}$ - коэффициент трения покоя композита;

$\mu_{\mathrm{e}}$ - коэффициент трения торцов волокон;

$v$ - частота колебаний;

$v_{\mathrm{b}}$ - изгибные колебания скелета молекул;

$v_{i}$ - частота i - го колебания атомов

$v_{\mathrm{m}}$ - частота максимума элементарной полосы;

$v_{\max }$ - максимальная частота колебаний атомов; 
$v_{\mathrm{s}}$ - валентные колебания скелета молекул;

$v_{\mathrm{t}}$ - торсионные колебания скелета молекул;

$v_{0}$ - частота колебаний недеформированной молекулы;

$\mathrm{v}(0)$ - частота колебаний при температуре $\mathrm{T} \rightarrow 0 \mathrm{~K}$;

$\widetilde{v}$ - волновое число;

$\Sigma=\mathrm{E}_{\mathrm{c}} \varepsilon$ - локальное напряжение, действующее на участок полимерной молекулы;

$\sigma-$ прочность;

$\sigma_{\mathrm{c}}$ - эффективное напряжение сжатия скелета полимерных молекул;

$\sigma_{\mathrm{g}}-$ прочность при $\mathrm{T}_{\mathrm{g}}$;

$\sigma_{\mathrm{f}}$ - величина разрывной прочности при постоянной скорости нагружения;

$\sigma_{\mathrm{m}}$ - максимальное значение прочности адгезионного покрытия;

$\sigma_{\infty}$ - значение прочности, которое было бы у покрытия при $\mathrm{t} \rightarrow \infty$ в отсутствии разупрочнения;

$\sigma_{i}^{\text {exp }}$ - экспериментальное значение прочности;

$\sigma_{i}^{\text {th }}-$ расчетное значение прочности;

$\sigma\left(\mathrm{T}_{\mathrm{t}}\right)$ - значение прочности при температуре $\mathrm{T}_{\mathrm{t}}$

б - скорость нагружения;

$\tau$ - время до разрушения при постоянном напряжении;

$\tau_{0}-\approx\left(10^{-12} \div 10^{-14}\right) \mathrm{c}$;

$\varphi\left(v-v_{\mathrm{m}}\right)$ - форма элементарной полосы;

$v^{2}$-несмещенная дисперсия;

$\chi=\partial(\Delta \mathrm{a}) / \Delta \mathrm{a}-$ относительное изменение коэффициента температуропроводности при единичном изменении $\mathrm{L} / \mathrm{d}$;

* - свободный радикал - «разорванная химическая связь». 


\section{Переводные множители}

\section{Энергия}

\begin{tabular}{|l|l|l|l|l|}
\hline Единицы & $\mathrm{cm}^{-1}$ & Гц & эВ & кДж/моль \\
\hline $\mathrm{cm}^{-1}$ & 1 & $3^{*} 10^{10}$ & & 12,004 \\
\hline$\Gamma_{ц}$ & 3,34 & 1 & 4,14 & $17,37 * 10^{-15}$ \\
\hline эВ & 8066 & $2,42 * 10^{14}$ & 1 & 9,69 \\
\hline ккал/моль & 35 & $1,05^{*} 10^{13}$ & $4,33 * 10^{-2}$ & 4,2 \\
\hline кДж/моль & $1,47^{*} 10^{3}$ & $4,41 * 10^{13}$ & 104 & 1 \\
\hline
\end{tabular}

Активационный объем

1 кДж/(моль*МПа $)=1,67$ нм $^{3}$. 


\section{Введение}

Увеличение масштабов применения полимерных композиционных материалов для узлов и механизмов, используемых в космическом, морском и др. видах машиностроения поставило на первый план как первостепенную задачу прогнозирование их механических и теплофизических свойств.

В данной монографии описаны основные результаты исследований в этом направлении, полученные авторами за последние несколько десятков лет.

Несмотря на значительные успехи, достигнутые в области повышения долговечности машин и механизмов, эта проблема по мере расширения задач машиностроения, продолжает оставаться одной из самых актуальных. Проблемой особого внимания стали вопросы долговечности узлов, работающих в широком диапазоне температур (от близких к абсолютному нулю до нескольких тысяч градусов Кельвина), в условиях сухого трения и повышенных контактных давлений.

До последнего времени не были известны закономерности, связывающие прочность, упругость и теплофизические свойства (коэффициент теплового расширения, теплоемкость, теплопроводность) с концентрацией и видом наполнителей. Поэтому вид и концентрация наполнителей выбирались эмпирически - путем перебора.

Стабильность свойств получаемых при этом композиционных материалов определяются природой адгезионных связей между полимером и наполнителем, которая, до самого последнего времени оставалась практически не изученной.

Не были известны закономерности, связывающие прочность с температурой и нагрузкой в условиях хранения. Эта задача решалась при помощи метода, так называемых, ускоренных испытаний, включающих измерения прочности после выдержки при заданных темпеpaтyрах в течение некоторого времени, как правило, - несколько десятков суток. Однако не было известно насколько достоверно можно рассчитать более продолжительную долговечность

В последнее время резко увеличилось число механизмов и изделий, которые должны работать в условиях сухого трения в сухой и влажной атмосфере, вакууме, углекислом газе, воде и т.п. Эта задача 
решалась опытным путем, т.к. отсутствовали методы оценки долговечности композиционных материалов при сухом трении.

В значительной мере эта ситуация связана с тем, что не существовало метода определения температуры в зоне трения, которая, будучи предопределена величиной коэффициента трения, также зависит от условий теплопередачи в зоне трения, т.е. от теплопроводности и температуропроворности материалов. Не были известны законы, связывающие скорость и величину изнашивания с давлением и температурой.

Таким образом, решение вопроса о долговечности полимерного композиционного материала в конкретных условиях эксплуатации узла трения оказывается комплексной задачей, включающей вопросы антифрикционных, прочностных и теплофизических свойств, а также их зависимости от состава композита, температуры, времени и режима нагружения.

За последние десятилетия авторами данной работы были проведены исследования механических и теплофизических свойств композиционных материалов, направленные на решение этих проблем.

В результате были развиты методы контроля разрушения композиционных материалов непосредственно во время процесса сухого трения. Были установлены законы, которым подчиняется кинетики разрушения при растяжении и изнашивании, силы трения и разогрева композитов в процессе трения. Показано, что они контролируются спектрами молекулярных колебаний. Установлена природа адгезионных связей между металлами и полимерными покрытиями, исследована природа изменения прочности таких связей в условиях хранения. Наконец, были найдены закономерности, описывающие зависимость теплофизических констант композитов от вида и концентрации наполнителей.

Bсе это позволяет утверждать, что в результате проведенных исследований заложены физические основы прогнозирования долговечности и теплофизики полимерных конструкционных материалов. 


\section{1. Механизм разрушения полимерных материалов и композитов}

В этой главе будут кратко описаны основные результаты исследования механизма их разрушения на нано- и микроуровнях.

\section{1. Роль термических флуктуаций в механизме разрушения полимеров и композитов}

Систематические исследования разрушения материалов под воздействием постоянной нагрузки, которые были начаты в 50-х года в Физико-техническом институте им. А.Ф. Иоффе РАН под руководством С.Н. Журкова, привели к установлению следующего эмпирического выражения, связывающего величину прочности $\sigma_{f}$ при одноосном растяжении со временем до разрушения $\tau$ [1-3]:

$$
\tau=\tau_{0} \exp \left[\left(\mathrm{U}_{0}-\gamma \sigma_{\mathrm{f}}\right) / \mathrm{kT}\right]
$$

где $\tau_{0}, \mathrm{U}_{0}, \gamma$ - эмпирические параметры, a $\mathrm{k}$ - константа Больцмана.

Это уравнение Журкова, оказалось справедливым для металлов, сплавов, кристаллов, полимеров, композитов и т.д. Оно выполняется в широком диапазоне температур и времен нагружения в вакууме, воздухе, инертной и коррозионной средах.

Логарифмируя левую и правую части этого уравнения, получим:

$$
\operatorname{Ln} \tau=\operatorname{Ln} \tau_{0}+\frac{\mathrm{U}_{0}}{\mathrm{k}_{\mathrm{B}} \mathrm{T}}-\frac{\gamma}{\mathrm{k}_{\mathrm{B}} \mathrm{T}} \sigma=\mathrm{A}-\mathrm{B} \sigma
$$

где $\mathrm{A}=\mathrm{Ln} \tau_{0}+\mathrm{U}_{0} / \mathrm{kT}$ и $\mathrm{B}=\gamma / \mathrm{kT}$ - постоянные, зависящие от температуры.

Для примера, на рис. 1 приведены зависимости логарифма долговечности - $\ln \tau$ от величины разрывного напряжения для высокоориентированных волокон ПА 6, при различных температурах. 


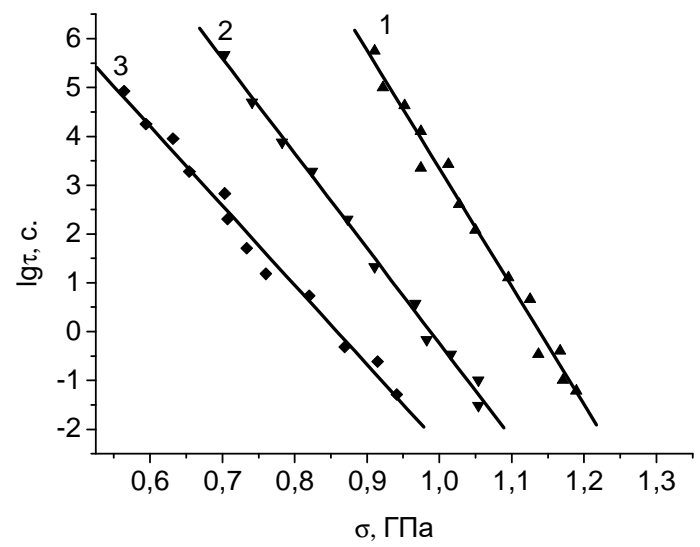

Рис. 1. Зависимость логарифма долговечности от напряжения $\sigma$ для высокоориентированных волокон ПА 6 при различных температурах T, K: 1 - 203; 2 - 293; $3-353$.

Видно, что экспериментальные точки укладываются на прямые линии, наклон которых уменьшается при увеличении температуры. Обрабатывая эти зависимости, можно найти значения параметров $\tau_{0}, \mathrm{U}_{0}$ и $\gamma$.

Оказалось, что параметр $\tau_{0}$ имеет значение, близкое к периоду межатомных колебаний - $\approx\left(10^{-12} \div 10^{-14}\right)$ с. Величина $\mathrm{U}_{0}$ равна энергии активации разрыва межатомных связей в ненагруженном теле [13]. Единственной характеристикой прочности, зависящей от структуры материала, оказался параметр $\gamma$, имеющий размерность объема.

Перепишем уравнение (1) в следующем виде:

$$
\sigma_{\mathrm{f}}=\frac{\mathrm{U}_{0}}{\gamma}-\frac{\mathrm{kT}}{\gamma} \operatorname{Ln} \frac{\tau}{\tau_{0}}
$$

Видно, что предел прочности, как константа материала, отсутствует, т.к. величина прочности зависит от температуры и времени действия нагрузки. Константами материала являются энергия активации разрыва связей $\mathrm{U}_{0}$ и параметр $\gamma$. 
Рассмотрим величину $\mathrm{k}_{\mathrm{f}}$ - константу скорости разрушения обратную времени $\tau$

$$
\mathrm{k}_{\mathrm{f}}=\tau_{0}^{-1} \exp [-(\mathrm{U} / \mathrm{kT}),
$$

где $\mathrm{U}=\mathrm{U}_{0}-\gamma \sigma$.

Подобное выражение было найдено впервые Аррениусом в 1884 г. для константы скорости инверсии сахарозы [4]. Впоследствии оказалось, что оно описывает различные процессы: химические реакции, диффузию, фазовые переходы, ползучесть и т.д. Скорость таких процессов возрастает при увеличении температуры, поэтому они получили название "термоактивируемых". Рассматриваемые процессы происходят в метастабильных системах, элементы которых релаксируют путем преодоления потенциального барьера $\mathrm{U}=\mathrm{U}_{0}-\gamma \sigma$ под действием термических флуктуаций. Роль внешней нагрузки сводится лишь к тому, что она снижает величину барьера $\mathrm{U}_{0}$ на величину $\gamma$ б. Среднее время ожидания разрушающих термических флуктуаций определяет скорость развития разрушения и тем самым - его долговечность. Мерой теплового движения (вероятности возникновения флуктуаций) является температура. Следовательно, зависимость разрушающего напряжения от времени неотделима от его зависимости от температуры.

Коррозия, старение, деформация и другие изменения структуры и строения материала играют роль внешних по отношению к процессу разрушения факторов, которые изменяют значение параметров, управляющих вероятностью образования тепловых флуктуаций ( $\mathrm{U}_{0}, \gamma$ и $\left.\tau_{0}\right)$.

Установление термофлуктуационной природы разрушения открывает возможность оценки ресурса долговечности нагруженных конструкций в заданных условиях эксплуатации.

Уравнение Журкова позволяет рассчитать при заданных температурах и нагрузках долговечность любого конструкционного материала.

На практике часто используют режим постоянной скорости растяжения. Если напряжение изменяется приблизительно пропорционально деформации, то можно использовать уравнение (1) и критерий Бейли [5], согласно которому тело разрушается, когда накапливается 
критическая концентрация повреждений, при которой удовлетворяется условие:

$$
\int_{0}^{\mathrm{t}_{\mathrm{f}}} \frac{\mathrm{dt}}{\tau[\dot{\sigma}(\mathrm{t}), \mathrm{T}]}=1,
$$

где $\mathrm{t}_{\mathrm{f}}$ - время до разрушения при постоянной скорости нагружения $\dot{\sigma}$.

Обычно на опыте $\exp \left(\mathrm{kT} / \gamma \sigma_{\mathrm{f}}\right)<<1$, это выражение можно переписать в следующем виде:

$$
\sigma_{\mathrm{f}}(\mathrm{T}) \approx \frac{\mathrm{U}_{0}}{\gamma}-\left[(\mathrm{k} / \gamma) \ln \left(\gamma \dot{\sigma} \tau_{0} / \mathrm{kT}\right)\right] \mathrm{T}
$$

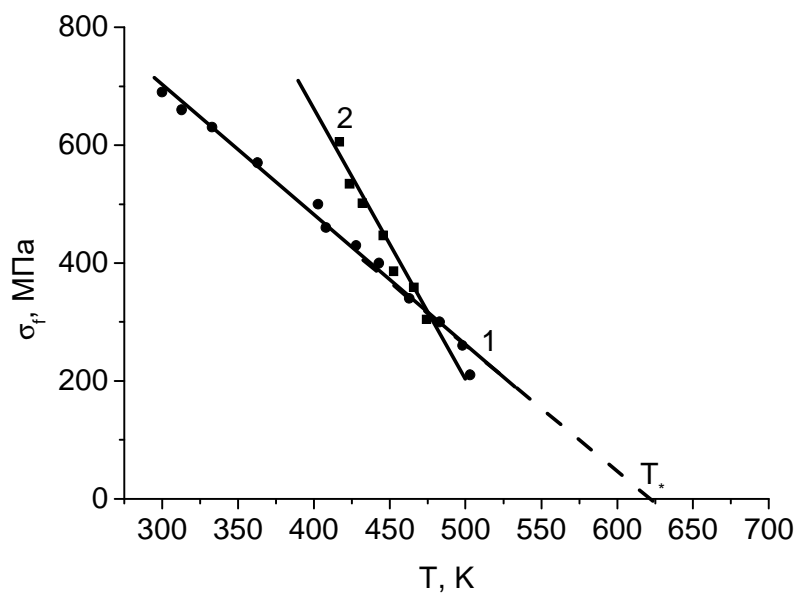

Рис. 2. Температурные зависимости прочности ориентированных волокон полимеров при скорости растяжения 0,2 \%/мин.: 1 - ПЭТФ, 2 ПАН.

Величина $\gamma$ для полимеров и композитов обычно составляет несколько нм ${ }^{3}$ (см. ниже). При вариации температуры от 20 до $500 \mathrm{~K}$ величина $\ln \left(\gamma \dot{\sigma} \tau_{0} / \mathrm{kT}\right)$ изменяется от $\approx 29$ до $\approx 35$, т.е., в среднем со- 
ставляет $\approx 32 \pm 3$. Поэтому для наших условий выражение (2.6) удобнее переписать как

$$
\sigma_{\mathrm{f}}(\mathrm{T}) \approx \frac{\mathrm{U}_{0}}{\gamma}-32 \frac{\mathrm{k}}{\gamma} \mathrm{T}
$$

Отсюда следует, что прочность при постоянной скорости нагружения должна уменьшаться линейно от температуры. Для примера, на рис. 2 показаны температурные зависимости прочности высокоориентированных волокон ПЭТФ и ПАН при постоянной скорости растяжения. Видно, что прочность действительно уменьшается линейно от температуры. Продолжение прямых линий к $\sigma=0$ отсекает от оси температур отрезок $\mathrm{T}_{*}$.

Из уравнения (7) следует, что

$$
\mathrm{U}_{0} \approx 32 \mathrm{kT} *
$$

Тангенс угла наклона прямых линий - $\mathrm{d} \sigma / \mathrm{dT} \approx 32(\mathrm{k} / \gamma)$. Откуда

$$
\gamma \approx 32 \mathrm{k} /(\mathrm{d} \sigma / \mathrm{dT})
$$

Перейдем теперь к рассмотрению механизма разрушения.

\section{2. Возбужденные («перенапряженные») химические связи}

В любом из упомянутых выше подходов, силовом и флуктуационном, предполагается, что в теле существуют межатомные связи, деформированные до величины близкой к разрывному удлинению. Они получили название перенапряженных или позже - «возбужденных» химических связей.

В силовом подходе такие связи располагаются около концентраторов напряжений - вершин трещин или в дефектных местах строения, а во флуктуационном - создаются при термических флуктуациях.

В 70 годах прошлого столетия в Физико-Техническом институте им. А.Ф. Иоффе РАН была создана методика обнаружения и исследования возбужденных межатомных связей в полимерах и полимерных 
композитах [2,3, 6 - 18]. Методика использует результаты анализа смещения частоты колебаний регулярно построенных участков молекул длиной 0,5 - 2 нм. Для демонстрации на рис. 3 и 4 показано строение таких участков в молекулах ПЭ и ПА 6.

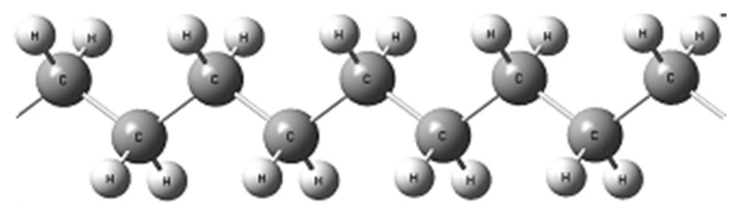

Рис. 3. Фрагмент регулярно построенного участка молекулы ПЭ.

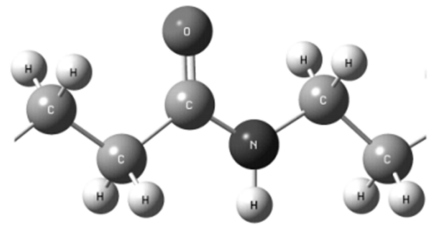

Рис. 4. Фрагмент регулярно построенного участка ПА-6.

При взаимодействии электромагнитного изучения с образцом полимера часть его энергии затрачивается на возбуждение колебаний регулярно построенных участков. Поэтому в ИК- и Рамановских спектрах полимеров возникают полосы, частоты максимума которых равны частоте колебаний таких участков. Напомним об основах этих методов и применяемой в них терминологии.

Полосы в ИК - спектрах поглощения образуются, когда частота ИК излучения, пропускаемого через образец, совпадает с частотой колебаний атомов. В этом случае в зависимости интенсивности поглощенного света от частоты появляется максимум. Принято частоту максимумов полос выражать в волновых числах, которые равны $1 / \lambda_{\mathrm{w}}$, где $\lambda_{\text {w }}$ - длина волны ИК излучения в вакууме.

Полосы в спектрах Рамановского рассеяния образуются следующим образом. Если на образец падает излучение монохроматического источника (обычно лазера), то в спектре рассеяния появляются спутники, частота которых отличается от частоты источника на величину 
$v_{\mathrm{R}}$, равную частоте колебаний атомов. Величину $v_{\mathrm{R}}$ также отсчитывают в волновых числах.

Поскольку в данной работе мы будем использовать данные ИК и Рамановской спектроскопии, для простоты будет применяться термин частота $v$, вместо терминов «волновое число» или «Рамановское смещение».

Для примера на рис. 5 показана полоса $1130 \mathrm{~cm}^{-1}\left(\approx 3,39 * 10^{13}\right.$ Гц) в Рамановском спектре ПЭ. Она соответствует валентным колебаниям углеродного скелета молекулы ПЭ длиной $\approx 1$ нм.

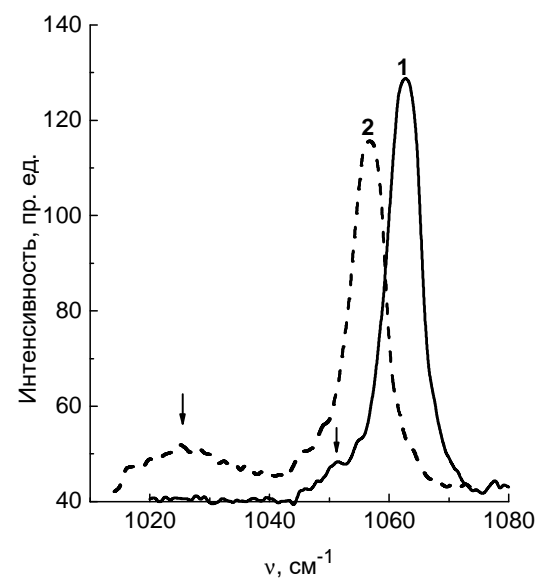

Рис. 5. Полоса $1130 \mathrm{~cm}^{-1}$ в Рамановском спектре волокна ПЭ до (1) и после приложения растягивающего напряжения 1 ГПа (2). Стрелками показаны положения максимума, соответствующего возбужденным химическим связям до и после приложения напряжения.

На следующем рисунке показана полоса $975 \mathrm{~cm}^{-1}\left(\approx 2,92510^{13}\right.$ Гц) в ИК спектре ПП. Она соответствует колебаниям молекулы ПП длиной $\approx 0,7 \mathrm{HM}$. 


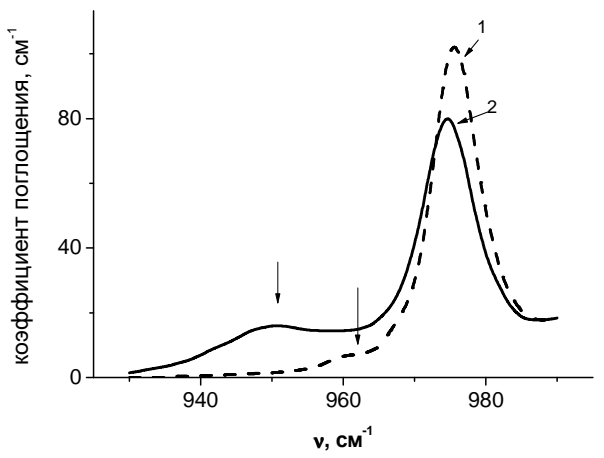

Рис. 6. Полоса $975 \mathrm{~cm}^{-1}$ в ИК-спектре ориентированной пленки ПП до (1) и после приложения растягивающего напряжения 0,7 ГПа (2). Стрелками показаны дополнительные максимумы, соответствующие возбужденным химическим связям.

Из этих рисунков видно, что под действие растягивающих напряжений максимумы полос смещаются в сторону низких частот. Смещение $\Delta v$ прямо пропорционально относительной величине деформации $\varepsilon$ участка молекулы или локальному напряжению, действующему на участок полимерной молекулы $-\Sigma=\mathrm{E}_{\mathrm{c}} \varepsilon\left(\mathrm{E}_{\mathrm{c}}-\right.$ модуль упругости молекулы):

$$
\Delta v=-\mathrm{Gv}_{0} \varepsilon=\alpha \Sigma,
$$

где G - параметр Грюнайзена, $v_{0}$ - частота колебаний недеформированной молекулы и $\alpha=-\left(v_{0} / \mathrm{E}_{\mathrm{c}}\right) \mathrm{G}$ - тензовибрационный коэффициент. Величины G и $\alpha$ могут быть определены экспериментально [6 - 18]. Основная часть участков молекул находится под напряжением равным действующим на образец. Им соответствует основной максимум полосы.

Однако существует небольшое число участков, напряжение на которых значительно больше внешнего, приложенного к образцу. Частота их колебаний смещена больше, чем для остальных участков молекул. Соответствующие им элементарные полосы, накладываются друг 
на друга и формируют дополнительный слабый максимум на низкочастотном крыле полосы.

Выражение, описывающее зависимость оптической плотности D от частоты для такой неоднородно уширенной полосы в ИК спектре, имеет вид:

$$
\mathrm{D}(v)=\int_{-\infty}^{\infty} \mathrm{f}\left(v_{\mathrm{m}}\right) \varphi\left(v-v_{\mathrm{m}}\right) \mathrm{d} v_{\mathrm{m}}
$$

где $\mathrm{f}\left(v_{\mathrm{m}}\right)$ - распределение частот максимумов $v_{\mathrm{m}}$ элементарных полос, $\varphi\left(v-v_{\mathrm{m}}\right)-$ форма элементарной полосы.

Это выражение можно рассматривать как интегральное уравнение относительно $\mathrm{f}\left(v_{\mathrm{m}}\right)$. Решая его, можно найти распределение их максимумов элементарных полос $\mathrm{f}\left(v_{\mathrm{m}}\right)$. Затем, пользуясь уравнением (10), можно определить распределение локальных напряжений $\Sigma$ по участкам полимерных молекул.

Для примера, на рис. 7 показано найденное таким путем распределение напряжений по участкам молекул в высокоориентированной пленке ПП, находящейся под нагрузкой 700 МПа.

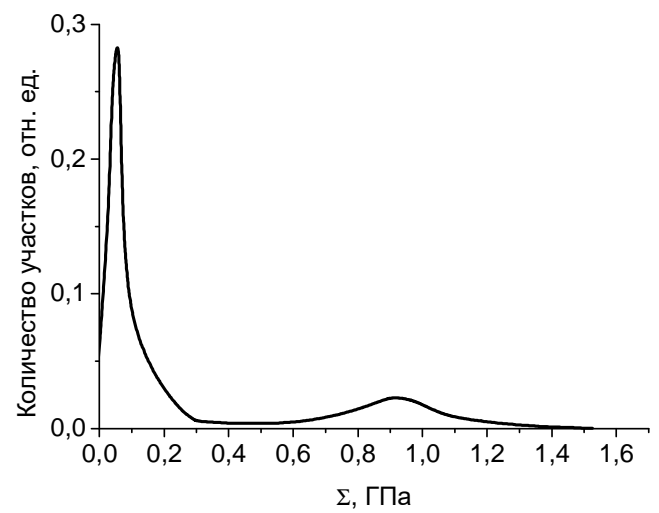

Рис. 7. Распределение напряжений по участкам молекул длиной $\approx 0,7$ нм в образце ПП, на который действует растягивающее напряжение 700 МПа. 
Видно, что основная масса участков в молекулах ПП находится под напряжением, близким к приложенному - 0,7 ГПа. Однако существует небольшое число участков молекул (несколько процентов от общего числа), напряжение на которых на порядок больше и достигает 1,6 ГПа. Столь же неравномерные распределения локальных напряжений были обнаружены для большого числа полимеров и композитов [2,3, $6-18]$.

Оказалось, «перенапряженные» участки в молекулах полимеров существуют в любом полимерном теле, независимо от того нагружено оно или нет [15 - 18]. Исследования показали, что они образуются под действием термических флуктуаций.

Эмпирические выражения, связывающие скорость накопления $\dot{\mathrm{C}}_{\mathrm{d}}$ и деформацию $\varepsilon_{\mathrm{d}}$ возбужденных связей с температурой и временем $\mathrm{t}_{\mathrm{i}}$ после изменения температуры имеют вид $[17,18]$ :

$$
\begin{gathered}
\dot{\mathrm{C}}_{\mathrm{d}}=\dot{\mathrm{C}}_{0} \exp \left(-\mathrm{U}_{0 \mathrm{~d}} / \mathrm{e} \mathrm{T}\right) \\
\frac{\varepsilon_{\mathrm{d}}}{\varepsilon_{*}}=\frac{\mathrm{kT}}{\mathrm{U}_{0 \mathrm{~d}}} \ln \frac{\mathrm{t}}{\tau_{0}}
\end{gathered}
$$

Здесь где $\mathrm{U}_{0 \mathrm{~d}}$ - энергия активации возбуждения связей, а $\dot{\mathrm{C}}_{0}-$ эмпирическая постоянная, $\varepsilon_{*} \approx 0,1-$ разрывное удлинение химических связей. Важно, что $\mathrm{U}_{0 \mathrm{~d}}=\mathrm{U}_{0}$ [13]. Это означает, что скорость накопления возбужденных химических связей задает скорость и долговечность разрушения полимеров. Все остальные процессы (разрывы возбужденных связей, образование и укрупнение трещин) происходят скоростями существенно большими скорости накопления возбужденных связей и не вносят вклада в прочность и долговечность. 


\section{3. Разрывы полимерных молекул}

При разрыве возбужденных химических связей образуются свободные радикалы и ионы $[2,3,19$ - 25]. Они могут быть зарегистрированы методом электронного парамагнитного резонанса (ЭПР).

Для примера, на рисунке 8 показан (в виде первой производной) спектр ЭПР свободных радикалов $\mathrm{R}-\mathrm{H}_{2} \mathrm{C}^{*}$, образующихся при разрыве углерод - углеродных связей в молекулах ПЭ. (Значок * означает «разорванную» химическую связь, a R- часть молекулы, примыкающая к разорванной связи.).

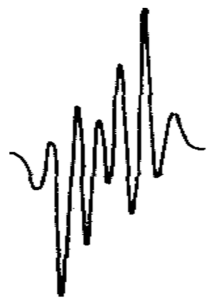

Рис. 8. Первая производная спектра ЭПР свободных радикалов R$\mathrm{H}_{2} \mathrm{C}^{*}$, образующихся при разрыве углерод - углеродных связей в молекулах ПЭ.

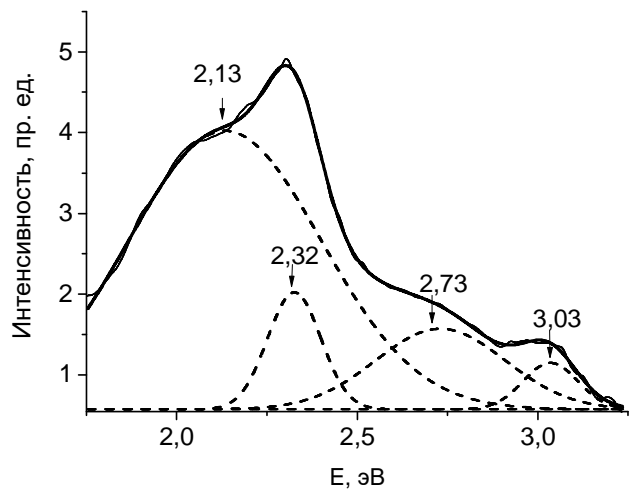

Рис. 9. Спектр МЛ композита с матрицей из ПФС, армированной углеродными волокнами, при трении о стальной валик. 
Часто такие радикалы возбуждены - электроны в химических связях занимают возбужденные электронные уровни. При переходе электронов на основные уровни выделяется энергия в видимой области спектра - возникает механолюминесценция (МЛ) [23 - 25]. Например, на рис. 9 показан спектр МЛ композита с матрицей из полифениленсульфида (ПФС), армированной углеродными волокнами. Полосы $2,13,2,32$ и 2,73 эВ в этом спектре соответствуют свободным радикалам R-C*, образовавшимся при разрыве химических связей в угольных волокнах, а 3,03 эB - радикалам R-S*. Отметим, что интенсивность полос 2,13, 2,32 и 2,73 эВ по крайней мере на порядок больше, чем 3,03 эВ. Это означает, что общая интенсивность МЛ определяется концентрацией свободных радикалов R-C*, образовавшимся при разрыве химических связей в угольных волокнах.

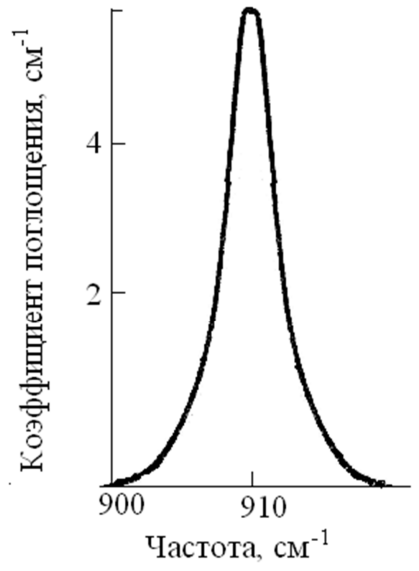

Рис. 10. Полоса поглощения в ИК - спектре ПЭ, соответствующая колебаниям новых концов $\mathrm{R}-\mathrm{CH}_{2}-\mathrm{CH}_{2}=\mathrm{CH}_{2}$, образовавшимся в результате "гибели" радикалов - $\mathrm{R}-\mathrm{CH}_{2}-\mathrm{CH}_{2}-\mathrm{HC} *$

При комнатных температурах свободные радикалы и ионы обычно нестабильны (Время их жизни составляет $10^{-6}-10^{-8}$ с) и «гибнут» вступая в различные химические реакции [2,3, 19 - 22]. В результате реакций образуются новые химические группировки, которые могут быть зарегистрированы при помощи ИК спектроскопии [2,3, 26 - 33]. 
На рисунке 10 показана полоса в ИК спектре ПЭ, соответствующая новым концам молекул ПЭ, имеющим строение - $\mathrm{R}_{-}-\mathrm{CH}_{2}-\mathrm{CH}_{2}=\mathrm{CH}_{2}$ и образовавшимся в результате "гибели" свободных радикалов $-\mathrm{CH}_{2-}$ $\mathrm{CH}_{2}-\mathrm{H}_{2} \mathrm{C} *$.

\section{4. Трещины и механизм их укрупнения}

Концы полимерных молекул в основном располагаются на берегах мельчайших «зародышевых» трещин [2, 3, 34 - 37]. Для примера, в таблице 1 приведены средние размеры $\left\langle\mathrm{D}_{\mathrm{cr}}>\right.$ и концентрация $\mathrm{C}_{\mathrm{cr}}$ таких трещин, накопленных к моменту разрыва в образца полимеров.

Таблица 1. Средние размеры и концентрация «зародышевых» трещин в образцах полимеров, накопившаяся к моменту разрыва [33].

\begin{tabular}{|l|l|l|}
\hline Материал & $\begin{array}{l}<\mathrm{D}>, \\
\mathrm{HM}\end{array}$ & $\begin{array}{l}\mathrm{C}_{\mathrm{cr}}, \\
\text { мкм }^{-3}\end{array}$ \\
\hline ПЭ ориентированный & 15 & 6000 \\
\hline ПП ориентированный & 20 & 700 \\
\hline ПВХ & 300 & 10 \\
\hline ПММА & 90 & 10 \\
\hline ПА 6 ориентированный & 10 & $10^{3}$ \\
\hline
\end{tabular}

На этом мы закончим краткое рассмотрение механизма разрушения полимеров и займемся детальным рассмотрением кинетики разрушения полимеров и композитов на их основе. 


\section{2. Кинетика разрушения полимеров и композитов на их ос- нове в широком диапазоне температур}

\section{1. Температурные зависимости прочности полимеров}

Согласно кинетической концепции разрушения, основы которой были изложены в главе 1 , химические связи в полимерах и полимерных композитах разрываются под действием термических флуктуаций. Энергия для создания и развития этих флуктуаций заимствуется из энергии молекулярных колебаний. Поэтому особенности спектра этих колебаний проявляются в кинетике разрушения полимеров и композитов на их основе.

Напомним, что молекулы полимера содержат большое число атомов (несколько десятков тысяч) и, следовательно, несколько десятков тысяч колебаний (согласно механике число колебаний равно утроенному числу атомов в молекуле). Однако не все колебания вносят одинаковый вклад в разрушение. Было показано, что скорость разрушения полимеров задана скоростью накопления разрывов химических связей в основном скелете полимерных молекул $[2,3]$. Поэтому в кинетику разрушения полимеров основной вклад вносят колебания основного скелета их молекул. Таких колебаний всего три - торсионные $v_{\mathrm{t}}$, изгибные $v_{\mathrm{b}}$ и валентные $v_{\mathrm{s}}[38,39]$.
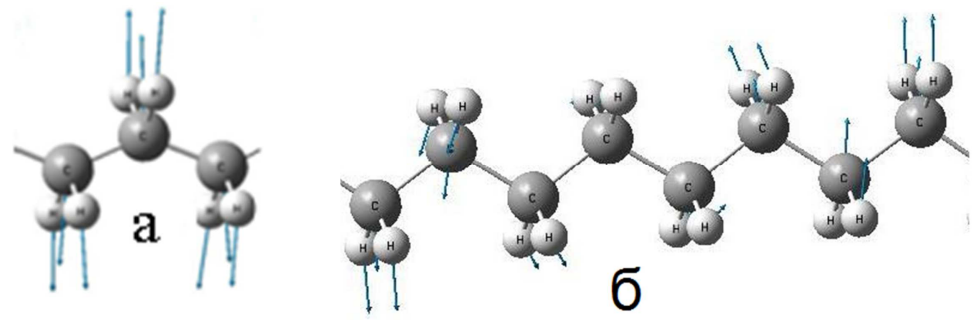

Рис. 11. Форма валентных (а) и изгибных (б) колебаний молекулы ПЭ. Стрелками показаны направления движения атомов.

При валентных колебаниях изменяются длины валентных связей между атомами углерода (рис. 11a). Атомы скелета молекулы, участ- 
вующие в торсионных колебаниях совершают вращательные движения вокруг оси молекулы. При изгибных колебаниях атомы изменяются валентные углы между углерод-углеродными связями в скелете молекулы (рис. 11б).

Для возбуждения каждой из указанных мод колебаний необходимо, чтобы температура испытаний Т была больше некоторого значения $\mathrm{T}_{\mathrm{i}}$, связанной с частотой $v_{\mathrm{i}} \mathrm{i}$ - го колебания следующим образом:

$$
\mathrm{T}_{\mathrm{i}}=\frac{\mathrm{h} \mathrm{v}_{\mathrm{i}}}{\mathrm{k}}
$$

где $\mathrm{h}$ - постоянная Планка. Ниже $\mathrm{T}_{\mathrm{i}}$ энергия теплового движения недостаточна, чтобы возбудить тепловые колебания частотой $v$, а выше они возбуждаются.

Исследования показали (см. ниже), что температурно-временные зависимости прочности полимеров и композитов описываются уравнением Журкова только в интервале температур между $\mathrm{T}_{\mathrm{t}}$ и $\mathrm{T}_{\mathrm{b}}$, где $\mathrm{T}_{\mathrm{t}}$ и $\mathrm{T}_{\mathrm{b}}$ - температуры размораживания торсионных и деформационных колебаний. Они связаны с частотами $v_{\mathrm{t}}$ и $v_{\mathrm{b}}$ следующими уравнениями: $\mathrm{T}_{\mathrm{t}}=\mathrm{h} v_{\mathrm{t}} / 3 \mathrm{k}$, a $\mathrm{T}_{\mathrm{b}}=\mathrm{h} v_{\mathrm{b}} / 3 \mathrm{k}$. Выше $\mathrm{T}_{\mathrm{b}}$ и ниже $\mathrm{T}_{\mathrm{t}}$ указанных температур существуют отклонения от этого уравнения.

Начнем с рассмотрения температурных зависимостей прочности неориентированных полимеров и адгезионных соединений при фиксированной скорости нагружения. Для примера, на рис. 12 демонстрируются температурные зависимости прочности неориентированной пленки ПП и адгезионного соединения стали 3 на основе эпоксидного клея марки КВС.

Такие же зависимости наблюдались и для других неориентированных полимеров и адгезионных соединений [40-43].

Их можно разбить на 3 участка:

- первый соответствует диапазону температур ниже $\mathrm{T}_{\mathrm{t}}$, в пределах этого диапазона прочность не зависит от температуры;

- в пределах второго участка - между температурами $\mathrm{T}_{\mathrm{t}}$ и $\mathrm{T}_{\mathrm{b}}$, прочность уменьшается пропорционально температуре;

- на третьем участке, при $\mathrm{T}>\mathrm{T}_{\mathrm{b}}$, наклон температурной зависимости прочности постепенно уменьшается при повышении температуры. 

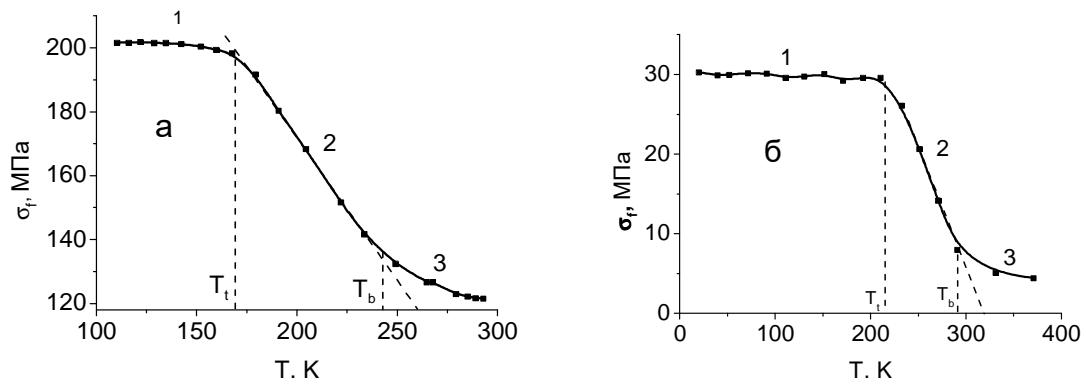

Рис. 12. Температурные зависимости прочности: а - неориентированной пленки ПП; адгезионного соединения стали 3 на основе эпоксидного клея марки КВС-31. Скорость нагружения $5 \mathrm{MПа/мин.}$

Значения температур $T_{t}$ и $T_{b}$ для неориентированных полимеров, приведены в таблице 2, а адгезионных соединений - в таблице 3.

Таблица 2. Температуры $\mathrm{T}_{\mathrm{t}}$ и $\mathrm{T}_{\mathrm{b}}$ для неориентированных полимеров.

\begin{tabular}{|c|c|c|}
\hline Полимеры & $\mathrm{T}_{\mathrm{t}}$ & $\mathrm{T}_{\mathrm{b}}$ \\
\cline { 2 - 3 } & \multicolumn{2}{|c|}{$\mathrm{K}$} \\
\hline ПЭ & 100 & 250 \\
\hline ПА 6 & 160 & 340 \\
\hline ПЭТФ & 130 & 380 \\
\hline ПП & 220 & 270 \\
\hline ПОМ & 220 & 390 \\
\hline ПАН & 150 & 380 \\
\hline
\end{tabular}

Таблица 3. Температуры $\mathrm{T}_{\mathrm{t}}$ и $\mathrm{T}_{\mathrm{b}}$ адгезионных соединений стали 3 на основе эпоксидных клеев и полиамидов.

\begin{tabular}{|c|c|c|}
\hline \multirow{2}{*}{} & $\mathrm{T}_{\mathrm{t}}$ & $\mathrm{T}_{\mathrm{b}}$ \\
\cline { 2 - 3 } \multicolumn{2}{|c|}{ К } \\
\hline \multicolumn{2}{|c|}{ Полиамиды } \\
\hline ПА 6 & 140 & 340 \\
\hline ПА 5,4 & - & 350 \\
\hline ПА 6,6 & 180 & 320 \\
\hline \multicolumn{2}{|c|}{ Эпоксидные клеи } \\
\hline КДС-19 & 210 & 290 \\
\hline КГ-1м & 160 & 290 \\
\hline КВС-31 & 200 & 290 \\
\hline К-300 & 200 & 350 \\
\hline Криосил & - & 400 \\
\hline
\end{tabular}

Рассмотрим теперь температурные зависимости высокоориентированных полимеров [41, 42] (Рис. 13). 
На этих зависимостях также наблюдаются отклонения от формулы Журкова при температурах $\mathrm{T}_{\mathrm{t}}$ и $\mathrm{T}_{\mathrm{b}}$. Ниже $\mathrm{T}_{\mathrm{t}}$ прочность высокоориентированных, как и неориентированных полимеров, не зависит от температуры.
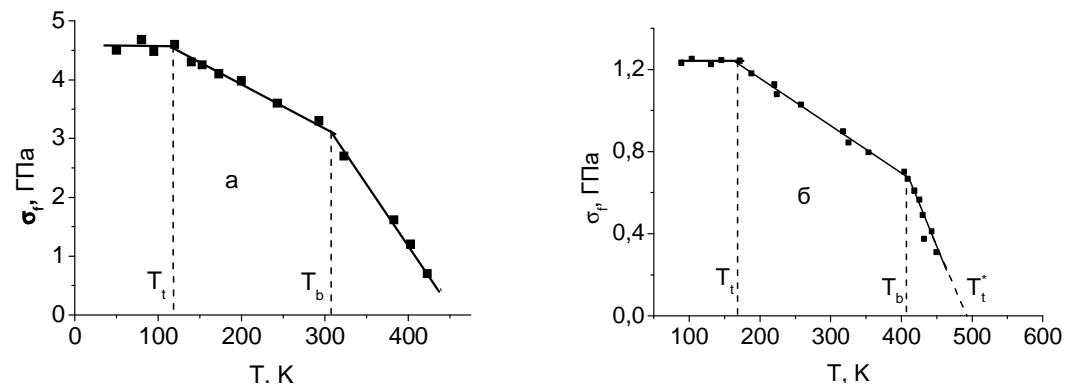

Рис. 13. Температурные зависимости прочности высокоориентированных волокон ПЭ (а), ПА 6 (б).

Однако выше $\mathrm{T}_{\mathrm{b}}$ наблюдается существенное различие - для высокоориентированных полимеров температурная зависимость прочности остается линейной, но увеличивается ее наклон.

Это потребовало провести дополнительные исследования, в результате которых были получены новые уравнения, обобщающие уравнение Журкова на интервалы температур ниже $\mathrm{T}_{\mathrm{t}}$ и выше $\mathrm{T}_{\mathrm{b}}$.

Прежде чем рассмотреть их результаты, приведем значения энергии активации разрушения, полученной в результате анализа температурных зависимостей прочности в интервале между $\mathrm{T}_{\mathrm{t}}$ и $\mathrm{T}_{\mathrm{b}}$.

\section{2. Энергия активации разрушения композитов в диапазоне температур между $T_{t} u T_{b}$}

На рис. 14 и 15 показаны температурные зависимости прочности наполненных полимеров. Видно, что при изменении концентрации наполнителя температурные зависимости прочности остаются линейными. 


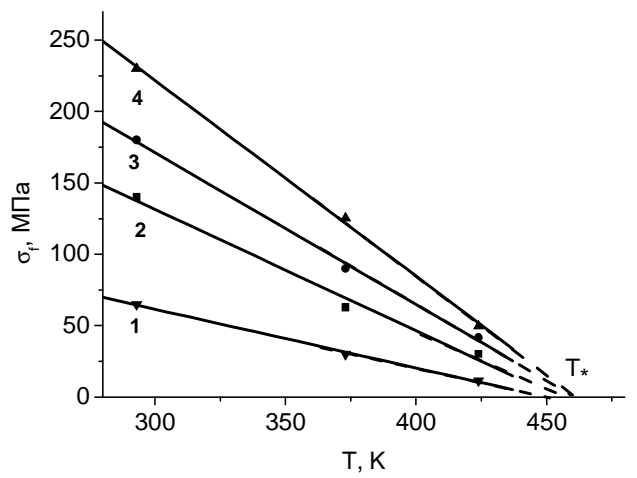

Рис. 14. Температурные зависимости прочности композита с матрицей из ПФО с различной концентрацией $\mathrm{C}_{\text {об }}$ отрезков волокон ПАБИ, $\mathrm{C}_{\text {об }}$, $\%: 1-0 ; 2-5 ; 3-20 ; 4-40$.

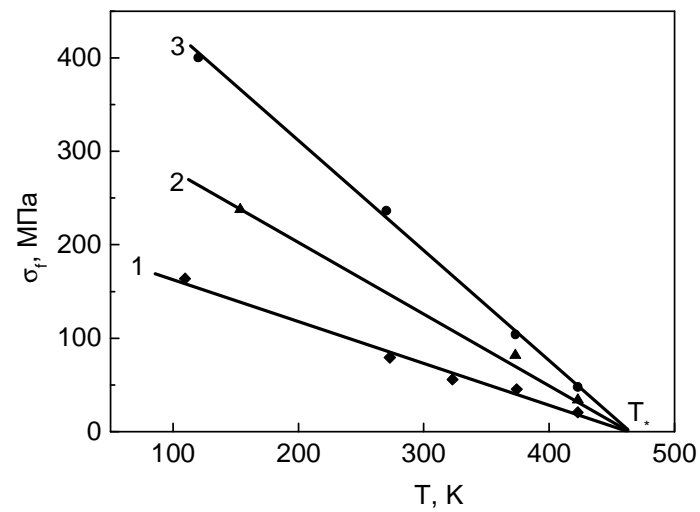

Рис. 15. Температурные зависимости прочности на изгиб композита с матрицей из ПФО с различной концентрацией отрезков волокон из углерода и ПАБИ, $\mathrm{C}_{\text {об, }} \%: 1-0,20 ; 2-15,20 ; 3-25$. 
Концентрация частиц наполнителя и природа волокон наполнителя влияет только на наклон температурных зависимостей прочности, т.е. на величину параметра $\gamma$ (уравнение 9). При экстраполяции прямолинейных участков к $\sigma_{\mathrm{f}}=0$ они отсекают от оси температур отрезок приблизительно одинаковый отрезок - Т*. Это означает, что энергия активации $\mathrm{U}_{0 t}$ (Значок $\mathrm{t}$ означает, что она определена в диапазоне температур между $T_{t}$ и $T_{b}$ ) разрушения композита не зависит от концентрации наполнителя (уравнение 8).

Таблица 2. Значения $\mathrm{U}_{0 \mathrm{t}}$ наполненных композитов.

\begin{tabular}{|l|l|}
\hline Матрица & $\mathrm{U}_{0 \mathrm{t}}, \mathrm{\ni} \mathrm{B}$ \\
\hline ПА 6 & 1,2 \\
\hline ПА 6/6,6 & 1 \\
\hline ПФО & 1,2 \\
\hline угольная & 6 \\
\hline ПМ 69 & 2 \\
\hline
\end{tabular}

Таблица 3. Значения энергий активации разрушения $\mathrm{U}_{0 t}$ для адгезионных соединений стали 3.

\begin{tabular}{|l|l|}
\hline Полиамид & $\mathrm{U}_{0 \mathrm{t}}$ \\
\cline { 2 - 2 } или клей & эВ \\
\hline К-300 & 1,1 \\
\hline КВС-31 & 1,5 \\
\hline Криосил & 1.05 \\
\hline КДС-19 & 1,25 \\
\hline КГ-1м & 1,15 \\
\hline ПА 6 & 1,10 \\
\hline ПА 54 & 1,0 \\
\hline ПА 6,6 & 0,95 \\
\hline
\end{tabular}

Такой же результат был получен и для других наполненных полимеров, а также для адгезионных соединений металлов с полиамидами 
и клеями. Оказалось, что вид наполнителей, их концентрация влияет только на параметр $\gamma$.

Значения $\mathrm{U}_{0 \mathrm{t}}$ для наполненных полимеров приведены в таблице 2, а для адгезионных соединений металлов с полиамидами и клеями - в таблице 3.

Рассмотрим теперь, как будут выглядеть температурные зависимости прочности за пределами интервала между $\mathrm{T}_{\mathrm{t}}$ и $\mathrm{T}_{\mathrm{b}}$.

\section{3. Влияние статистики молекулярных колебаний на кинетику разрушения полимеров и композитов}

Покажем, что причина отклонений от уравнения Журкова в областях низких и высоких температур лежит в особенностях распределения энергии по модам молекулярных колебаний.

Вспомним, что уравнение Журкова содержит в знаменателе дроби показателя экспоненты произведение kT. Такая запись основана на предположении, что энергия, затрачиваемая на разрывы межатомных связей, распределена равномерно по модам колебаний атомов, и на каждую из них приходится величина энергии равная kT.

Это верно, если $\mathrm{T}>\mathrm{T}_{\mathrm{m}}$, где $\mathrm{T}_{\mathrm{m}}$ связана с максимальной частотой колебаний атомов $v_{\mathrm{m}}$ уравнением:

$$
\mathrm{T}_{\mathrm{m}} \approx \frac{\mathrm{h} \mathrm{v}_{\mathrm{m}}}{3 \mathrm{k}}
$$

Максимальная частота колебаний скелета молекул полимеров достигает 1200 - $1600 \mathrm{~cm}^{-1}[38,39]$. Поэтому максимальное значение $\mathrm{T}_{\max }$ для полимеров составляет $\approx 600$ - $800 \mathrm{~K}$, и часто превышает температуру их плавления. По этой причине указанное условие выполняется только для колебаний с низкими частотами и не выполняется для колебаний с высокими значениями последних.

Другими словами, в диапазоне температур эксплуатации полимеров и полимерных композитов энергия неравномерно распределяется по модам колебаний атомов, и уравнение Журкова в виде (1) не выполняется. 
Для учета неравномерного распределения энергии по модам колебаний в это уравнение вместо температуры вводят квантовую функцию $\mathrm{F}_{\mathrm{q}}[40$ - 43]. Тогда оно приобретает вид:

$$
\sigma=\frac{\mathrm{U}_{0}}{\gamma}-\frac{\mathrm{kF}_{\mathrm{q}}}{\gamma} \operatorname{Ln} \frac{\tau}{\tau_{0}},
$$

или, при испытаниях на разрывной машине -

$$
\sigma \approx \frac{\mathrm{U}_{0}}{\gamma}-32 \frac{\mathrm{k}}{\gamma} \mathrm{F}_{\mathrm{q}}
$$

Из последней записи видно, что, если параметр $\gamma$ при испытаниях остается неизменным, прочность должна уменьшаться линейно от $\mathrm{F}_{\mathrm{q}}(\mathrm{T})$.

Для полимеров эту функцию можно найти, например, при помощи ИК - или Рамановской спектроскопии, если провести измерения температурной зависимости частот $v(\mathrm{~T})$ полос регулярности. Частота таких полос связана с квантовой функцией уравнением [41 - 43].

$$
v(\mathrm{~T}) \approx v(0)-(\partial v / \partial \mathrm{T})_{\mathrm{T}>\mathrm{T}_{\mathrm{b}}} \mathrm{F}_{\mathrm{q}},
$$

где $v(0)$ - частота при температуре $\mathrm{T} \rightarrow 0 \mathrm{~K}$, a $(\partial v / \partial \mathrm{T})_{\mathrm{T}>\mathrm{T}_{\mathrm{t}}}$ - наклон зависимости $v(\mathrm{~T})$ при $\mathrm{T}>\mathrm{T}_{\mathrm{b}}$.

Переписав это уравнение относительно $\mathrm{F}_{\mathrm{q}}$, получим:

$$
\mathrm{F}_{\mathrm{q}}(\mathrm{T})=\frac{v(\mathrm{~T})-\mathrm{v}(0)}{(\partial v / \partial \mathrm{T})_{\mathrm{T}>\mathrm{T}_{\mathrm{b}}}}
$$

Для примера на рис. 16 показаны температурные зависимости частоты максимума полосы регулярности 929 см$^{-1}$ в ИК спектрах ПА 6 и функции $\mathrm{F}_{\mathrm{q}}$.

Функция $\mathrm{F}_{\mathrm{q}}$ состоит из двух составляющих:

$$
\mathrm{F}_{\mathrm{q}}=\mathrm{F}_{\mathrm{q}}(0)+\mathrm{F}_{\mathrm{q}}(\mathrm{T}),
$$


где первая $-\mathrm{F}_{\mathrm{q}}(0)$ - значение квантовой функции при $\mathrm{T} \leq \mathrm{T}_{\mathrm{t}}$, независящее от температуры, а вторая - $\mathrm{F}_{\mathrm{q}}(\mathrm{T})$ растет увеличении температуры.
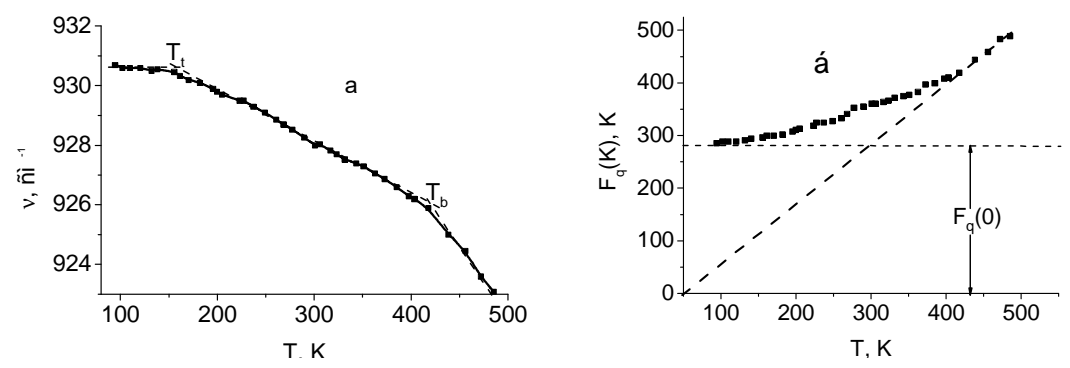

Рис. 16. Температурные зависимости частоты максимума полосы 929 $\mathrm{cm}^{-1}(\mathrm{a})$ и функции $\mathrm{F}_{\mathrm{q}}($ б) для ПА 6.
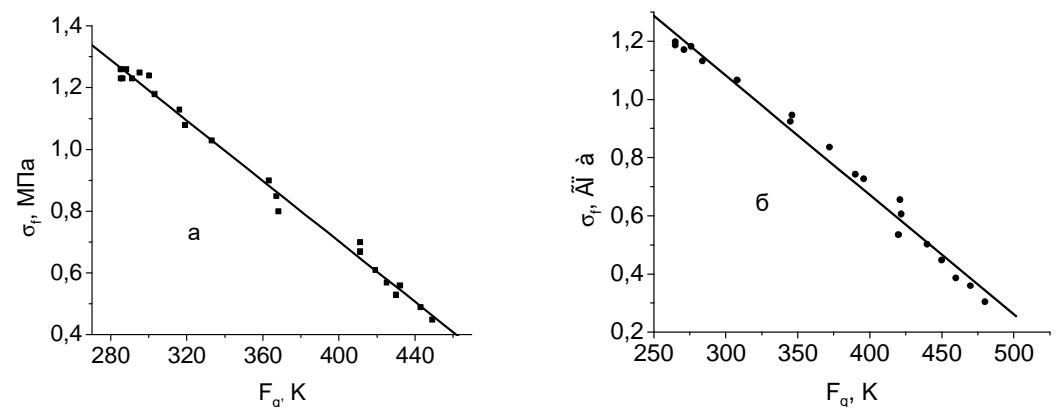

Рис. 17. Зависимости разрывной прочности ориентированных волокон ПА 6 (a), ПЭТФ (б) от квантовой функции $\mathrm{F}_{\mathrm{q}}$.

Легко убедиться, что вид температурной зависимости прочности ориентированных полимеров полностью задан температурной зависимостью квантовой функции $\mathrm{F}_{\mathrm{q}}$. Для этой цели достаточно построить зависимость прочности от $\mathrm{F}_{\mathrm{q}}$. В этом случае экспериментальные точки укладываются на прямые линии (рис. 17).

Следовательно, изменение наклона прямых линий на графиках температурных зависимостей прочности высокоориентированных по- 
лимеров обусловлено температурной зависимостью квантовой функции $\mathrm{F}_{\mathrm{q}}$.

Однако это не так для неориентированных полимеров и клеевых соединений. Например, на рис. 18 построена зависимость прочности от $\mathrm{F}_{\mathrm{q}}$ для неориентированной пленки ПА 6.

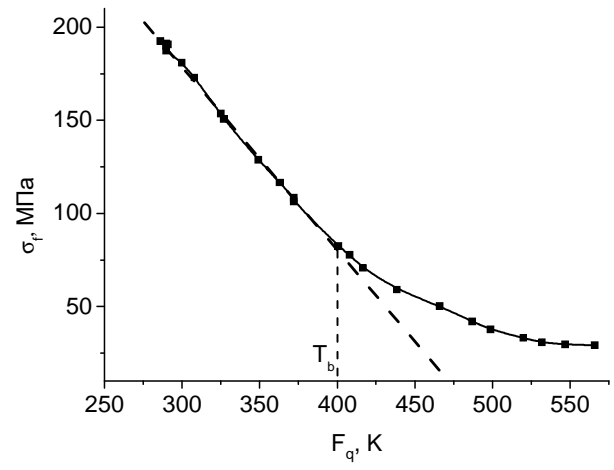

Рис. 18. Зависимость прочности от $\mathrm{F}_{\mathrm{q}}$ для неориентированной пленки ПА 6.

Видно, что, когда $\mathrm{T}<\mathrm{T}_{\mathrm{b}}$ экспериментальные точки укладываются на линейную зависимость. Это означает, что температурная зависимость прочности неориентированной пленки полиамида 6 при $\mathrm{T}<\mathrm{T}_{\mathrm{b}}$ определяется температурной зависимостью квантовой функции. Выше $\mathrm{T}_{\mathrm{b}}$ наблюдаются отклонения от линейной зависимости, и температурная зависимость прочности зависит не только от $\mathrm{F}_{\mathrm{q}}$.

Опыт показал [43], что $\mathrm{T}_{\mathrm{b}} \approx \mathrm{T}_{\mathrm{g}}$, где $\mathrm{T}_{\mathrm{g}}$ - температура стеклования. При $\mathrm{T}>\mathrm{T}_{\mathrm{g}}$ величина разрывного удлинения $\varepsilon_{\mathrm{f}}$ для неориентированных полимеров резко увеличивается и достигает сотен процентов. Известно, что параметр $\gamma$ зависит от разрывного удлинения как: $\gamma=\gamma_{0} /(1+\varepsilon)$ [44], где $\gamma_{0}$ - величина параметра $\gamma$ для неориентированного полимера. Поэтому резкое увеличение разрывного удлинения приводит к уменьшению $\gamma$. По этой причине наклон температурной зависимости прочности от квантовой функции $\mathrm{F}_{\mathrm{q}}$ выше $\mathrm{T}_{\mathrm{b}}$ уменьшается. 
В тоже время для высокоориентированных полимеров разрывное удлинение выше $\mathrm{T}_{\mathrm{b}}$ не превышает $20 \%$ во всем диапазоне температур. Поэтому параметр $\gamma$ остается приблизительно неизменным и зависимость прочности от температуры полностью определяется только зависимостью $\mathrm{F}_{\mathrm{q}}$ от $\mathrm{T}$.

В этой связи для прогнозирования долговечности полимеров выяснение природы температур $\mathrm{T}_{\mathrm{t}}$ и $\mathrm{T}_{\mathrm{b}}$ приобретает важное значение. Легко убедиться в том, что значения этих температур и заданы частотами торсионных $v_{\mathrm{t}}$ и изгибных $v_{\mathrm{b}}$ колебаний. С этой целью подставим в уравнение (15) значения $\mathrm{T}_{\mathrm{t}}$ и $\mathrm{T}_{\mathrm{b}}$ и вычислим соответствующие значения частот (таблица 6).

Таблица 6. Температуры $\mathrm{T}_{\mathrm{t}}, \mathrm{T}_{\mathrm{b}}$ и частоты $\mathrm{v}_{\mathrm{t}}, \mathrm{v}_{\mathrm{b}}$ торсионных и изгибных мод колебаний полимеров [41,42].

\begin{tabular}{|c|c|c|c|c|c|c|}
\hline Полимер & $\mathrm{T}_{\mathrm{t}}$, & $\mathrm{T}_{\mathrm{b}}$ & $\mathrm{v}_{\mathrm{t}}$ & $\mathrm{v}_{\mathrm{b}}$ & $\mathrm{v}_{\mathrm{t}}$ & $\mathrm{v}_{\mathrm{b}}$ \\
\cline { 2 - 7 } & \multicolumn{2}{|c|}{$\mathrm{K}$} & \multicolumn{5}{|c|}{$\mathrm{cm}^{-1}$} \\
\hline & \multicolumn{1}{|c|}{ Рассчитанные } & \multicolumn{1}{|c|}{ Измеренные [37,38] } \\
\hline ПЭ & 100 & 250 & 230 & 530 & 250 & 520 \\
\hline ПА 6 & 160 & 340 & 340 & 720 & 340 & 760 \\
\hline ПЭТФ & 130 & 380 & 280 & 810 & 350 & 800 \\
\hline ПП & 220 & 270 & 470 & 570 & 470 & 570 \\
\hline ПОМ & 220 & 390 & 470 & 830 & 470 & 840 \\
\hline ПАН & 150 & 380 & 320 & 810 & 340 & 800 \\
\hline
\end{tabular}

Видно, что вычисленные и измеренные значения частот $v_{\mathrm{t}}$ и $v_{\mathrm{b}}$ совпадают. Это вскрывает физический смысл температур $\mathrm{T}_{\mathrm{t}}$ и $\mathrm{T}_{\mathrm{b}}$. Ниже $\mathrm{T}_{\mathrm{t}}$ энергия теплового движения недостаточна, чтобы возбудить торсионные колебания скелета молекул. В этом случае тепловые флуктуации не образуются. Прочность не зависит от температуры. При $\mathrm{T}_{\mathrm{t}}$ возбуждаются торсионные колебания, и величина квантовой функции начинает расти линейно с температурой. Это приводит к линейной зависимости прочности от температуры. 
При $\mathrm{T}_{\mathrm{b}}$ возбуждаются изгибные колебания скелета молекул. Это приводит к увеличению наклона температурной зависимости $\mathrm{F}_{\mathrm{q}}$ для высокоориентированных полимеров.

\section{4. Временная зависимость прочности при $T<T_{t}$}

Ниже $T_{t}$ квантовая функция $F_{q}$ не зависит от температуры, поэтому и прочность, но зависит от времени. В этом случае полимерные молекулы разрываются путем туннельных переходов [40 - 43].

Выражение для временной зависимости прочности в этом случае имеет вид:

$$
\sigma=\frac{\mathrm{U}_{0}}{\gamma}-\frac{\mathrm{kF}_{\mathrm{q}}(0)}{\gamma} \operatorname{Ln} \frac{\tau}{\tau_{0}}=\sigma\left(\mathrm{T}_{\mathrm{t}}\right)
$$

или, при испытаниях на разрывной машине -

$$
\sigma(\mathrm{T}) \approx \frac{\mathrm{U}_{0}}{\gamma}-32 \frac{\mathrm{k}_{\mathrm{B}}}{\gamma} \mathrm{F}_{\mathrm{q}}(0) \approx \sigma\left(\mathrm{T}_{\mathrm{t}}\right),
$$

где $\sigma\left(\mathrm{T}_{\mathrm{t}}\right)$ - значение прочности при температуре $\mathrm{T}_{\mathrm{t}}$.

\section{5. Описание температурно-временной зависимости прочности при $T>T_{b}$}

Помимо флуктуаций, разрывающих химические связи, существуют еще и флуктуации, вызывающие подвижность молекул и приводящие к появлению первичных очагов деформации. Оказалось, что из изгибной моды колебаний могут черпать энергию не только разрушающие тепловые флуктуации, но и флуктуации, обуславливающие за формирование релаксационного $\alpha$ - перехода. Для примера в таблице 7 приведены значения температур $\mathrm{T}_{\mathrm{b}}$ и $\mathrm{T}_{\mathrm{g}}$, где $\mathrm{T}_{\mathrm{g}}$ - температура $\alpha-$ перехода для некоторых полимеров. 
Известно, что выше $\mathrm{T}_{\mathrm{g}}$ резко увеличивается подвижность молекул, вследствие чего предразрывная деформация недеформированных полимеров увеличивается до нескольких сотен процентов, что приводит к изменению параметра $\gamma$ при измерении прочности.

Таблица 7. Сравнение температур $\mathrm{T}_{\mathrm{b}}$ и $\mathrm{T}_{\mathrm{g}}$.

\begin{tabular}{|c|c|c|}
\hline Полимер & $\mathrm{T}_{\mathrm{b}}$ & $\mathrm{T}_{\mathrm{g}}[48,49]$ \\
\cline { 2 - 3 } & \multicolumn{2}{|c|}{$\mathrm{K}$} \\
\hline ПА6 & 340 & 340 \\
\hline ПЭ & 240 & 250 \\
\hline ПП & 270 & 270 \\
\hline ПЭТФ & 370 & 370 \\
\hline
\end{tabular}

В [44 - 46] было показано, что в этой области температур зависимость долговечности полимеров от температуры и нагрузки описывается следующим эмпирическим уравнением:

$$
\tau=\tau_{0}\left(\sigma_{\mathrm{g}} / \sigma\right)^{\frac{\mathrm{U}_{0}}{3 \mathrm{kT} T_{\mathrm{g}}}} \exp \frac{\mathrm{U}_{0}}{\mathrm{kT}}
$$

После логарифмирования (19) получаем:

$$
\ln \sigma \approx \ln \sigma_{\mathrm{g}}-\frac{3 \mathrm{kT} \mathrm{T}_{\mathrm{g}}}{\mathrm{U}_{0}} \ln \frac{\tau}{\tau_{0}}+\frac{3 \mathrm{~T}_{\mathrm{g}}}{\mathrm{T}}=\mathrm{A}_{\sigma}+\frac{3 \mathrm{~T}_{\mathrm{g}}}{\mathrm{T}}
$$

где: $\mathrm{A}_{\sigma}=\ln \sigma_{\mathrm{g}}-\frac{3 \mathrm{kT}}{\mathrm{U}_{0}} \ln \frac{\tau}{\tau_{0}}, \sigma_{\mathrm{g}}-$ прочность при $\mathrm{T}_{\mathrm{g}}$. 


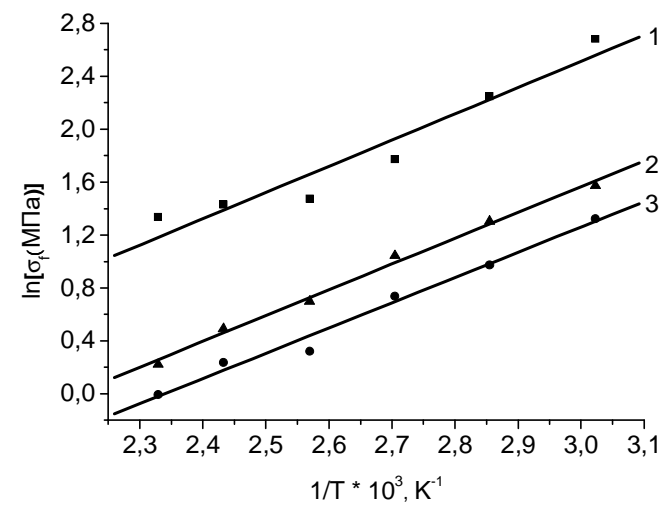

Рис. 19. Зависимость $\ln \sigma=\mathrm{f}(1 / \mathrm{T})$ для ПЭТФ при различном времени до разрушения, $\mathrm{t}_{\mathrm{f}}, \mathrm{c}: 1-10 ; 2-10^{2} ; 3-10^{3}$.

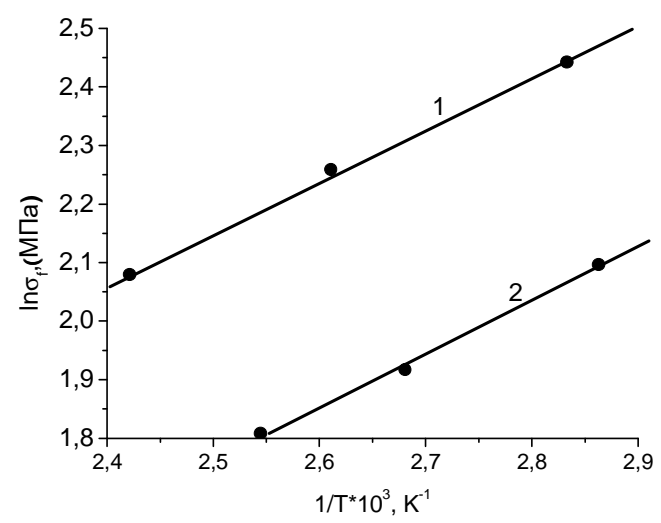

Рис. 20. Зависимость $L n \sigma=f(1 / \mathrm{T})$ в области температур выше $\mathrm{T}_{\mathrm{g}}$ для покрытия 1 - ПА 66,6 на стали Ст 3 при различном времени до разрушения, $\mathrm{t}, \mathrm{c}: 1-10 ; 2-10^{2}$.

Из (19) следует, что при фиксированной скорости нагружения логарифм прочности $\sigma$ должен увеличиваться линейно от обратной тем- 
пературы, причем тангенс угла наклона прямой не зависит от времени $\tau$ до разрушения и равен $3 \mathrm{~T}_{\mathrm{g}}$.

На рис. 19 и 20 показаны зависимости $\ln \sigma$ от обратной температуры для неориентированной пленки ПЭТФ и покрытия ПА 6,6 на стали 3.

Видно, что экспериментальные точки, полученные при различном времени до разрушения, ложатся на прямые параллельные линии.

Определенная из наклона прямых линий величина $\mathrm{T}_{\mathrm{g}}$ совпала с найденной из данных дифференциальной сканирующей калориметрии и инфракрасной спектроскопии (Таблица 6).

Таблица 6. Сравнение значений $\mathrm{T}_{\mathrm{g}}$, определенных из зависимостей $\ln \sigma=\mathrm{f}(\mathrm{T})$, и приведенных в литературе.

\begin{tabular}{|c|c|c|c|}
\hline № & Покрытие или клей & $\begin{array}{c}\text { Литературные } \\
\text { данные [47, 48] }\end{array}$ & $\begin{array}{c}\text { Из зависимости } \\
\ln \sigma=\mathrm{f}(\mathrm{T})\end{array}$ \\
\hline 1 & ПА 6 & 340 & 340 \\
\hline 2 & ПА 6+5\% $\mathrm{MoS}_{2}$ & 340 & 340 \\
\hline 3 & ПА 6+10\% графита & 340 & 340 \\
\hline 4 & ПА 5,4 & - & 350 \\
\hline 6 & ПА 66,6 & 320 & 320 \\
\hline 8 & КДС-19 & 310 & 370 \\
\hline 9 & К-300 & 330 & 360 \\
\hline 10 & КВС-31 & 370 & 350 \\
\hline
\end{tabular}

Таким образом, эмпирическое уравнение (18) удовлетворительно описывает зависимость долговечности адгезионных соединений от нагрузки и температуры при $\mathrm{T}>\mathrm{T}_{\mathrm{g}}$. Оно может быть использовано для определения энергии активации $\mathrm{U}_{0}$. Ее значение можно оценить, экстраполируя линейные зависимости в координатах $\ln \sigma=\mathrm{f}(1 / \mathrm{T})$ к $1 / \mathrm{T}=$ 0 , как

$$
\mathrm{U}_{0}=\frac{3 \mathrm{kT}}{\mathrm{A}-\ln \sigma_{\mathrm{g}}} \ln \frac{\tau}{\tau_{0}}
$$


Они приведены в таблице 7.

Таблица 7. Значения энергий активации $\mathrm{U}_{0 \mathrm{t}}$ и $\mathrm{U}_{0}$ разрушения адгезионных связей между полиамидными покрытиями и сталью.

\begin{tabular}{|l|l|l|l|}
\hline № & Покрытие & $\begin{array}{l}\mathrm{U}_{0 \mathrm{t},} \\
\text { эВ }\end{array}$ & $\begin{array}{l}\mathrm{U}_{0}, \\
\text { эB }\end{array}$ \\
\hline 1 & ПА 6 & 1,1 & 0,8 \\
\hline 2 & ПА 6+5\% $\mathrm{MoS}_{2}$ & 1,1 & 0,8 \\
\hline 3 & ПА 6+10\% графита & 1,0 & 0,8 \\
\hline 4 & ПА 5,4 & 1,0 & - \\
\hline 5 & ПА 5,4+5\% $\mathrm{MoS}_{2}$ & 1,1 & - \\
\hline 6 & ПА 6,6 & 1,0 & 0,75 \\
\hline 7 & ПА 6,6/6 & 0,9 & 0,73 \\
\hline
\end{tabular}

Видно, что значения энергии активации разрушения полиамидов составляют $\approx 1,0-1,3$ эВ. Такое же значение имеет энергия активации разрушения адгезионных связей. Этот результат показывает, что разрушение адгезионных связей в действительности является когезионным, т.е. трещина проходит по полимеру.

Мы еще вернемся к обсуждению этого вопроса в главе 5. где будет рассматриваться вопрос о природе адгезионных связей.

Рассмотрим, теперь, как проявляется неравномерность распределения энергии по колебаниям для случая композита, армированного угольными волокнами. Интерес к этому рассмотрению вызван тем, что деформация волокон до разрыва мала, а матрица податлива.

\section{6. Температурная зависимость прочности трехмерно армированного углерод-углеродного композита}

Температурная зависимость прочности углеродного волокна приведена на рис. 21 [49].

Видно, что Т<2000 $K$ наблюдаются отклонения от линейной зависимости. Они обусловлены неравномерностью распределения энергии 
по колебаниям кристаллической решетки графита. В этом случае зависимость квантовой функции можно определить, используя температурную зависимость теплоемкости $\mathrm{C}_{\mathrm{p}}$ графита [50] по формуле:

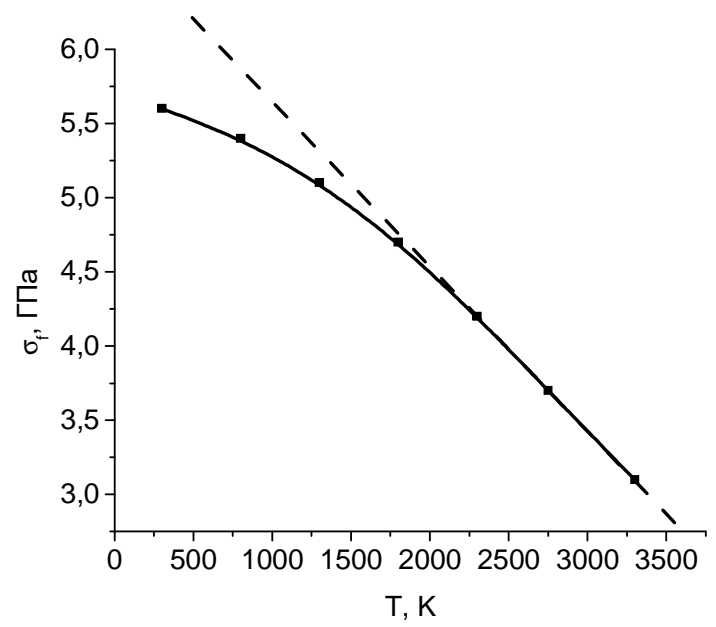

Рис. 21. Температурная зависимость прочности углеродного волокна.

$$
\mathrm{F}_{\mathrm{q}}=\mathrm{F}_{\mathrm{q}}(0)+\mathrm{F}_{\mathrm{q}}(\mathrm{T})=\mathrm{F}_{\mathrm{q}}(0)+\frac{\int_{0}^{\mathrm{O}} \tilde{\mathrm{N}}_{\mathrm{V}}(\mathrm{O}) \mathrm{dT}}{\tilde{\mathrm{N}}_{\mathrm{V}_{\mathrm{cl}}}},
$$

где $\mathrm{C}_{\mathrm{Vcl}} \approx 2,1$ кДж/кГ*К- теплоемкость при температуре, превышающей 2250 К.

На рис. 22 показана зависимость квантовой функции $\mathrm{F}_{\mathrm{q}}$ от температуры, а на 23 - зависимость прочности от $\mathrm{F}_{\mathrm{q}}$. Видно, что последняя зависимость линейна. 


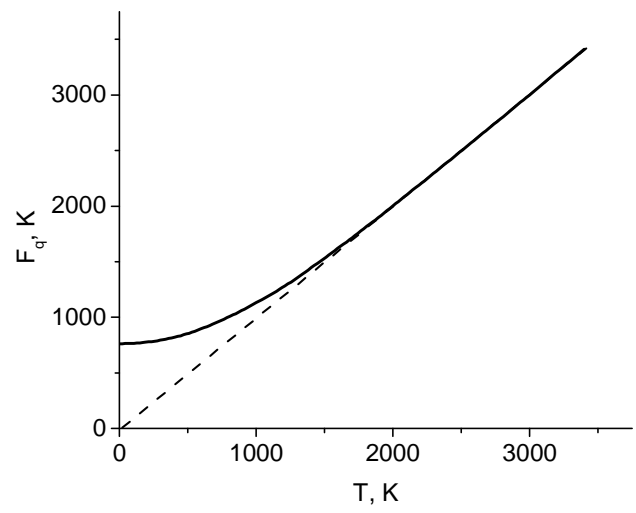

Рис. 22. Зависимость квантовой функции $\mathrm{F}_{\mathrm{q}}$ от температуры.

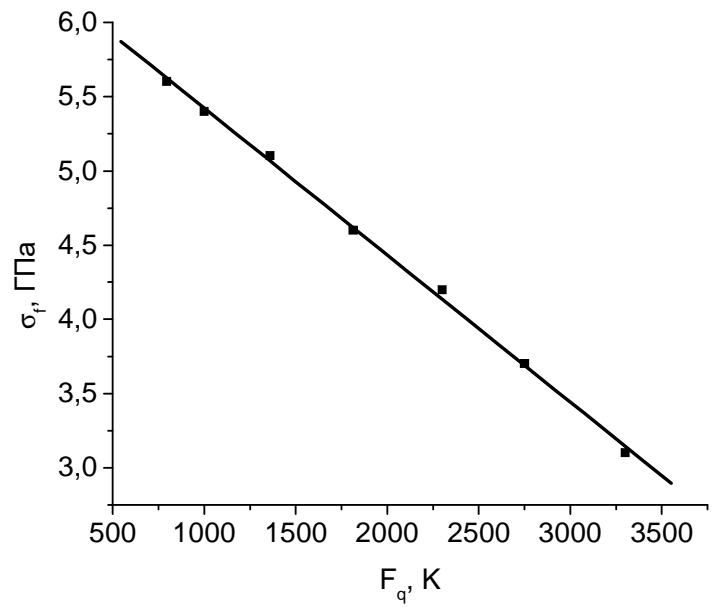

Рис. 23. Зависимость прочности углеродного волокна от квантовой функции $\mathrm{F}_{\mathrm{q}}$. 
Воспользуемся уравнениями (8) и (9), чтобы вычислить значения $\mathrm{U}_{0}$ и $\gamma$. Прямая линия рис. 23 отсекает от оси температур отрезок $\mathrm{T}_{*} \approx$ 6400 К. Из уравнения (8) имеем: $\mathrm{U}_{0} \approx 32 * \mathrm{kT} *=18$ эВ

Известно, что энергия активации разрушения $\mathrm{U}_{0}$ равна энергии активации разрыва химических связей и не зависит от структуры полимера, т.е. такое же значение энергии активации разрушения $\approx 18 \mathrm{eV}$ имеет и углеродная матрица. Важно, что оно превосходит в $3-4$ раза энергию активации разрыва одиночных С-C связей - $4-5 \mathrm{eV}$. Столь высокое значение $\mathrm{U}_{0}$ обеспечивает сохранение целостности волокнистых углерод-углеродных композитов при высоких температурах.

Измерив тангенс угла наклона $\Delta \sigma / \Delta \mathrm{T}$ прямой линии на рис. 24 , можно определить величину параметра $\gamma$ для углеродного волокна:

$$
\gamma_{\tilde{\mathrm{n}}} \approx-30 \mathrm{k}\left(\Delta \sigma_{\mathrm{f}} / \Delta \mathrm{T}\right)^{-1} \approx 0,15 \mathrm{нм}^{3}
$$

Рассмотрим, теперь, температурную зависимость прочности $\sigma_{\mathrm{c}}$ углерод - углеродного композита (рис. 24).

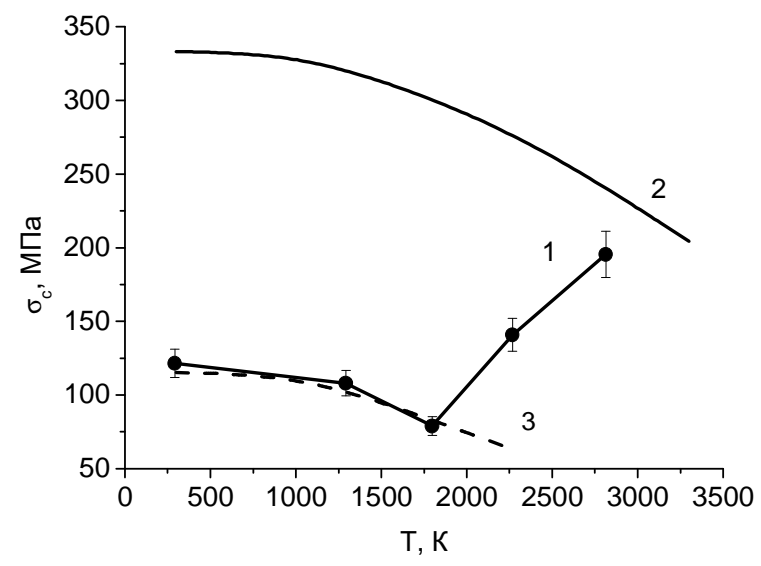

Рис. 24. Температурные зависимости прочности образцов, вырезанных из волокнистого углерод-углеродного композита: 1 - измеренная; 2 рассчитанная в предположении, что механическое усилие держат только углеродные нити, в которых волокна идеально уложены вдоль их оси; 3 - значения расчетной прочности уменьшены в $\approx 2,5$ раза. 
Видно, что прочность уменьшается до $\approx 1800$ К, а затем увеличивается приблизительно линейно с температурой. В исследованном нами образце композита доля сечения, перпендикулярного направлению растяжения, приходящаяся на углеродные нити, составляет $\approx 6,7$ $\%$. Поэтому легко рассчитать температурную зависимость прочности виртуального образца, в котором матрица отсутствует, а нагрузку держат только углеродные волокна (кривая 2 на рис. 24).

Как и следовало ожидать, прочность виртуального образца уменьшается во всем диапазоне температур. Уменьшим ее приблизительно в $\approx 2,5$ раза. Тогда, как видно из графика (пунктирная линия), в диапазоне температур от 300 до 1800 К она совпадет с прочностью реального образца.

Этот результат показывает, что нелинейное уменьшение прочности композита в этом диапазоне температур имеет такую же кинетическую природу, как и уменьшение прочности волокон. Поскольку энергия активации разрушения для композита имеет одно и тоже значение для углеродного волокна и матрицы, можно определить значение параметра $\gamma_{\mathrm{c}}$ для композита, сравнив прочности волокна $\sigma_{\mathrm{f}}$ и композита $\sigma_{\mathrm{c}}$ :

$$
\gamma_{\tilde{\mathrm{n}}} \approx \frac{\sigma_{\mathrm{f}}}{\sigma_{\mathrm{c}}} \gamma_{\mathrm{f}} \approx 7 \mathrm{HM}^{3}
$$

т.е. в $\approx 50$ раз больше, чем для углеродного волокна.

Как уже отмечалось, при Т> $1800 \mathrm{~K}$ прочность композита начинает увеличиваться и достигает 190 МПа, а параметр $\gamma_{\text {c }}$ - уменьшается до $\approx 4$ нм$^{3}$. Чтобы выяснить причины этого явления сопоставляли прочность образца с предразрывной деформацией $\varepsilon$ при различных температурах. Из рис. 25 видно, что между ними наблюдается линейная корреляция.

При анализе наблюдаемых изменений разрывных деформаций и прочностей необходимо учесть, что прочность матрицы приблизительно на два порядка меньше прочности углеродных волокон и основную долю нагрузки, приложенной к композиту "несут" волокна. В свою очередь, волокна, уложены в нитях недостаточно регулярно, и механическое напряжение распределяется по ним неравномерно. 


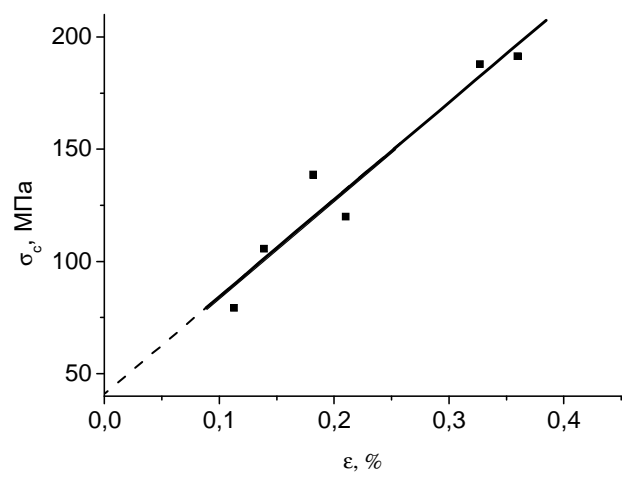

Рис. 25. Корреляция между разрывными деформацией и напряжением для образцов углерод-углеродного композита.

При комнатной температуре матрица находится в стеклообразном состоянии, и адгезионные связи между ней и волокнами препятствуют их проскальзыванию относительно друг друга и "выравниванию" напряжений. Однако, при повышении температуры прочность адгезионных связей между волокном и матрицей уменьшается и при $1800 \mathrm{~K}$, они становятся неспособными воспрепятствовать перемещению волокон относительно друг друга. Несмотря на то, что прочность волокон продолжает уменьшаться, выравнивание напряжений на волокнах нивелирует этот эффект и вызывает увеличение прочности.

При $\approx 2800$ К прочность образца достигает максимального значения - 190 МПа, которое лишь на $\approx 30 \%$ меньше прочности виртуального образца, составленного из идеально уложенных волокон. Следовательно, несмотря на то, что доля сечения приходящегося на матрицу, составляет $\approx 93 \%$, она "держит" только $\approx 1 / 3$ нагрузки, а $2 / 3$ - приходится на угольные волокна.

Таким образом, температурная зависимость прочности трехмерно армированного углерод - углеродного композита определяется главным образом температурной зависимостью прочности углеродных волокон и их взаимной укладкой в нитях. 


\section{7. К вопросу о величине параметров $U_{0}$ u $Y$}

Как показано выше даже в том случае, когда предразрывное удлинение мало и зависимостью параметра $\gamma$ от деформации можно пренебречь, температурные зависимости прочности линейны в ограниченных интервалах температур. А именно, ниже $\mathrm{T}_{\mathrm{b}}$ прочность не зависит от температуры, в интервале $\mathrm{T}_{\mathrm{t}}<\mathrm{T}<\mathrm{T}_{\mathrm{b}}$ она уменьшается линейно от температуры, а выше $\mathrm{T}_{\mathrm{b}}$ линейность остается, но увеличивается наклон температурной зависимости. Эти изменения наклона температурной зависимости вызваны изменением квантовой функции $\mathrm{F}_{\mathrm{q}} \mathrm{c}$ тостом температуры.

Часто $\mathrm{F}_{\mathrm{q}}$ не известна. Как же определить описать температурную зависимость прочности в этом случае?

Сначала рассмотрим область температур меньше $\mathrm{T}_{\mathrm{t}}$, в которой прочность не зависит от температуры. Это вызвано тем, что температура слишком мала, чтобы возбудить торсионные и изгибные колебания молекул, термические флуктуации не образуются. Но, как показал эксперимент [40], прочность зависит от времени, в течение которого действует напряжение. В этом случае химические связи разрываются не под действием термических флуктуаций, а, так называемых «туннельных переходов.

Перейдем теперь к диапазону температур $\mathrm{T}_{\mathrm{t}}>\mathrm{T}>\mathrm{T}_{\mathrm{b}}$. Продолжим линейные зависимости прочности от температуры (рис.18) до пересечения с осью температур и найдем значения активационных параметров $\mathrm{U}_{0}$ и $\gamma$. Строго говоря, этого делать нельзя, поскольку такая операция не учитывает неравномерность распределения энергии по модам колебаний. Полученные таким образом значения отличны от истинных. Чтобы отличать их от истинных, мы использовали обозначения $\mathrm{U}_{0 \mathrm{t}}$ и $\gamma_{\mathrm{t}}$. Значок $\mathrm{t}$ означает, что в данной области температур термически возбуждены только торсионные колебания и тепловые флуктуации могут черпать энергию для своего образования только из них.

Рассмотрим теперь диапазон температур $\mathrm{T}>\mathrm{T}_{\mathrm{b}}$. Поступим как ранее - на графиках $\sigma=f(T)$ продолжим линейные участки температурных зависимостей прочности до пересечения с осью температур и найдем значения $\mathrm{T}_{\mathrm{b}}^{*}$ и затем - новые значения энергии - $\mathrm{U}_{0 \mathrm{~b}}$. Необходимо отметить, что при $\mathrm{T}>\mathrm{T}_{\mathrm{b}}$ квантовая функция $\mathrm{F}_{\mathrm{q}} \approx \mathrm{T}$. Поэтому 
найденные таким образом значения $\mathrm{U}_{0 \mathrm{~b}} \approx \mathrm{U}_{0}$, т.е. истинной энергии активации разрушения. Величины $\mathrm{U}_{0}$ приведены в таблице 7. Из нее следует, что $\mathrm{U}_{0}$ меньше $\mathrm{U}_{0 \mathrm{~b}}$ всего на $20-25 \%$. Поэтому для грубой оценки энергии активации можно использовать значение $\mathrm{U}_{0 b}$.

\section{Заключение}

Долговечность полимерных материалов и композитов на их основе определяется спектром торсионных и изгибных колебаний скелета макромолекул. А именно, частоты этих колебаний определяют значения температур $T_{t}$ и $T_{b}$, при которых появляется резервуар энергии для возникновения тепловых флуктуаций, разрывающих химические связи и ведущих к появлению молекулярной подвижности.

Для учета спектра в уравнение Журкова вместо температуры вводят квантовую функцию $\mathrm{F}_{\mathrm{q}}$. Новое, обобщенное уравнение Журкова, описывает температурно-временную зависимость прочности ниже температуры $\mathrm{T}_{\mathrm{b}}$, при которой резко возрастает деформация образца до разрыва.

Получено эмпирическое уравнение, описывающее зависимость прочности от температуры и времени при испытаниях в диапазоне температур выше температуры стеклования $\mathrm{T}_{\mathrm{g}}$. 


\section{3. Граничные слои и их влияние на прочность композитов}

\section{Введение}

В последние десятилетия было установлено, что около границ, разделяющих матрицу и наполнители или покрытие и покрываемый металл, молекулы полимера стремятся уложиться параллельно границам [51 - 54]. В результате образуются, так называемые, «граничные слои, механические и теплофизические свойства которых отличны от свойств материалов, составляющих композит. Считалось, что, если между составляющими и существует химическое взаимодействие, то оно осуществляется только между ближайшими атомами на границе, в слое толщиной $\approx 1$ нм.

Такой подход построен на игнорировании теплового движения и обусловленной им диффузии, из-за которой, как будет показано ниже, молекулы и атомы способны проникать от границы раздела контактирующих поверхностей на расстояние 100 мкм и более. По этой причине граничный слой размывается на сотни мкм.

Считалось, что химическое взаимодействие между полимером и металлом не способно привести к механическим напряжениям. Принимали, что единственной причиной таких напряжений в полимере на границе с металлом является различие коэффициентов теплового расширения полимера и металла. Ниже также будет показано, что химическое и межмолекулярное взаимодействие между составляющими композита само по себе способно вызвать возникновение значительных напряжений в граничном слое.

\section{1. Внутренние напряжения в граничных слоях и их влияние на прочность композитов}

\subsection{1. Напряжения, вызванные адгезионной связью полимеров с металлами}

Распространено представление, что при контакте полимера и стали в результате взаимодействия между полярными группировками, входящими в состав молекул полимера, и окислом, который всегда 
существует на поверхности стали, могут образовываться новые химические связи. Наряду с ними молекулы окисла на поверхности стали могут образовывать водородные связи с группировками $\mathrm{OH}$ или $\mathrm{NH}$ входящими в состав молекул полимера [55 - 58].

В этом случае толщина граничного слоя между полимером и окислом не должна значительно превышать $\approx 1$ нм и при разрушении адгезионного соединения трещина должна проходить между металлом и полимером. Между тем, исследование поверхностей разрушения адгезионных соединений сталей с эпоксидными клеями и полиамидами, показывает, что трещина, как правило, проходит на расстоянии 100 мкм и более от границы раздела. Это означает, что толщина граничного слоя межу металлом и полимером составляет по крайней мере $\approx 100$ мкм.

Это противоречит мнению, что измеряемая на опыте прочность соответствует прочности химических или водородных связей молекул полимеров со сталями.

Чтобы выяснить природу адгезионной связи, рассмотрим рис. 26 и 27 на которых изображено строение молекулы ПА 6 и клея КВС 31.<smiles>CCNCCCCCCC(=O)NC</smiles>

Рис. 26. Фрагмент молекулы ПА 6.<smiles>[R]NCc1ccccc1CNCC(O)COc1ccc(C(C)(C)c2ccc(OCC(O)CNCc3ccccc3CN[R])cc2)cc1</smiles>

Рис. 27. Фрагмент молекулы КВС-31. 
Отметим, что молекулы этих полимеров содержат атомы азота, обладающие неподеленными электронными парами, и могут служить донорами электронов.

Далее, напомним, что при приготовлении клея сначала на поверхность стали наносят жидкую смесь эпоксидной смолы и отвердителя. Со временем в результате реакции между смолой и отвердителем образуется жесткий эпоксидный клей. Для приготовления покрытия из полиамидов на сталях сначала стальное изделие разогревают выше температуры плавления полимера. Затем на него наносят порошок полимера, который расплавляясь, покрывает поверхность. С течением времени изделие остывает и на его поверхности остается жесткое покрытие. Общим является в начальный момент наличие жидкого слоя на поверхности металла.

Известно, что железо способно растворяться в полярных жидкостях. Процесс растворения заключается в проникновени ионов $\mathrm{Fe}^{2+}$ в жидкость. Эти ионы имеют свободные гибридные d - орбитали, и могут выступать в роли акцепторов электронов.

При обменном взаимодействии между группировками $\mathrm{CN}$ и ионами $\mathrm{Fe}^{2+}$ образуются координационные соединения [59 - 61]. В результате в полиамиде или смеси эпоксидной смолы и отвердителя около поверхности металла образуется «диффузный» слой, насыщенный такими соединениями. Его прочность после затвердевания, как будет показано ниже, больше прочности клея или полиамида, и трещина должна проходить над этим слоем. Поэтому и энергия активации разрушения адгезионного соединения должна совпадать с энергией активации разрыва химических связей клея, как это и наблюдается в эксперименте (см. п. 2.3).

Сначала рассмотрим данные, показывающие, что ионы $\mathrm{Fe}^{2+}$ действительно диффундируют в покрытие [62]. Опустим в смесь эпоксидной смолы и отвердителя две стальных пластинки и создадим разность потенциалов между ними. Если ионы $\mathrm{Fe}^{2+}$ действительно проникают в покрытие, то они переносят заряд и разность потенциалов должна со временем уменьшаться.

Были приготовлены пластинки из стали 3 с размерами 20x40x2 мм. Их полировали до зеркального блеска, используя пасту ГОИ. Затем на одну из стальных пластинок опускали в сосуд, содержащий 
смесь эпоксидной смолы и отвердителя, и выдерживали в течение часа. Как показали предварительные опыты, в течение этого времени, между сталью 3 и эпоксидной смолой устанавливалось равновесное состояние. Затем в этот же сосуд на расстоянии $\approx 100-200$ мкм от первой пластинки опускали вторую пластинку со свежеприготовленной смесью смолы и отвердителя (ксилилендиамина). Она была закрыта мембраной, препятствующей обмену молекулами смеси и смолы, но пропускающей ионы $\mathrm{Fe}^{2+}$.

Оказалось, после опускания второй пластины между ней и первой пластиной возникала разность потенциалов $\approx 100-160$ мВ (рис. 28).

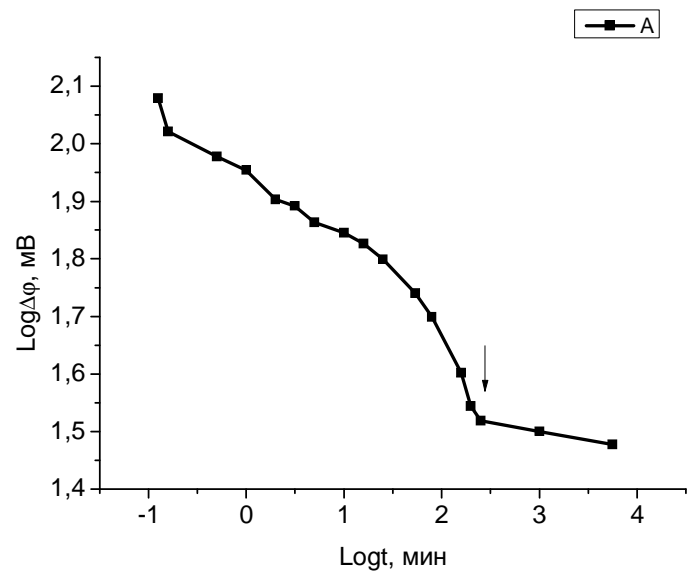

Рис. 28. Временная зависимость разности потенциалов между электродами (в двойных логарифмических координатах). Стрелкой показан момент времени, при котором смесь смолы с отвердителем становилась жесткой.

С течением времени она уменьшалась до 20 - 30 мВ из-за протекания электрического тока, переносимого ионами $\mathrm{Fe}^{2+}$. Этот процесс продолжался до тех пор, пока смесь смолы с отвердителем сохраняла свойства вязкой жидкости, в нашем случае - в течение $\approx 4$ часов. К этому времени (отмечено стрелкой на рис. 28) смесь становилась жесткой. С этого времени скорость перемещения ионов и изменения разности потенциалов резко уменьшались. Эти результаты являются 
прямым доказательством предположения о проникновении ионов $\mathrm{Fe}^{2+}$ в полимер на расстояние 100 - 200 мкм.

Выясним, теперь, - образуются ли в покрытиях КВС 31 и ПА 6 координационные соединения? Для ответа на этот вопрос были получены и проанализированы спектры ФЛ и ИК покрытия из КВС 31 и ПА 6 на поверхности стали $3(62,63)]$.

Начнем с рассмотрения спектров ФЛ. Их возбуждали лазером, излучающим свет с энергией $3,67 \mathrm{eV}$, который возбуждал $\pi \rightarrow \pi^{*}$ переход в ароматическом кольце КВС 31 и $\mathrm{C}=\mathrm{O}$ группировке в молекулах ПА 6. Спектры излучения при обратном переходе показаны на рис. 29 и 30.

Из представленных спектров видно, что энергия максимума полос в УФ спектрах уменьшается. Что же означают эти изменения? Выше уже отмечалось, что группировки CN могут вступать в координационную связь с ионами $\mathrm{Fe}^{2+}$. При этом энергия молекулярных орбиталей между атомами С и $\mathrm{N}$, а, значит, и между атомами углерода ароматического кольца в КВС 31 и $\mathrm{C}=\mathrm{O}$ группировок в ПА 6 изменяется.

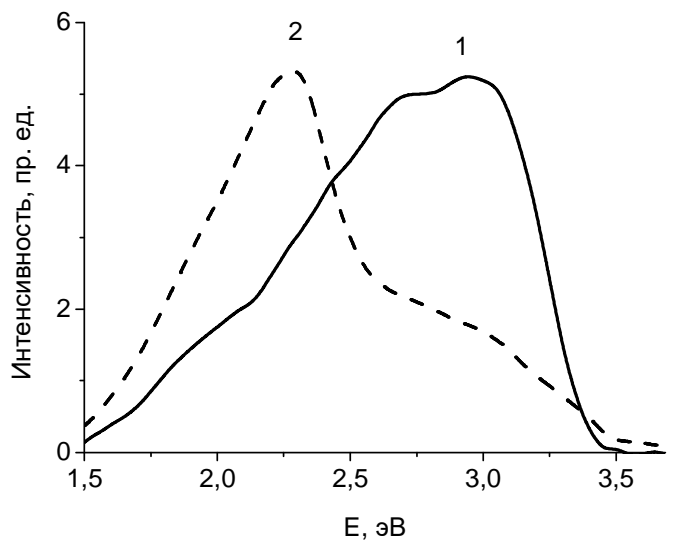

Рис. 29. Спектры флуоресценции пленки (1) и покрытия (2) (толщина 20 мкм) из КВС 31 на поверхности стали. 


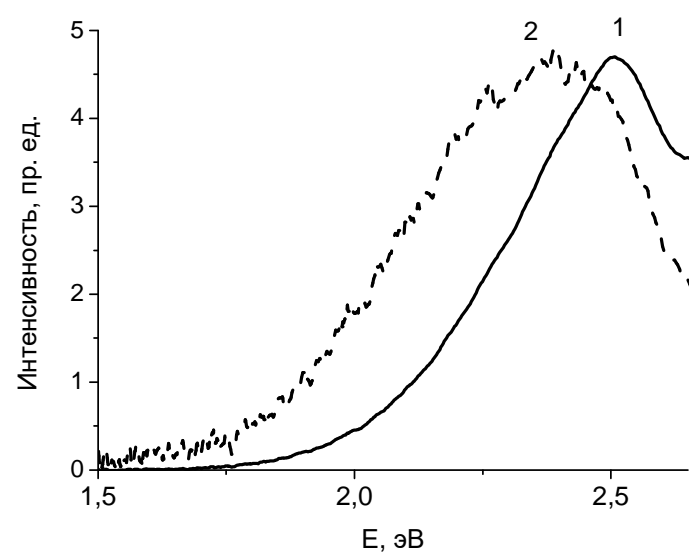

Рис. 30. Спектры ФЛ пленки (1) и покрытия (2) из ПА 6 (толщина покрытия - 2.3 мкм) на поверхности стали 3.

Из литературы известно [64 - 67], что при образовании координационных соединений между ионами $\mathrm{Fe}^{2+}$ и атомами азота, энергия $\pi$ $\rightarrow \pi$ переходов уменьшается. Поэтому наблюдаемые изменения в УФ спектрах покрытий из КВС 31 и ПА 6 однозначно указывают на образование координационных соединений в них.

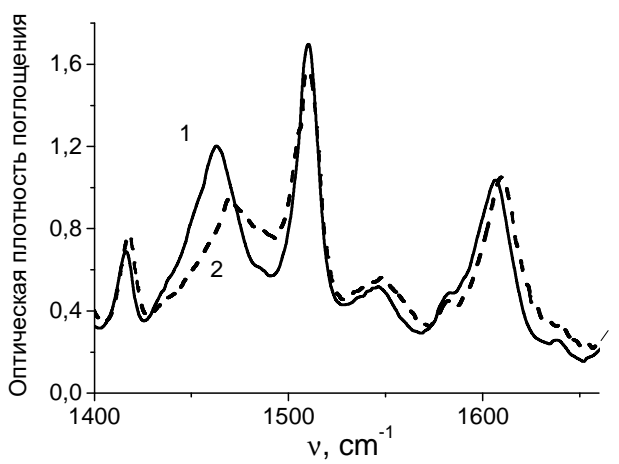

Рис. 31. Фрагменты ИК-спектров пленки (1) и слоя клея на поверхности стали 3 (2). 
Перейдем к рассмотрению ИК - спектров.

На рис. 31 показаны фрагменты ИК-спектров пленок КВС 31, как не содержащих координационных соединений, так и насыщенных ими. Видно, что частоты максимумов полос $1416,3 \mathrm{~cm}^{-1}$ (колебания $\mathrm{CH}_{2}$ группировок [68, 69), $1463,1 \mathrm{~cm}^{-1}$ (колебания $\mathrm{CH}_{3}$ группировок) и $1600,6 \mathrm{~cm}^{-1}$ (колебания ароматического кольца) в ИК - спектре пленки на поверхности стали увеличились. Такой же эффект увеличения частоты наблюдался и для других полос, приписанных колебаниям ароматического кольца $\left(790,8,1083,5 \mathrm{~cm}^{-1}\right)$, колебаниям углеродного скелета между ароматическими кольцами $\left(1033,7,1160,4 \mathrm{~cm}^{-1}\right)$, и колебаниям боковых группировок $\mathrm{CH}_{2}$ и $\mathrm{CH}_{3}\left(1463,1,1373 \mathrm{~cm}^{-1}\right)$. Частоты их максимумов увеличились в пределах от 1 до $\approx 6,6 \mathrm{~cm}^{-1}$. Это показывает, что при образовании координационного соединения между ионом $\mathrm{Fe}^{2+}$ и группировкой $\mathrm{CN}$ изменяются частоты колебаний не только химических связей в молекулах клея, непосредственно примыкающих к этой группировке, но и, что особенно важно, всех связей в скелете молекулы КВС 31. Из уравнения (10) следует, что образование координационного соединения приводит к сжатию химических связей в молекул КВС 31.

На рис. 32 показаны фрагменты ИК спектры пленки ПА 6 и покрытия из ПА 6 на поверхности стали 3 [63].

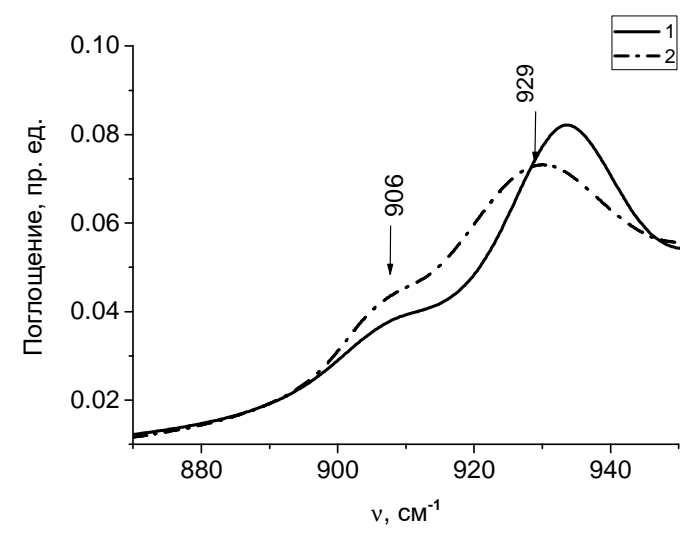

Рис. 32. Полоса валентных колебаний скелета молекул ПА 6 в ИКспектрах покрытия (1) и плёнки (2). 
Сначала рассмотрим спектр пленки. В нем наблюдается полоса с максимумом $929 \mathrm{~cm}^{-1}$. Она приписана валентным колебаниям участка молекулы РА 6 длиной $\lambda \sim 0,7$ нм [68].

Известно, что полосы в инфракрасных спектрах образуются в результате наложения друг на друга «элементарных» полос, соответствующих колебаниям каждого из участков длиной $\lambda$. «Элементарные» полосы имеют дисперсионную, симметричную относительно максимума, форму [69]. Однако суммарная полоса, изображенная на рис. 3, несимметрична: на ее длинноволновом крыле наблюдается слабо выраженный дополнительный максимум около $908 \mathrm{~cm}^{-1}$. Несимметричная форма суммарной полосы обусловлена тем, что в пленке существуют деформированные (растянутые) на различную величину участки полимерных молекул [6-18]. По этой причине частоты их колебаний смещены в сторону низких частот на различную величину (см. уравнение (10) и, накладываясь друг на друга, «размывают» низкочастотное крыло полосы.

Рассмотрим теперь спектр покрытия. В нем максимум суммарной полосы смещен в сторону высоких частот на $~ 3 \mathrm{~cm}^{-1}$. Из уравнения (1) следует, что молекулы РА 6 сжаты. Величина деформации сжатия составляет $\varepsilon \approx \Delta v / \mathrm{Gv}(0)=3 / 925=0,32 \%$ (для полосы $929 \mathrm{~cm}^{-1} \mathrm{Gv}(0)=$ 925 , а $\alpha=3,5 \mathrm{~cm}^{-1} / \Gamma$ Па [72 - 74]). Чтобы получить такое сжатие концам участков нужно приложить напряжение $\Sigma \approx \Delta v / \alpha=3 / 3,5=0,86$ ГПа.

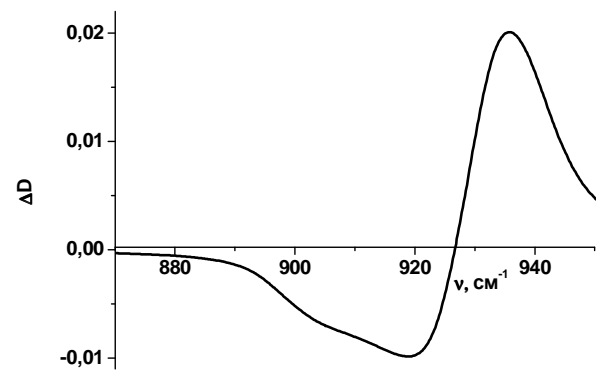

Рис. 34. Разность спектров покрытия и пленки. 
Одновременно со смещением интенсивность основного максимума увеличилась, а дополнительного - уменьшилась. Для большей наглядности рассмотрим дифференциальный спектр $\Delta \mathrm{D}$, полученный путем вычитания из спектра покрытия спектра пленки (рис. 34).

Видно, что поглощение в низкочастотном крыле полосы уменышается, а в высокочастотном растет. Это означает, что в покрытии наиболее растянутые участки молекул РА 6 становятся сжатыми. Оценим деформацию $\varepsilon$ молекулы РА 6 и величину напряжения, которую нужно приложить к концам участков, чтобы ее вызвать. Диапазон частот, в котором поглощение в спектре покрытия уменьшается, имеет границы от 880 до 926 см $^{-1}$. Это показывает, что в покрытии уменьшается концентрация участков, деформация растяжения которых варьирует в пределах от $\varepsilon \approx 0,5 \%$ до $\approx 5,5 \%$. Чтобы вызвать такие деформации нужно приложить растягивающие напряжения от 1,3 до = 14,5 ГПа.

В диапазоне частот от 926,7 до $950 \mathrm{~cm}^{-1}$, наоборот, поглощение растет. Это показывает, что в покрытии растет концентрация участков молекулы РА 6, деформация которых изменяется от растяжения на $\varepsilon=$ $0,4 \%$ до сжатия на величину $\varepsilon \approx 2,1 \%$. Чтобы вызвать такие деформации, нужно приложить растягивающие напряжения равные $\Sigma=1,3$ ГПа или сжимающие - 5,5 ГПа. Следовательно, под воздействием стальной подложки часть наиболее растянутых участков молекулы РА 6 сжалась.

В области 625 - 800 см$^{-1}$ наблюдаются две полосы 729,5 и 697,5 $\mathrm{cm}^{-1}$ (рис. 35). Первая из этих полос приписана крутильным колебаниям $\mathrm{CH}_{2}$ группировок, а вторая - деформационным колебаниям $\mathrm{NH}$ связей [70]. Из рис. 35 видно, что частота максимума полосы 697, 5 см${ }^{1}$ в спектре покрытия уменьшается на 10 и $4 \mathrm{~cm}^{-1}$, соответственно. В тоже время частота максимума полосы 729,5 $\mathrm{cm}^{-1}$ остается практически низменной. Это показывает, что смещаются частоты колебаний только основного скелета молекул, содержащего атомы азота.

Из литературы $[75,76]$ известно, что именно такое смещение в сторону низких частот должно возникать при образовании координационной связи между атомами азота и железа. С другой стороны образование новой химической связи влечет за собой перестройку элек- 
тронных орбиталей между всеми атомами в скелете полимерной молекулы, что приводит к изменению длины химических связей.

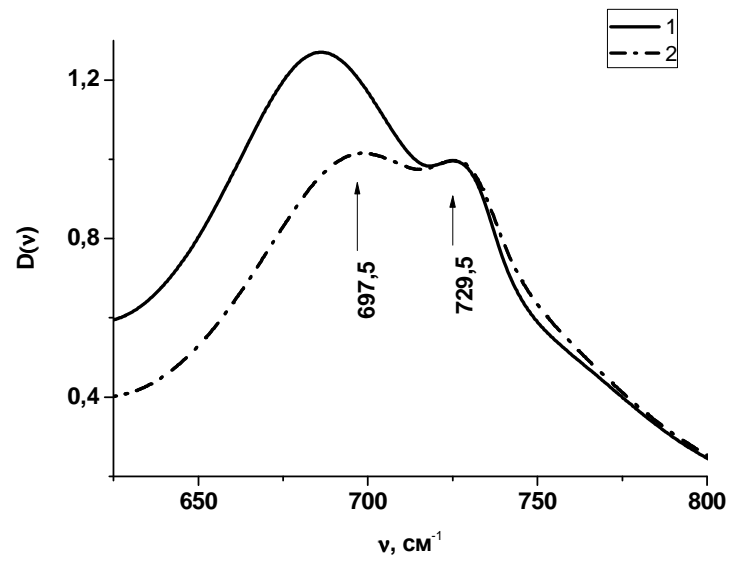

Рис. 35. Фрагменты спектра покрытия (1) и пленки (2) РА 6 в области $675-800 \mathrm{~cm}^{-1}$.

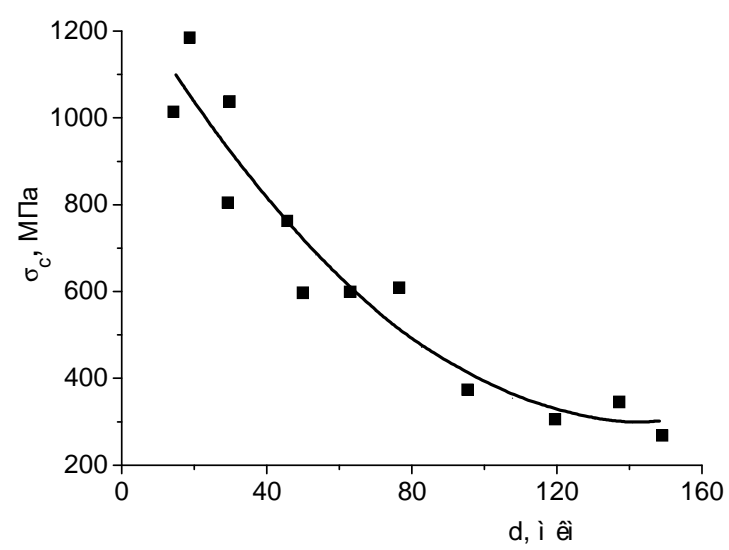

Рис. 36. Зависимость напряжения сжатия $\sigma_{\mathrm{c}}$ скелета молекул ПА 6 на поверхности стали 45 от его толщины [77, 78]. 
Интересно выяснить какова толщина слоя, в котором молекулы ПА 6 сжаты? Чтобы ответить на этот вопрос на поверхность стали 45 наносили слои ПА 6 разной толщины. Затем измеряли смещение полосы $929 \mathrm{~cm}^{-1}$ и рассчитывали величину сжимающего напряжения. Результаты измерений приведены на рис. 36. Оказалось, что величина напряжения сжатия в слое толщиной 20 мкм достигает 1,2 ГПа, и при увеличении толщины слоя до 150 мкм уменьшается до $\approx 300 \mathrm{MПа,} \mathrm{что}$ близко к разрывной прочности ПА 6.

Вышеприведенные результаты показывают, что диффузия ионов $\mathrm{Fe}^{2+}$ приводит к образованию координационных соединений с группировками C-N. В таких соединениях скелет молекул полимеров сжат. Именно по этой причине при разрушении адгезионного соединения трещина, как правило, проходит не между сталью и полимером, а выше его на расстоянии $\approx 100$ и более мкм.

\subsection{2. Внутренние напряжения, обусловленные различием КТР полимера и металла}

Теперь рассмотрим принципиальной иной механизм возникновения напряжений. Он вызван не взаимодействием между полимером, металлом или окружающей полимер атмосферой, а различием теплофизических свойств полимеров и металлов, а именно, различием их KTP.

Проще всего исследовать внутренние напряжения в полимерных композитах на примере покрытий на поверхности металлов, возникающих из-за разности КТР полимеров и металлов. Формула для их расчета в полимерном покрытии, нанесенном на металлическую подложку при температуре $\mathrm{T}_{0}$, записывается в виде:

$$
\sigma=\mathrm{E}_{\mathrm{i}}\left(\alpha_{\mathrm{i}}-\alpha_{\tilde{\mathrm{n} o}}\right)\left(\grave{O}_{0}-\grave{O}\right),
$$

где: $\alpha_{\text {п }}$ и $\alpha_{\text {м }}$ - КТР полимера и металла, соответственно, $\mathrm{E}_{\text {п }}$ - модуль упругости полимера.

Применительно к антифрикционным покрытиям на основе эпоксидных смол Чесноковым [79] была разработана методика, основанная на нанесении полимера на внутреннюю поверхность металлического 
разрезного кольца (рис. 37). По деформации зазора под действием возникающих в композиции напряжений рассчитывалась их величина. При этом деформационные свойства композиции, включающей материалы с различным модулем упругости, автор моделировал Тобразным однородным профилем.

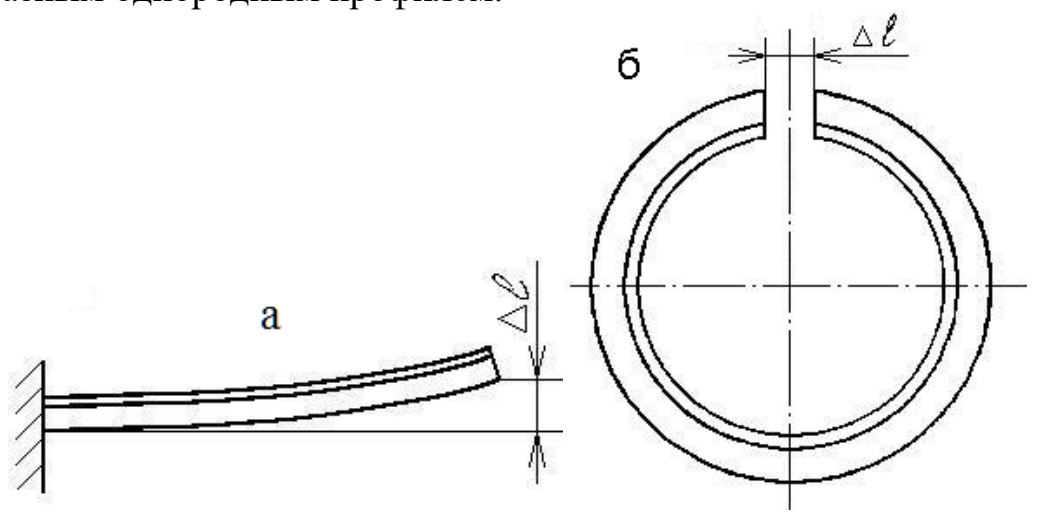

Рис. 37. Методы измерения величины «внутренних» напряжений в покрытиях: а) - по деформации консоли; б) - по деформации зазора.

Антифрикционные полиамидные покрытия обычно имеют значительно меньшую толщину, при которой силовое воздействие на более жесткую металлическую подложку оказывается весьма незначительным. Поэтому Стукачем был использован консольный метод [80], согласно которому измеряется отклонение свободного конца подложки и по теории упругости рассчитываются напряжения.

Для примера, на рис. 38 представлена зависимость величины внутренних напряжений от толщины полимерного покрытия из ПА 6,6 . 


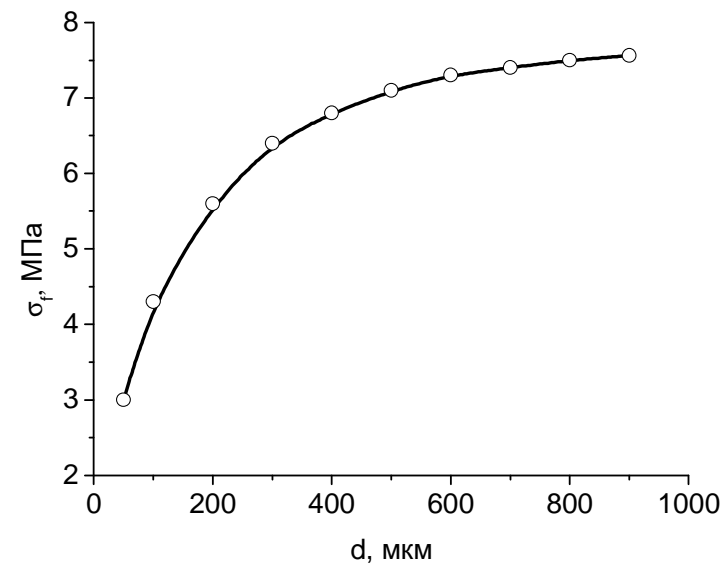

Рис. 38. Зависимость величины внутренних напряжений от толщины покрытия.

Покрытие формировали путем насыпания порошка из ПА 6,6 на полированную поверхность стали 45 нагретую до $300 \mathrm{C}$, которая выше температуры плавления полимера - 215 С. Поэтому после нанесения полимер расплавлялся и после остывания на поверхности стальной пластинки образовывалось прочное полимерное покрытие. Т.к. КТР стали на порядок меньше, чем ПА 6,6, в покрытии возникают растягивающие напряжения (рис. 38).

Обращает на себя внимание, что внутренние напряжения, вызванные различием КТР полимера и металла, растут при увеличении толщины полимерного покрытия. Выше мы уже отмечали, что напряжения вызванные образованием координационных соединений, наоборот, уменьшаются при увеличении толщины покрытия и стремятся к нулю, когда толщина покрытия превысит 100 - 200 мкм. Это означает, что при толщинах 200 - 400 мкм напряжения, обусловленные различием КТР, становятся преобладающими и, вероятно, они и приводят к образованию трещины в покрытии и его разрушению. 


\section{2. Динамика прочности адгезионных соединений между полимерами и металлами}

Ранее мы рассматривали температурную зависимость разрушающих напряжений после того как адгезионная связь между металлом и полимером образовалась. Мы пришли к выводу, что кинетика разрушения адгезионного соединения контролируется кинетикой разрыва химических связей в покрытии на расстоянии, по крайней мере, 100 мкм от поверхности раздела металл полимер. Это явление вызвано увеличением прочности химических связей покрытий из-за образования координационных соединений между ними и ионами $\mathrm{Fe}^{2+}$, выделившимися с поверхности стали.

Теперь мы можем приступить к рассмотрению вопроса о долговечности адгезионных соединений с момента начала образования адгезионных связей. Вначале рассмотрим типичные временные зависимости прочности эпоксидных клеев и полиамидных покрытий (Рис. $39-41)$.

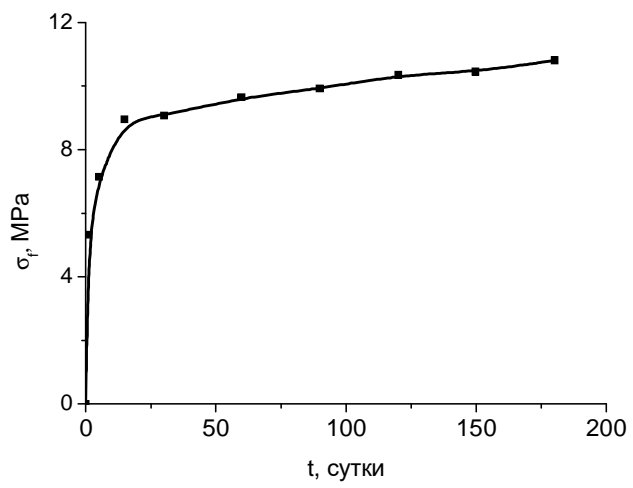

Рис. 39. Временная зависимость адгезионной прочности клеевой композиции на основе клея КВС-31 от времени выдержки при 343 К. 


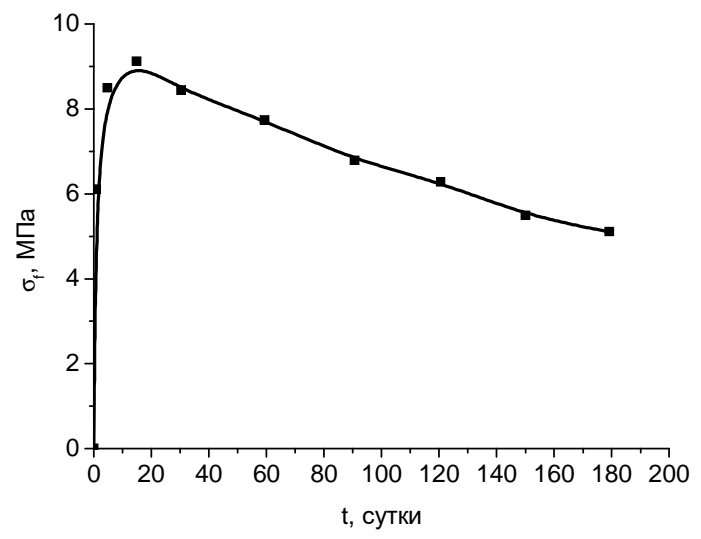

Рис. 40. Временная зависимость адгезионной прочности клеевой композиции на основе клея КВС-31 от времени выдержки при $383 \mathrm{~K}$.

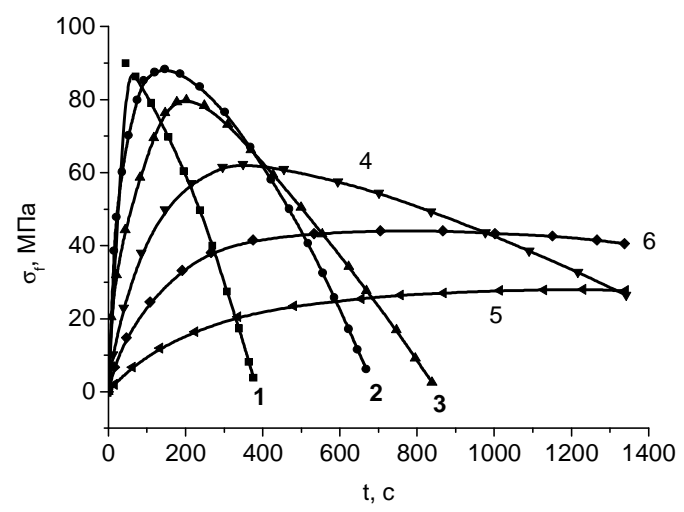

Рис. 41. Зависимость адгезионной прочности ПА 54 к стали 45 от времени при различных температурах, К: 1 - 673; 2 - 633; 3 - 593; 4 $553 ; 5-513 ; 6-473$.

Видно, что сначала прочность растет, достигает максимального значения, а затем уменьшается. Чем выше температура, тем меньше время $\mathrm{t}_{\mathrm{m}}$, при котором прочность имеет максимальное значение $\sigma_{\mathrm{m}}$. 
Такие же зависимости прочности были получены и для других адгезионных соединений.

Какова же природа изменений прочности с ростом температуры?

Выше уже было показано (см. п. 2.4.1), что энергия активации разрушения $\mathrm{U}_{0}$, разрушения сформированных (т.е. при $\mathrm{t}>\mathrm{t}_{\mathrm{m}}$ ) адгезионных соединений равна энергии активации разрушения химических связей покрытия. Поэтому наблюдаемые изменения прочности при $\mathrm{t}>\mathrm{t}_{\mathrm{m}}$ следует связывать с зависимостью параметра $\gamma$ в уравнении Журкова от времени выдержки.

Принято считать, что величина этого параметра пропорциональна коэффициенту перенапряжений $\chi: \gamma=\chi \Delta \mathrm{V}_{\mathrm{a}}$, где $\Delta \mathrm{V}_{\mathrm{a}}-$ активационный объем разрушения. Поскольку, энергия активации $\mathrm{U}_{0}$ при образовании адгезионного соединения не меняется, то не меняется и активационный объем разрушения. Это значит, что изменения прочности адгезионного соединения при увеличении времени выдержки связаны с изменением коэффициента перенапряжений $\chi$.

Из уравнения (3) следует, что

$$
\chi \Delta \mathrm{V}_{\mathrm{a}}=\frac{\mathrm{U}_{0}}{\sigma}-\frac{\mathrm{kT}}{\sigma} \operatorname{Ln} \frac{\tau}{\tau_{0}}
$$

Отсюда следует, что при времени $\mathrm{t}>\mathrm{t}_{\mathrm{m}}$ коэффициент перенапряжений увеличивается, распределение напряжений становится все более и более неравномерным. Этот результат может быть объяснен следующим образом. Коэффициент теплового расширения покрытия на порядок выше, чем металла. Это обуславливает существование напряжений в покрытии, способствующих отрыву покрытия. По-видимому, под влиянием этих напряжений в покрытии развивается процесс накопления микротрещин. Микротрещины являются концентраторами напряжений, что и приводит к увеличению коэффициента перенапряжений $\chi$.

Наоборот, при $\mathrm{t}<\mathrm{t}_{\mathrm{m}}$ развивается процесс затвердевания покрытия, что и ведет к росту его прочности.

Таким образом, временная зависимость прочности задана скоростью протекания двух последовательных событий: упрочнения вследствие затвердевания полимера и разупрочнения из-за разрушения под 
действием напряжений вызванных различием КТР покрытия и металла. Предположим, что после охлаждение образца до комнатной температуры происходит настолько быстро, что прочность за время охлаждения остается неизменной, и при комнатной температуре не зависит от времени.

Пусть $\sigma(\mathrm{t})$ прочность в момент времени $\mathrm{t}$, а $\Delta \sigma$ - уменьшение прочности из-за растрескивания образца. Тогда выражения для скоростей упрочнения $\mathrm{d} \sigma / \mathrm{dt}$, и разупрочнения $\mathrm{d} \Delta \sigma / \mathrm{dt}$ имеют следующий вид:

$$
\begin{gathered}
\mathrm{d} \sigma / \mathrm{dt}=\mathrm{k}_{\mathrm{s}}\left(\sigma_{\infty}-\sigma-\Delta \sigma\right) \\
\mathrm{d} \Delta \sigma / \mathrm{dt}=\mathrm{k}_{\mathrm{c}} \sigma
\end{gathered}
$$

где $\sigma_{\infty}$ - значение прочности, которое было бы у покрытия при $\mathrm{t} \rightarrow \infty$ в отсутствии разупрочнения, $\mathrm{k}_{\mathrm{s}}$ - константа скорости упрочнения, вызванного отвердеванием образца, а $\mathrm{k}_{\mathrm{c}}$ - константа скорости разупрочнения, связанная с изменением параметра $\gamma$ под влиянием температуры, $\Delta \sigma-$ величина разупрочнения.

Эти константы связаны с энергиями активации затвердевания, $\mathrm{U}_{\mathrm{s}}$, и разупрочнения, $\mathrm{U}_{\mathrm{c}}$, уравнениями Аррениуса:

$$
\begin{aligned}
& \mathrm{k}_{\mathrm{s}}=\mathrm{k}_{0 \mathrm{~s}} \exp \left(\frac{\mathrm{U}_{\mathrm{s}}}{\mathrm{kT}}\right) \\
& \mathrm{k}_{\mathrm{c}}=\mathrm{k}_{0 \mathrm{c}} \exp \left(\frac{\mathrm{U}_{\mathrm{c}}}{\mathrm{kT}}\right)
\end{aligned}
$$

Поскольку прочность при малых временах растет, то $\mathrm{k}_{\mathrm{s}}>\mathrm{k}_{\mathrm{c}}$. Это позволяет существенно упростить дальнейшие расчеты.

Решив уравнения (21) и (22) находим:

$$
\sigma=\sigma_{\infty}\left[\exp \left(-\mathrm{k}_{\mathrm{s}} \mathrm{t}\right)-\exp \left(-\mathrm{k}_{\mathrm{c}} \mathrm{t}\right)\right.
$$


Эта формула получена при условии, что в начальный момент склеивания прочность равна нулю.

Аппроксимация временных зависимостей прочности адгезионных соединений показана на рис. 39 - 41 сплошными линиями. Оказалось, что они хорошо описывают экспериментальные данные для соединений сталей, склеенных различными эпоксидными клеями и полиамидами.

Рассмотрим вопрос о точности такого описания. С этой целью определим величину вероятности $\mathrm{R}^{2}$, которая рассчитывается по формуле

$$
\mathrm{R}^{2}=1-\frac{\mathrm{E}}{\mathrm{T}} ; \quad 0 \leq \mathrm{R}^{2} \leq 1
$$

где

$\mathrm{E}=\sum_{\mathrm{i}}\left(\sigma_{\mathrm{i}}^{\mathrm{exp}}-\sigma_{\mathrm{i}}^{\text {th }}\right)^{2}-$ сумма квадратов ошибок,

$\mathrm{T}=\sum_{\mathrm{i}}\left(\sigma_{\mathrm{i}}^{\exp }-\langle\sigma\rangle\right)^{2}=\mathrm{N} v^{2}$,

$\sigma_{i}^{\text {exp }}$ и $\sigma_{i}^{\text {th }}-$ экспериментальные и рассчитанные значения прочности, a $v^{2}$-несмещенная дисперсия.

Величина $\mathrm{R}^{2}=1$ соответствует тому, что кривая проходит через все экспериментальные точки $(\mathrm{E}=0), \mathrm{a} \mathrm{R}^{2}=0$ означает, что модель не описывает эксперимент.

Для примера, значения вероятностей клеевого соединения стали 3 на основе КВС-31 приведены в таблице 8.

Таблица 8. Вероятности $\mathrm{R}^{2}$ для клеевого соединения на основе клея КВС-31.

\begin{tabular}{|l|l|l|l|l|}
\hline $\mathrm{T}, \mathrm{K}$ & 340 & 360 & 380 & 400 \\
\hline $\mathrm{R}^{2}$ & 0.95 & 0.90 & 0.93 & 0.90 \\
\hline
\end{tabular}

Из таблицы мы видим, что модель очень хорошо описывает кинетику изменения прочности. Оказалось, что для всех исследованных адгезионных соединений, погрешность описания не ниже 85 - 90\%. Эти данные указывают, что для всех исследованных клеевых соедине- 
ний использованная модель описывает кинетику прочности с высокой достоверностью.

Посмотрим теперь: с какой точностью определяются значения $\boldsymbol{\sigma}_{\infty}$, $\mathrm{k}_{\mathrm{s}}$ и $\mathrm{k}_{\mathrm{c}}$. Для примера в таблице 9 приведены значения $\mathrm{k}_{\mathrm{s}}$ и $\mathrm{k}_{\mathrm{c}}$, вычисленные по этой модели.

Таблица 9. Значения $\sigma_{\infty}, \mathrm{k}_{\mathrm{s}}$ и $\mathrm{k}_{\mathrm{c}}$ клеевого соединения стали 3 на основе клея КВС-31 при различных температурах.

\begin{tabular}{|l|l|l|l|l|}
\hline $\mathrm{T}, \mathrm{K}$ & 340 & 360 & 380 & 400 \\
\hline$\sigma_{\infty}, \mathrm{M \Pi a}$ & $8,5 \pm 0,5$ & $8,8 \pm 0,5$ & $8,9 \pm 0,5$ & $9,9 \pm 0,2$ \\
\hline $\mathrm{k}_{\mathrm{s}}$ & $0.9 \pm 0.3$ & $0.5 \pm 0.1$ & $1.1 \pm 0.3$ & $0.9 \pm 0.8$ \\
\hline $\mathrm{k}_{\mathrm{c}} \cdot 10^{3}$ & $1 \pm 5$ & $1 \pm 6$ & $3 \pm 7$ & $7 \pm 5$ \\
\hline
\end{tabular}

Из таблицы следует, что константа $\sigma_{\infty}$ определяется с хорошей степенью точности и слабо зависит от температуры испытаний. Это позволяет ее использовать для расчета прочности.

В то же время, константа скорости разрушения $\mathrm{k}_{\mathrm{c}}$ определяется с очень большим разбросом, величина которого возрастает при понижении температуры и ее погрешность определения $\mathrm{k}_{\mathrm{c}}$ превосходит вычисленное значение.

Погрешность определения другой константы скорости $\mathrm{k}_{\mathrm{s}}$ несколько меньше, однако, тоже весьма велика - от 30 до $90 \%$.

Природа высокой погрешности ясна: она является следствием большого разброса прочности клеевых соединений. В свою очередь высокая погрешность определения констант не позволяет прогнозировать сохранность прочности только на основе анализа кинетики временных зависимостей.

\section{3. Влияние формы и концентрации частиц наполнителя} на прочность композитов

Как уже упоминалось, молекулы полимера (матрицы) в композите, как правило, укладываются параллельно поверхности металла или наполнителя. Образуется ориентированный граничный слой, что су- 
щественно изменяет прочность композита. Одновременно химические связи в скелете молекул сжимаются, что также изменяет прочность. Удобнее всего продемонстрировать эффект влияния этих параметров на примере композитов, в которых наполнители, имеют различную форму - шароподобную или стержневидную [81]. Для создания композита в качестве матрицы использовали ПФО, а наполнителей - (порошки $\mathrm{Cu}$ и ПТФЭ диаметром $\approx 1$ мкм и $\mathrm{Al}$ диаметром $\approx 0,1$ мкм), и отрезки волокон длиной $\approx 3$ мм (угольного и стеклянного диаметром $\approx$ 6 мкм и ПАБИ - диаметром $\approx 15$ мкм). Интерес к этим композитам связан с тем, что они имеют низкий коэффициент трения, высокую износостойкость, технологичны в изготовлении и широко используются при создании узлов сухого трения изделий прецизионного машиностроения.

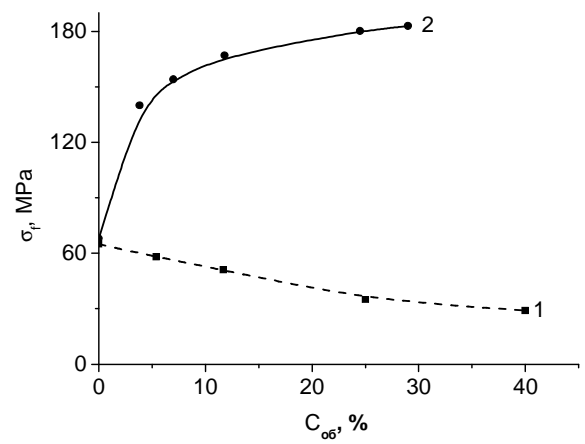

Рис. 42. Концентрационные зависимости прочности для композитов на основе ПФО. Наполнитель - порошок ПТФЭ (1) и отрезки волокон ПАБИ (2).

Для создания прочной адгезионной связи с матрицей наполнители подвергали специальной термохимической обработке. Затем порошок ПФО смешивали с ними в вибромельнице и выдерживали под давлением в течение нескольких часов при температуре $\approx 520$ К. В результате между наполнителем и матрицей образовывались прочные химические связи. Измерения показали, что при введении порошков прочность композитов уменьшается, а отрезков волокон - растет (рис. 42). 
В главе 1 было показано, что энергия активации разрушения композитов совпадает с энергией активации разрыва молекул матрицы. Введение наполнителя приводит только к изменению структурно чувствительного параметра $\gamma$ матрицы. Величину этого параметра можно найти, используя уравнение (9).

Оказалось, что при введении порошков параметр $\gamma$ увеличивается, а отрезков волокон - уменьшается (рис. 43).

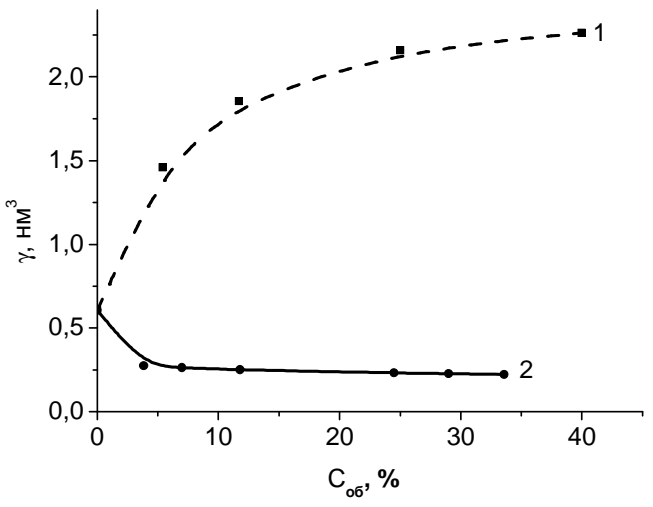

Рис. 43. Концентрационные зависимости параметра $\gamma$ для композитов на основе ПФО. Наполнитель - порошок ПТФЭ (1) и отрезки волокон ПАБИ (2).

Часто полагают, что параметр $\gamma$ можно представить в виде произведения коэффициента перенапряжений $\chi$ на активационный объем разрушения $\Delta \mathrm{V}: \gamma=\chi \Delta \mathrm{V}$ [2]. Тогда, полученные данные можно объяснить следующим образом. С одной стороны частицы наполнителя являются концентраторами напряжений. Это обусловливает уменьшение прочности и увеличение $\gamma$ для композитов, наполненных порошками. Как уже не раз упоминалось, при прессовании и высокой температуре отрезки волокон укладываются преимущес-твенно параллельно плоскости образца, а молекулы матрицы - параллельно оси волокон. Поэтому при увеличении концентрации отрезков волокон растет ориентация молекул в матрице. Это ведет к уменьшению параметра $\gamma$ 
композита и росту его прочности.

Рассмотрим эти явления более подробно.

Предположим, что изменение параметра $\gamma$ при введении порошков связано, главным образом, с тем, что они являются концентраторами напряжений. Вычислим коэффициент напряжений от них как

$$
\chi \approx \frac{\gamma_{\mathrm{K}}}{\gamma_{\mathrm{M}}}
$$

где $\gamma_{\kappa}$ и $\gamma_{\mathrm{m}}$ значения параметра $\gamma$ для матрицы ПФО и композита.

Будем полагать, что частицы порошков имеют вид шаров. Согласно теоретическим расчетам [82], напряжение около поверхности круглой поры в 3 раза превышает приложенное к телу и уменьшается на порядок на расстоянии в $\approx 1,7$ раза превышающем ее диаметр d. Чтобы сравнить результаты расчетов и измерений, построим зависимости параметра $\gamma$ от среднего расстояния между поверхностями частиц наполнителя L. Вычислим отношение L/d как:

$$
\frac{\mathrm{L}}{\mathrm{d}} \approx \frac{1}{\sqrt[3]{\mathrm{C}_{\text {об }}}}-1,
$$

где $\mathrm{C}_{\mathrm{V}}$ - объемная концентрация.

Зависимости $\gamma=\mathrm{f}(\mathrm{L} / \mathrm{d})$ приведены на рис. 44.

При их рассмотрении следует учесть, что в зависимости от упругости наполнителя форма шаров под действием растягивающих напряжений будет изменяться различным образом. Так в композите, наполненном порошком ПТФЭ, модуль упругости которого в несколько раз меньше, чем матрицы, и шар будет деформироваться в эллипсоид с главной осью вдоль приложенной силы. Величина напряжений около такого эллипсоида меньше, чем около шара. Модуль упругости меди и алюминия, наоборот, больше, чем ПФО. Поэтому под действием растягивающих напряжений их форма остается круглой.

Из рис. 44 видно, что при увеличении L/d от 0,07 до 1,65 значение $\chi$ для композита, наполненного "мягкими" частицами РТРЕ, уменьшается от $\approx 2,4$ до $\approx 1,1$. 


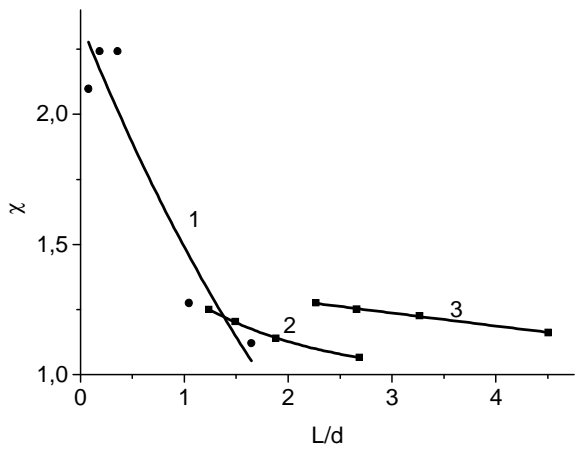

Рис. 44. Зависимости коэффициента перенапряжений $\chi$ от среднего расстояния между поверхностями частиц порошков (в единицах диаметра частиц): 1 - ПТФЭ; 2 - Al; 3 - Cu.

Для композитов, наполненных частицами $\mathrm{Cu}$ и $\mathrm{Al}$, коэффициент q, и изменяется медленнее, чем для композита, наполненного ПТФЭ. Этот результат качественно согласуется с вычисленным по теории упругости, но расстояние, на котором наблюдаются перенапряжения в $\approx 2$ - 4,5 раза превышает диаметр частиц наполнителей.

Чтобы согласовать теорию и результаты измерений, напомним, что поверхность наполнителя покрывали, так называемыми «аппретами» - веществами, обеспечивающими химическое взаимодействие наполнителей с матрицей. Затем композит подвергали специальной термической обработке. В этом случае, как показано выше на примере координационных соединений между ионами $\mathrm{Fe}^{2+}$, выделившихся из сталей и группами $\mathrm{CN}$ в молекулах полимеров, скелеты молекул полимеров сжимаются и их прочность растет. Предположим, что частицы $\mathrm{Cu}$ и $\mathrm{Al}$ окружены граничными слоями, прочность которых больше прочности матрицы. Толщину таких слоев можно оценить следующим образом. Наименьшее значение коэффициента напряжений $\chi \approx 1,1$ достигалось на расстоянии $\mathrm{L} / \mathrm{d}$ около частиц меди $\approx 4,4$, а алюминия $\approx$ 2,7 . Согласно расчетам, такое значение коэффициент напряжений около шара достигается на расстоянии $\mathrm{L} / \mathrm{d} \approx 0,7$. Отсюда получаем 
оценку толщины граничного слоя $\mathrm{L} \approx \mathrm{d} * 4,4 * 0,7 \approx 3$ мкм около частиц $\mathrm{Cu}$ и $\approx 0,3$ мкм около частиц $\mathrm{Al}$.

Перейдем к рассмотрению результатов, полученных при введении отрезков волокон. Сначала рассмотрим микрофотографию среза образца полифениленоксида, наполненном отрезками стеклянных волокон (Рис. 45).

Видно, что отрезки волокон укладываются приблизительно параллельно друг другу. Тогда среднее расстояние между их поверхностями $\mathrm{L}$, можно оценить как:

$$
\frac{\mathrm{L}}{\mathrm{d}_{\mathrm{f}}} \approx \frac{1}{\sqrt{\mathrm{C}_{\mathrm{o \sigma}}}}-1
$$

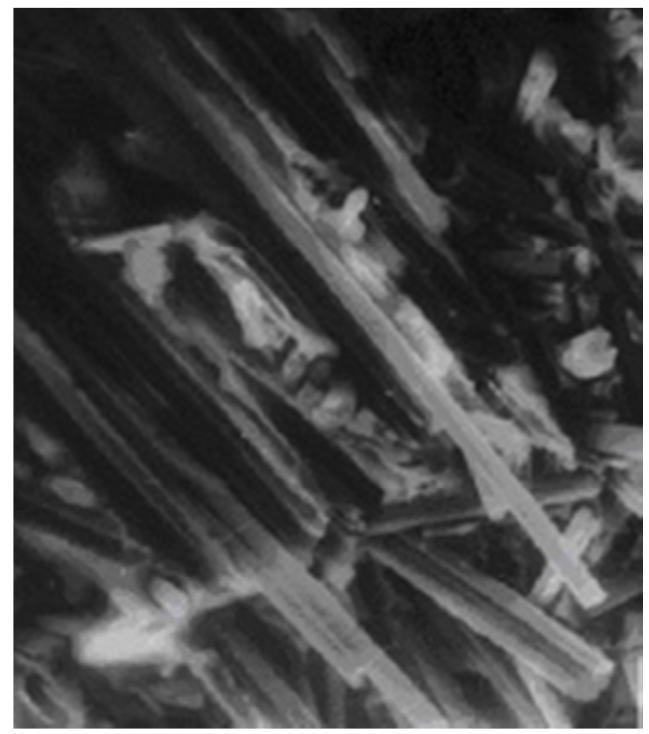

Рис. 45. Микрофотография среза ПФО, наполненного 35 \% об. отрезков стеклянных волокон.

На рис. 46 показана зависимость величины $\gamma$ от L/d. Видно, что в таких координатах экспериментальные точки для композитов, наполненных различными типами волокон, уложились на единую универсальную зависимость. При увеличении L/d от $\approx 0,7$ до 8 значение $\gamma$ 
монотонно увеличивается от $\approx 0,22 \mathrm{Hм}^{3}$ до $\approx 0,29 \mathrm{нм}^{3}$, но остается приблизительно в 2 раза меньше, чем для ненаполненной матрицы $\approx 0,6$ $\mathrm{HM}^{3}$.

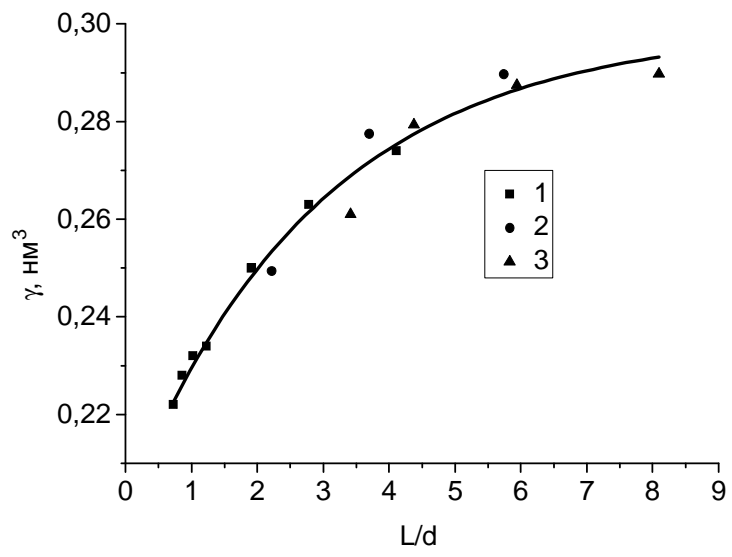

Рис. 46. Зависимость параметра $\gamma$ от среднего расстояния между поверхностями отрезков волокон (в единицах диаметра волокон): 1 ПАБИ; 2 - стеклянные; 3 -.угольные.

Следовательно, толщина граничного слоя больше среднего расстояния между поверхностями волокон в минимально наполненной матрице, когда $\mathrm{L} / \mathrm{d}_{\mathrm{f}} \approx 8$. Для примера, диаметр волокон ПАБИ составлял $\approx 15$ мкм, и толщина граничного слоя превышает $15 * 8=120$ мкм.

Изменение параметра $\gamma$ при введении частиц наполнителей представляет собой результат действия двух противоположных явлений. С одной стороны они являются концентраторами напряжений. Это свойство частиц обусловливает уменьшение прочности. С другой стороны молекулы матрицы около поверхности раздела с волокнами укладываются параллельно их оси, и прочность матрицы растет. Это приводит к уменьшению $\gamma$. 


\section{Заключение}

Вокруг частиц наполнителей в матрице образуются граничные слои, что приводит к изменению механических свойств композитов. 


\section{4. Механизм и кинетика трения полимеров и полимерных композитов}

\section{1. Введение}

В последние годы стремительно увеличивается использование полимерных композитов в узлах трения, работающих без смазки в атмосфере воздуха, углекислого газа, воде, вакууме и т.п. Эта ситуация поставила ряд фундаментальных проблем перед наукой о трении и изнашивании таких композитов. Первая из них - можно ли прогнозировать долговечность композитов в условиях трения и изнашивания? Ответу на этот вопрос посвящен п. 4.1 этой главы. Вторая проблема почему композиты обладают низким значением коэффициента трения и высокой износостойкостью в условиях работы без смазки? Эта проблема рассматривается в п. 4.2 этой же главы.

\section{2. Кинетика изнашивания}

Как было показано выше, в главе 1, в диапазоне температур между $\mathrm{T}_{\mathrm{b}}$ и $\mathrm{T}_{\mathrm{t}}$ зависимость долговечности от температуры и нагрузки может быть описана уравнением Журкова, с эффективными значениями энергии активации $\mathrm{U}_{0 \mathrm{t}}$ и структурно-чувствительного параметра $\gamma_{\mathrm{t}}$. Эта возможность осуществляется потому, ниже $\mathrm{T}_{\mathrm{b}}$ предразрывное удлинение мало и изменением параметра $\gamma_{\mathrm{t}}$ за счет деформации образца при испытаниях можно пренебречь. Скорость разрушения $\dot{\mathrm{C}}_{\mathrm{f}}$ обратно пропорциональна долговечности $\tau$. Поэтому ожидалось, что скорость изнашивания при трении может быть описана уравнением для скорости разрушения

$$
\dot{\mathrm{C}}_{\mathrm{f}}=\dot{\mathrm{C}}_{0} \exp \left[-\left(\mathrm{U}_{0 \mathrm{t}}-\gamma_{\mathrm{t}} \sigma\right) / \mathrm{kT}\right],
$$

где $\dot{\mathrm{C}}_{0}=\mathrm{q} / \tau_{0}$. Результатам проверки этого предположения посвящены п.п. 4.2.2 - 4.2.5.

Прежде чем к ним обратиться, оценим температуру в зоне трения. 


\subsection{1. Определение температуры в зоне трения}

Изнашивание представляет собой процесс разрушения под действием нормальных и касательных напряжений. Прямое использование уравнения Журкова для его описания его кинетики затруднено, т.к. в процессе трения температура в зоне трения растет. Для определения температуры до последнего времени её оценивали при помощи расчетов, требующих знания формы, твердости и коэффициентов теплопроводности трущихся тел [83 - 85]. Ниже будет изложен метод [86 - 88], основанный на использовании уравнения Пуассона и сопоставлении значений температур, измеренных с помощью термопары на некотором расстоянии от зоны трения, с температурами релаксационных переходов.

Продемонстрируем его на двух образцах.

Первый - тонкослойное $(\approx 0,3$ мм) полимерное покрытие из смеси ПА 6,6 и 6, нанесенное на стальной вал. Температуру определяли хромель-копелевыми термопарами, установленными во втулку с покрытием на расстоянии 0.5 мм от зоны трения. На рис. 47 показан фрагмент временной зависимости температуры под давлением $\approx 15$ МПа.

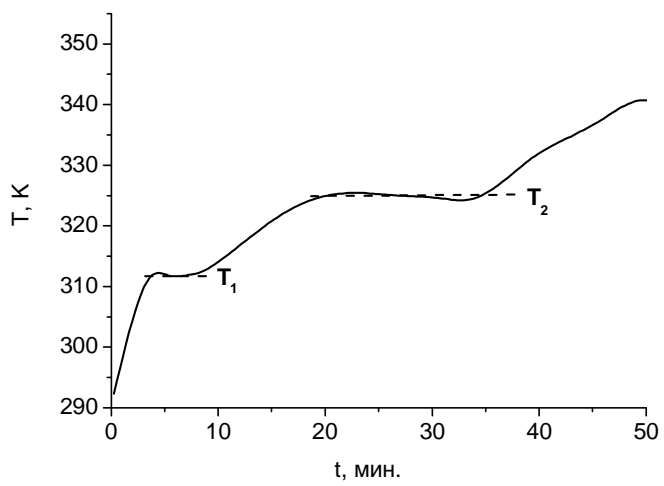

Рис. 47. Временная зависимость температуры в зоне трения полимерного покрытия из ПА 6/6,6, нанесенного на стальной вал, при испытаниях под давлением $\mathrm{P}=15 \mathrm{MПа}$. 
Для выяснения причины появления участков, на которых температура в течение некоторого времени остается неизменной, сравним её значения с температурами стеклования Т, ПА 6,6 и ПА 6. Т.к. исследуемый образец является смесью полимеров - ПА 6,6 и ПА 6, он имеет две температуры стеклования: $\mathrm{T}_{\mathrm{g}}=320 \mathrm{~K}$ для ПА 6,6 и $340 \mathrm{~K}$ - для ПА 6 [49].Оказалось, что значение для $\mathrm{T}_{1}$ на $\approx 8$, a $\mathrm{T}_{2}$ на $\approx 15$ градусов ниже $\mathrm{T}_{\mathrm{g}}$ для ПА 6,6 и ПА 6, соответственно.

Известно, что выше температуры стеклования возникает интенсивное движение молекул в аморфных областях полимеров. Поэтому появление рассматриваемых участков на временных зависимостях температуры можно объяснить резким увеличением затрат энергии на возбуждение такого движения. Такое объяснение позволяет оценить температуру в зоне трения покрытия по стали: она отличается от температуры, измеренной термопарой, не более, чем на $\approx 5$ - 10 градусов. Этот результат открывает возможности экспериментальной оценки температур в зоне трения, используя показания термопар, установленных вблизи от нее.

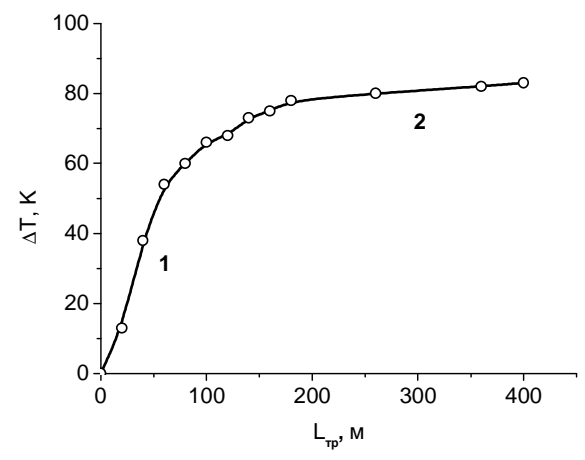

Рис. 48. Зависимость разогрева композита от пути трения на расстоянии 5 мм от зоны трения композита на основе ПФО, наполненном порошком ПЭ, о стальной ролик.

Второй образец - композит с матрицей из ПФО, наполненной порошком ПЭ, по поверхности которого бежит стальной ролик. Температура измерялась с использованием термопары, установленной на 
расстоянии 5 мм от зоны трения. Зависимость разогрева от пути трения $\mathrm{L}_{\mathrm{fr}}$ показана на рис. 48.

Ее можно, условно, разбить на два участка. На первом температура увеличивается приблизительно пропорционально времени, а на втором - скорость ее увеличения уменьшается.

В стационарных условиях значение температуры Т(x) на расстоянии х от источника нагрева описывается выражением (уравнение Пуассона) [89]:

$$
\mathrm{T}(\mathrm{x})=\mathrm{T}(0)-(\mathrm{F}(\mathrm{x}) \mathrm{dx}) / \lambda,
$$

где $\mathrm{F}(\mathrm{x})$ - плотность теплового источника.

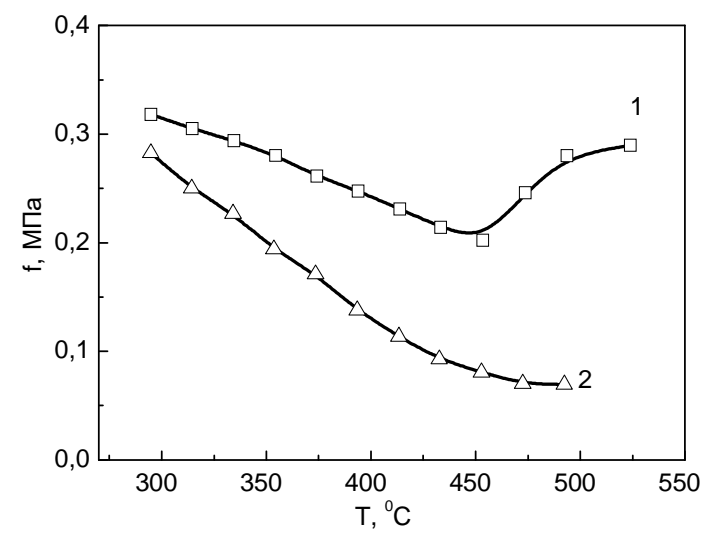

Рис. 49. Температурные зависимости силы трения композиционных материалов на основе ПФО (1) и ПМ-69 (2), наполненных углеродными волокнами, о стальной ролик (скорость скольжения $\approx 6 \mathrm{M} / \mathrm{c}$ ).

Чтобы оценить величину $\mathrm{F}(\mathrm{x}) \mathrm{x} / \lambda$, измеряли зависимость силы трения от температуры при фиксированных нагрузке и скорости скольжения. Типичные результаты таких исследований трения композиционных материалов на основе ПФО; ПМ-69 и ПМ-67 изображены на рис. 47.

Известно, что выше температуры стеклования $\mathrm{T}_{\mathrm{g}}$ матрицы резко уменьшается податливость матрицы, и значительно возрастает сила 
трения. Поэтому, сопоставляя значение температуры $\mathrm{T}_{\text {к }}$, выше которой сила трения начинает увеличиваться с $\mathrm{T}_{\mathrm{g}}$, можно оценить температуру в зоне трения.

Так, например, для ПФО температура стеклования $\mathrm{T}_{\mathrm{g}} \approx 480 \mathrm{~K}$, а для композиционного материала на его основе сила трения начинает возрастать при $\approx 450$ К. Разность между этими значениями дает Fx/ $\approx$ $30 \mathrm{~K}$. Следовательно, температуру в зоне разрушения $\mathrm{T}_{\mathrm{fr}}$ можно оценить как: $\approx \mathrm{T}_{\exp }+30$, где $\mathrm{T}_{\exp }-$ температура, измеренная на расстоянии 5 мм от зоны трения. Для композиционного материала на основе ПИ 67 отступления от линейной зависимости силы трения от температуры начинаются приблизительно при $380 \mathrm{~K}$, т.е. $\mathrm{Fx} / \lambda \approx 100 \mathrm{~K}$, и $\mathrm{T}_{\mathrm{fr}} \approx$ $\mathrm{T}_{\text {exp }}+100$.

Если предположить, что величина параметра F не зависит от природы и формы частиц наполнителя, то можно оценить $\mathrm{Fx} / \lambda$ и для других наполнителей, если известен коэффициент теплопроводности композита $\lambda$.

Так композиционных материалов на основе ПФО, наполненном углеродными волокнами, составляет $\lambda \approx 0,4 \mathrm{BT} /($ м К), т.е. $\mathrm{Fx} \approx 20 \mathrm{BT} / \mathrm{M}$, а наполненном порошком ПЭТФ - $\lambda \approx 0,2 \mathrm{BT} /(\mathrm{M} \mathrm{K}), \mathrm{Fx} / \lambda \approx 100 \mathrm{~K}$ и $\mathrm{T}_{\mathrm{fr}} \approx$ $\mathrm{T}_{\text {exp }}+100$.

Знание локальной температуры в зоне трения открывает возможности для детального исследования кинетики температуры

\subsection{2. Кинетика разогрева при трении}

Закономерности, описывающие кинетику разогрева при трении, получены в двух сериях экспериментов [86 - 88].

В первой серии исследовали разогрев при трении покрытия из смеси полиамида 6,6 и 6 на втулке со стальным валом в модели узла трения дорожных машин. На рисунке 50 приведены результаты измерения температуры уже в зоне трения на начальных этапах трения при различных значениях нормальных давлениях. 


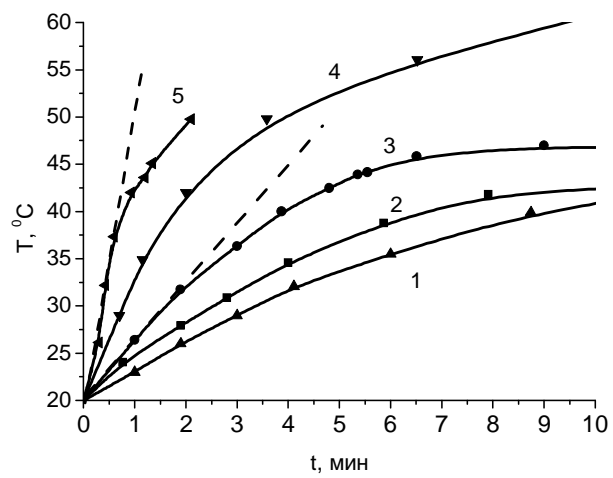

Рис. 50. Временные зависимости изменения температур в зоне трения полиамидного покрытия во время испытания при различных нормальных давлениях: Па. 1 - 6,3; 2 - 2,7; 3 - 4,7; 4 - 11; 5 - 15.

Очевидно, что в начале процесса трения отводом тепла из зоны трения можно пренебречь. В этом случае разогрев обусловлен выделением энергии, запасенной деформированными до разрыва химическими связями, после их разрыва. "Начальная" скорость разогрева $\dot{\mathrm{T}}$ покрытия (тангенс угла наклона прямых линий на рисунке 50) определяется скоростью разрушения связей внутри полимера (накопления разрывов) $\dot{\mathrm{N}}$ под нагрузкой: $\dot{\mathrm{T}}=\zeta \dot{\mathrm{N}}$, где $\zeta$ - коэффициент пропорциональности.

Зависимость скорости накопления разрывов от температур и нагрузки описывается уравнением $[2,3]$ :

$$
\dot{\mathrm{N}}=\dot{\mathrm{N}}_{0} \exp \left[-\left(\mathrm{U}_{0}-\gamma \sigma\right) / \mathrm{kT}\right]
$$

Откуда следует выражение для скорости разогрева:

$$
\dot{\mathrm{T}}=\dot{\mathrm{T}}_{0} \exp \left[-\left(\mathrm{U}_{0}-\gamma \sigma\right) / \mathrm{kT}\right]
$$

где: $\dot{\mathrm{T}}_{0} \approx 10^{13} \mathrm{~K} / \zeta \tilde{\mathrm{n}}$.

Логарифмируя, левые и правые части этого равенства, выражение для начальной скорости разогрева покрытия при трении: 


$$
\ln \dot{\mathrm{T}}=\ln \dot{\mathrm{T}}_{0}-\frac{\mathrm{U}_{0}}{\mathrm{kT}}+\frac{\gamma \mathrm{P}}{\mathrm{kT}}
$$

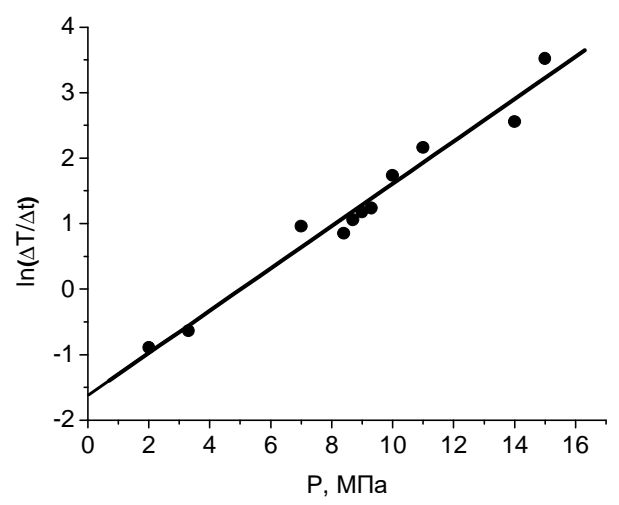

Рис. 51. Логарифмическая зависимость "начальной" скорости разогрева полиамидного покрытия полимера ПА6,6/6 в зоне трения от давления.

Оказалось, что действительно логарифм начальной скорости нагрева при трении увеличивается пропорционально величине нормального давления Р (рис. 51).

Экстраполируя прямые линии к давлению $\mathrm{P}=0$, получаем величину $\ln \dot{\mathrm{T}}\left(\mathrm{P}_{\mathrm{a}} \rightarrow 0\right)=-1,61$. Из формулы (24) можно найти значение энергии активации разогрева как:

$$
\mathrm{U}_{0}=\mathrm{kT} \ln \frac{\dot{\mathrm{T}}_{0}}{\dot{\mathrm{T}}(\mathrm{P} \rightarrow 0)}
$$

Найденное таким образом значение $\mathrm{U}_{0}=0,9$ эВ в пределах погрешности, совпадает с энергией активации разрушения ПА 6 и ПА 6,6 - 1 эВ (таблица 2.). Этот факт говорит о том, что в основе кинетики изменения температуры в зоне трения действительно лежит процесс разрыва химических связей в полимере.

Измерив, тангенс угла наклона прямой на рисунке 50, можно 
определить значение параметра $\gamma$ как:

$$
\gamma=\mathrm{kT} \frac{\ln \Delta \dot{\mathrm{T}}}{\Delta \mathrm{P}} .
$$

Оказалось, что для полимера ПА6,6/6 $\gamma=1,2$ нм$^{3}$.

Перейдем к рассмотрению результатов, полученных во второй серии экспериментов. Оказалось, что логарифм начальной скорости нагрева температурных зависимостей увеличивается пропорционально величине нормального давления Р в согласии с уравнением (24) (рис. 51).

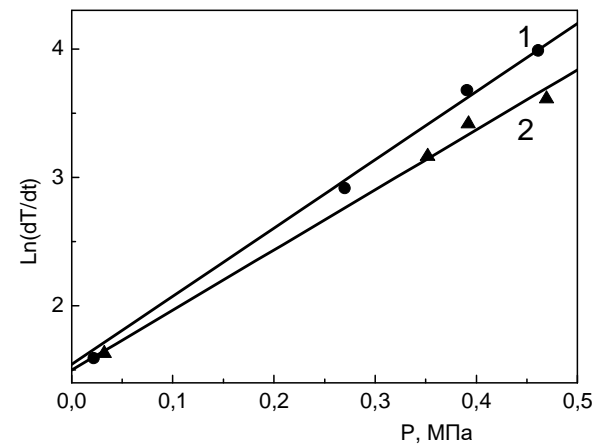

Рис. 51. Зависимость "начальной" скорости разогрева на расстоянии 5 мм от зоны трения от нагрузки для композиционных материалов на основе ПФО, наполненном порошком ПЭ: 1 - $15 \%$ масс. ; 2 - 10 \% масc.

Экстраполируя прямые линии к нулевому давлению, и используя (25) можно найти $\mathrm{U}_{0}$. Из данных, показанных на рис. 51, нашли, что для композиционных материалов, на основе ПФО, наполненном отрезками волокон полиэтилена, $\mathrm{U}_{0} \approx 1,2$ эВ.

Близкое значение было получено для композиционных материалов на основе ПФО, наполненном порошком ПЭТФ - $\approx 1,3$ эВ, и угольными волокнами - 1,2 эВ. Существенно, что найденные значения $\mathrm{U}_{0 \mathrm{~T}}$, в пределах погрешности, совпадают с энергией активации раз- 
рушения ПФО - 1,2 эВ (Таблица 2). Этот результат показывает, что в основе кинетики разогрева при трении лежит процесс разрушения химических связей в матрице.

\subsection{3. Зависимость фрикционных параметров от давления}

Для наполнения ПФО использовали: дискретное углеродное волокно, эпоксидную смолу (марки ЭД -20), порошок политетрафторэтилена и порошок рутила - $\mathrm{TiO}_{2}$. Их содержание варьировалось от I - 10 об. \% [86].

Задавали величину давления и измеряли величину изнашивания, коэффициент трения и температуру на расстоянии 5 мм от зоны трения при скорости скольжения $\approx 0,2$ м/с на пути трения 125 м. Затем давление увеличивали и повторяли процедуру измерений. Суммарная протяженность пути трения составляла 5 км.

Полученные результаты демонстрируются на рис. 52 для композиционных материалов на основе ПФО, наполненном углеродными волокнами.

Их можно условно разбить на три диапазона: 1, 2 и 3.

В диапазоне давлений 1 происходит "приработка" образца композиционных материалов, во время которой между полимером и металлом образуется слой из продуктов деструкции полимера (см. ниже, п. 4.2). При «приработке» скорость изнашивания и коэффициент трения уменьшаются, а температура растет.

В диапазоне давлений 2 изнашивание и коэффициент трения имеют минимальные значения, а температура на расстоянии $\approx 5$ мм от зоны трения приблизительно постоянна.

В диапазоне 3 изнашивание, коэффициент трения и температура быстро увеличиваются, вплоть до разрушения композиционных материалов.

Такие же закономерности изменения интенсивности изнашивания, коэффициента трения и температуры в зависимости от давления наблюдались и для других композиционных материалов. 

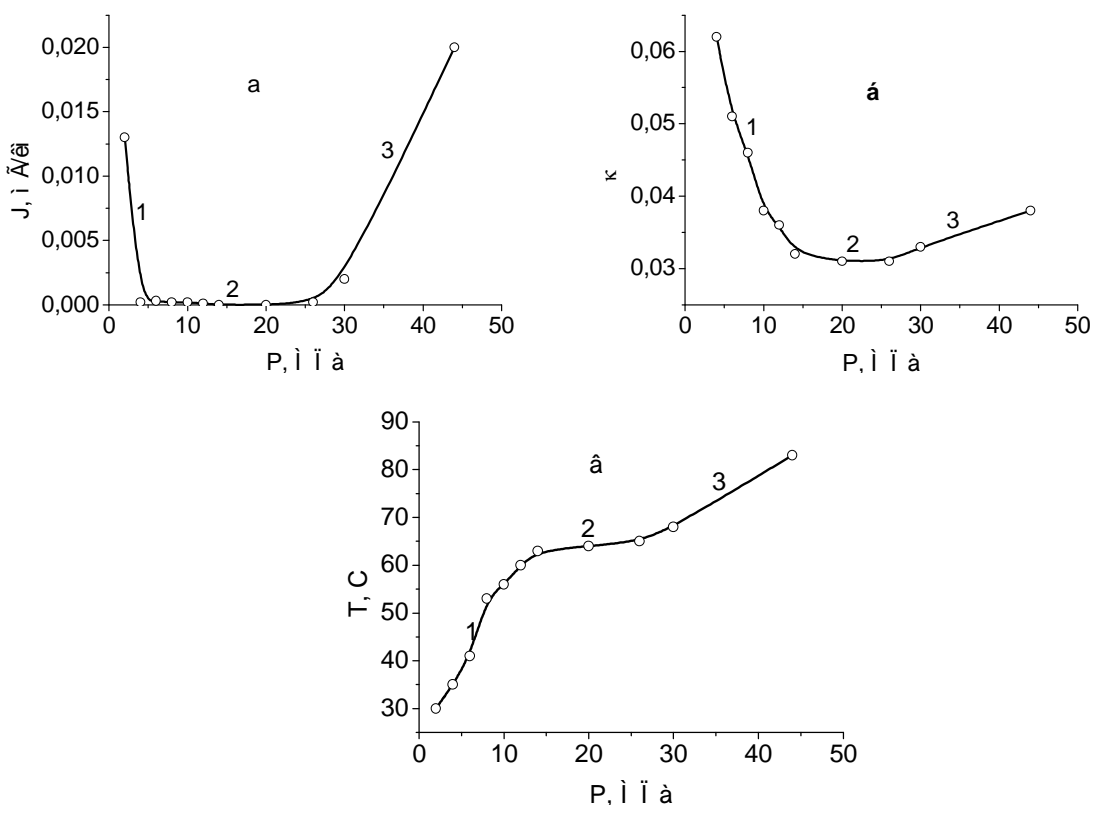

Рис. 52. Зависимость интенсивности изнашивания J, коэффициента трения к и температуры от давления Р для ПФО, наполненного 35 об. \% отрезков углеродных волокон.

Для практических приложений наибольший интерес представляют закономерности трения и изнашивания в зоне II, т.к. она соответствует диапазону нагрузок, в котором изделия из композиционных материалов могут длительно использоваться в узлах сухого трения.

Рассмотрим закономерности изнашивания и коэффициента трения в этой зоне более подробно.

\subsection{4. Кинетика изнашивания наполненных композитов}

Исследование зависимости интенсивности изнашивания от времени проводилось на образцах из композиционных материалов на основе ПФО и ПМ 69. Максимальная температура в зоне трения не превышала 400 К, т.е. не достигала температуры стеклования. 
На рис. 53 показаны зависимости изнашивания от пути трения для композиционных материалов на основе ПФО с различными наполнителями.

Видно, что скорость изнашивания монотонно уменьшается со временем $t$ и в пределе, при $\mathrm{t} \rightarrow \infty$, стремится к нулю. Все полученные зависимости степени изнашивания от времени $\mathrm{J}(\mathrm{t})$ описываются выражением для кинетики химической реакции первого порядка:

$$
J(t)=J_{\infty}\left[1-\exp \left(-k_{J} t\right)\right]
$$

где $\mathrm{k}_{\mathrm{J}}$ - константа скорости изнашивания, a $\mathrm{J}_{\infty}$ - значение изнашивания при $\mathrm{t} \rightarrow \infty$.

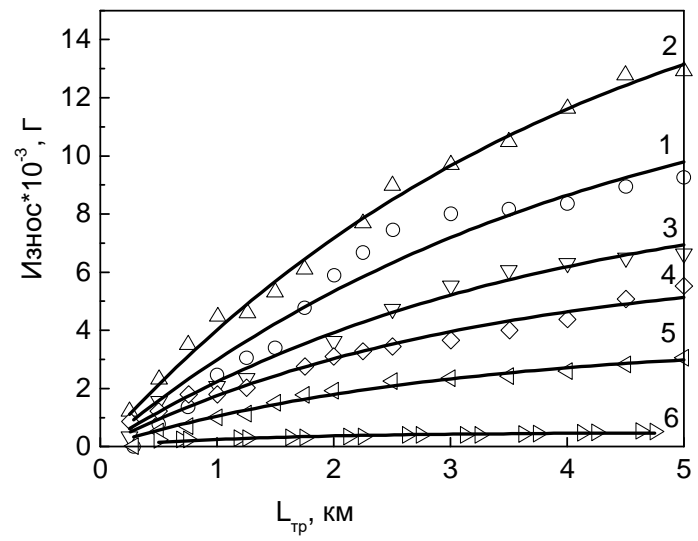

Рис. 53. Зависимость изнашивания композиционных материалов на основе ПФО с различными наполнителями от пути трения при скорости скольжения 0,6 м/с и комнатной температуре: 1 - 1 об.\% $\mathrm{TiO}_{2} ; 2$ 1 об.\% углеродное волокна; 3 - 1 об. \% углеродное волокна +1 об. \% $\mathrm{TiO}_{2} ; 4$ - 1 об.\% углеродное волокна +1 об. \%, эпоксидной смолы ЭД-20; 5 - 1 об.\% порошка ПЭТФ; 6 - 10 об.\% порошка ПЭТФ.

Следовательно, зависимость изнашивания от времени является функцией двух параметров: $\mathrm{k}_{\mathrm{J}}$ - константы скорости изнашивания и 
$\mathrm{J}_{\infty}$ - условного значения изнашивания, при котором его скорость стремится к нулю и трение становится "безизносным".

Оказалось, что константа скорости изнашивания растет при увеличении температуры $\mathrm{T}_{\text {tr }}$ в зоне трения. На рис. 54 построены зависимости $\ln k_{\mathrm{J}}=\mathrm{f}\left(1 / \mathrm{T}_{\mathrm{tr}}\right)$.

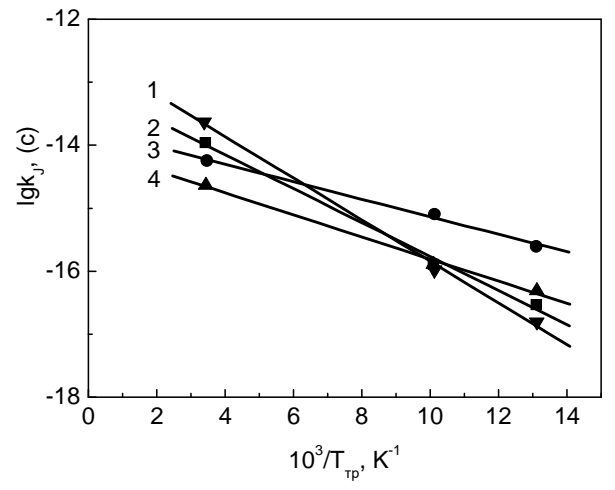

Рис. 54. Зависимость константы скорости изнашивания от обратной температуры в зоне трения для композиционных материалов на основе ПМ 69 с различными наполнителями: 1 - 10 масс. \% ПФО + 40 масс. \% углеродного волокна; 2 - 40 масс. \% . углеродного волокна; 3 - 10 масс. \% ПФО + 46 масс. \% углеродного волокна.

Видно, что экспериментальные точки укладываются на прямые линии. Экстраполируя их до пересечения с осью ординат, нашли $\mathrm{k}_{0 \mathrm{~J}}=\left(10^{12} \div 10^{14}\right) \mathrm{c}^{-1}$, что соответствует классическому значению константы скорости термофлуктуационных процессов (см. главу 1).

Следовательно, зависимость константы скорости от температуры можно записать как

$$
\ln \mathrm{k}_{\mathrm{J}}=\ln \mathrm{k}_{0 \mathrm{~J}}-\frac{\mathrm{U}_{0 \mathrm{~J}}}{\mathrm{kT}_{\mathrm{tr}}},
$$

где $\mathrm{U}_{0 \mathrm{~J}}$ - энергия активации изнашивания. 
Оказалось, что логарифм константы скорости изнашивания увеличивается пропорционально давлению (рис.53).

Комбинируя два последних выражения, нашли, что зависимость константы скорости изнашивания при $\mathrm{T}<\mathrm{T}_{\mathrm{g}}$ описывается выражением:

$$
\mathrm{k}_{\mathrm{J}}=\mathrm{k}_{0 \mathrm{~J}} \exp \left[-\left(\mathrm{U}_{0 \mathrm{~J}}-\gamma_{\mathrm{J}} \mathrm{P}\right) / \mathrm{kT}\right]
$$

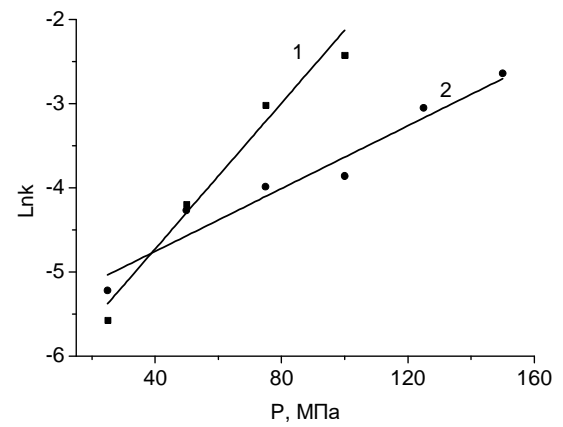

Рис. 55. Зависимость логарифма константы скорости изнашивания $\mathrm{k}_{\mathrm{J}}$ от давления для композиционных материалов на основе ПФО с различными наполнителями: 1 - отрезки углеродных волокон; 2 - порошок ПТФЭ.

Здесь $\mathrm{U}_{0 \mathrm{~J}}$ и $\gamma_{\mathrm{J}}$ - энергия активации и активационный объем изнашивания.

Из экспериментальных данных вычислили значение энергии активации - $\mathrm{U}_{0 \mathrm{~J}}$. Оказалось, что для всех композиционных материалов на основе ПФО ее величина $\approx 1,2$ эВ, а на основе ПМ-69 - 2,0 эВ. Важно, что найденные значения $\mathrm{U}_{0 \mathrm{~J}}$ совпали с энергией активации разрыва молекул матрицы $\mathrm{U}_{0}$ (таблица 2). Это совпадение согласуется с представлением, что в основе изнашивания лежит процесс термофлуктуационного разрыва химических связей матрицы.

Роль наполнителя при трении сводится к изменению величины параметра - $\gamma_{\mathrm{J}}$ матрицы. Так для композиционных материалов на ос- 
нове ПФО, наполненном углеродными волокнами величина, $\gamma_{\mathrm{J}} \approx 36$ нм $^{3}$, а для композиционных материалов на основе ПМ-69 наполненном порошком ПТФЭ - $\gamma_{\mathrm{J}} \approx 22 \mathrm{нм}^{3}$.

Рассмотрим теперь "предельную" степень изнашивания $\mathrm{J}_{\infty}$, при которой трение становится "безизносным". Как видно из табл. 10, она зависит от химической природы и формы частиц наполнителя. Наибольшее значение $\mathrm{J}_{\infty}$ имеют композиционных материалов $\mathrm{c}$ наполнителями из нитевидных кристаллов $\mathrm{TiO}_{2}$ и отрезков угольных волокон, а наименьшее - для композиционных материалов с порошком ПТФЭ.

Таблица 10. Значения параметра $\mathrm{J}_{\infty}$ для композиционных материалов на основе ПФО с различными наполнителями.

\begin{tabular}{|l|c|}
\hline Наполнитель & $\mathrm{J}_{\infty} * 10^{3}, \Gamma$ \\
\hline 1 об.\% $\mathrm{TiO}_{2}$ & 14,2 \\
\hline 1 об.\% углеродное волокно & 18,8 \\
\hline $\begin{array}{l}1 \text { об. \% углеродное волокно } \\
+1 \text { об. \% } \mathrm{TiO}_{2}\end{array}$ & 9,3 \\
\hline 1 об.\% ПТФЭ & 3,67 \\
\hline 10 об.\% ПТФЭ & 0,48 \\
\hline
\end{tabular}

Этот результат может быть объяснен следующим образом. Величина $\mathrm{J}_{\infty}$ соответствует степени разрушения слоя композиционных материалов на границе с контртелом, при которой его вязкость становится малой. Низкая вязкость такого слоя, обусловлена тем, что он состоит из обрывков молекул полимеров (см. п. 5.1.5), содержащих несколько десятков атомов углерода.

Толщина деструктированного слоя зависит от размеров продуктов разрушения матрицы и наполнителя, образующихся при износе.

Как уже упоминалось выше, вокруг волокон и нитевидных кристаллов образуются прочные слои матрицы, молекулы в которых ориентированы вдоль их оси. Вязкость слоя, содержащего фрагменты "разорванных" молекул матрицы, угольных волокон и нитевидных кристаллов, высока, что и обуславливает большое значение $\mathrm{J}_{\infty}$. Вокруг 
частиц ПТФЭ, наоборот, образуются рыхлые слои, прочность которых меньше прочности остальной матрицы. Поэтому вязкость слоя, содержащего фрагменты молекул ПТФЭ и ПФО, мала. Это и приводит к малому значению $\mathrm{J}_{\infty}$.

\subsection{5. Зависимость силы трения между композиционным материалом и металлическим контртелом от температуры}

Поскольку сила трения $\mathrm{F}_{\mathrm{fr}}$ пропорциональна нагрузке, то уравнение (27) можно переписать следующим образом:

$$
\mathrm{F}_{\mathrm{fr}}=\frac{\mathrm{U}_{0 \mathrm{f}}}{\gamma_{\mathrm{f}}}-\frac{\mathrm{kT}_{\mathrm{tr}}}{\gamma_{\mathrm{f}}} \ln \frac{\mathrm{v}_{0}}{\mathrm{v}},
$$

где $\mathrm{v}_{\mathrm{s}}$ - скорость скольжения, $\mathrm{U}_{0 \mathrm{f}}$ и $\gamma_{\mathrm{f}}$ - энергия активации и активационный объем трения, $\mathrm{a}_{0 \mathrm{~s}} \approx 10^{13} \mathrm{c}^{-1}$.

Из (28) следует, что при постоянной скорости зависимость силы трения от температуры должна быть линейной.

Рис. 56 показывает, что сила трения композиционных материалов о стальной ролик действительно уменьшается пропорционально температуре.

$$
\mathrm{kT}_{*} \ln \frac{\mathrm{v}_{0}}{\mathrm{v}}=\mathrm{U}_{0 \mathrm{f}}
$$

Значения $\gamma_{f}$ можно найти из наклона прямых линий:

$$
\gamma_{\mathrm{f}}=-\frac{\mathrm{k}}{(\mathrm{df} / \mathrm{dT})} \ln \frac{\mathrm{v}_{0}}{\mathrm{v}}
$$




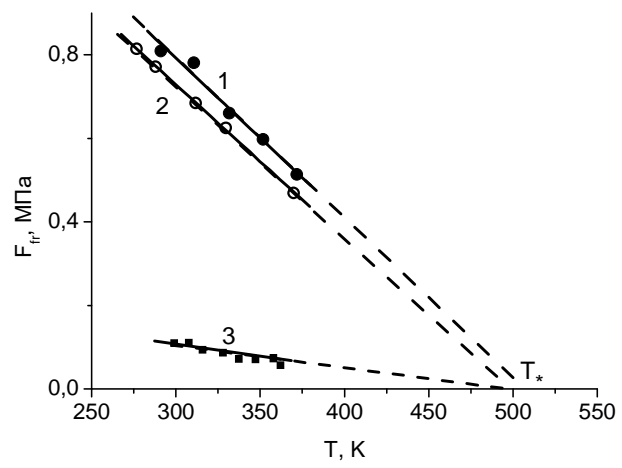

Рис. 56. Температурная зависимость силы трения $\mathrm{F}_{\mathrm{fr}}$ между композиционными материалами на основе ПФО и сталью 45 при скорости скольжения $0,6 \mathrm{~m} / \mathrm{c}$, наполнители: 1 - отрезки угольного волокна и волокна из ПМ 69; 2 - отрезки угольного волокна и волокна из ПМ 67; 3 - порошок ПТФЭ.

Прямые линии пересекают ось абсцисс в точке $\mathrm{T}_{*}$, такой что

Оказалось, что для всех композиционных материалов на основе ПФО составляет $\mathrm{U}_{0 \mathrm{f}} \approx 1,2$ эВ и совпадает с энергией активации разрушения матрицы ПФО (таблица 2). Этот результат показывает, что релаксации силы трения при повышении температуры вызвана разррывами химических связей в молекулах матрицы под действием термических флуктуаций.

Таким образом, в значения энергий активации изнашивания, нагрева и релаксации силы трения композиционных материалов совпали с энергией активации разрыва химических связей в матрице: $\mathrm{U}_{0 \mathrm{~J}}$ $=\mathrm{U}_{0 \mathrm{~T}}=\mathrm{U}_{\mathrm{of}}=\mathrm{U}_{0}$. Это означает, что для создания композиционных материалов с низким и стабильным коэффициентом трения, высокой износостойкостью в качестве матрицы нужно выбирать полимеры с высокой энергией активации разрушения, а в качестве наполнителей порошки полимеров и графита. 
На этом мы закончим рассмотрение кинетики трения и изнашивания при температурах ниже $\mathrm{T}_{\mathrm{b}}$ и рассмотрим случай, когда температура превышает это значение.

\subsection{6. Кинетика разогрева в области температур, превышающих $\mathrm{T}_{\mathrm{g}}$}

Для простоты будет рассматривать случай, когда направление трения остается неизменным. Испытанию подвергались стальные втулки (рис. 57) с покрытием толщиной 0,3 мм из смеси полимеров ПА 6 и ПА 6/6. Они были изготовлены из бронзы БрАЖ 9-4.

В качестве контртела использовали сменные втулки из закаленной стали 45.

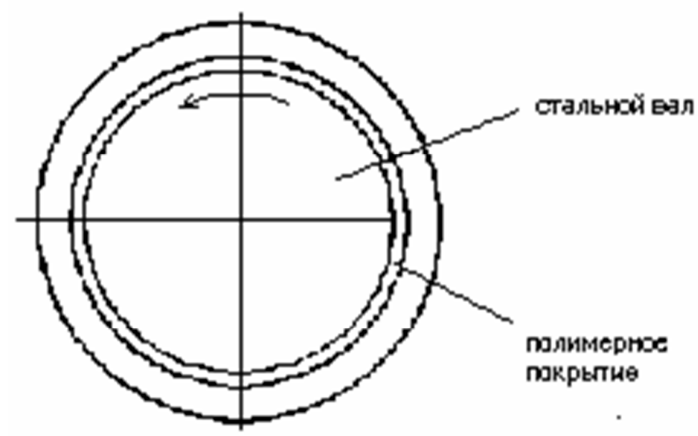

Рис. 57. Схематическое изображение втулки подшипника скольжения с покрытием.

Температуру измеряли хромель-копелевыми термопарами, которые были установлены во втулках с полимерным покрытием на расстоянии 0,5 мм от рабочей поверхности полимерного покрытия

Нагружение образцов производили ступенями - через 1,33 МПа. Продолжительность испытания на каждой ступени составляла 240 минут, что соответствовало 360 тыс. оборотов вала или 50 км пути. После этого рабочий узел разбирали и производили замеры втулок. Эксперимент заканчивали, когда температура достигала $125^{\circ} \mathrm{C}$. 
Как видно из рис. 57, скорость роста температуры уменьшается со временем. Это явление вызвано отводом тепла из зоны трения и затратами энергии на высокоэластическую деформацию покрытия в направлении вращения вала.

Попытаемся оценить вклад этих факторов. Сравним временные зависимости температуры 1 и 2 на рис. 58. Первая - получена при первом нагружении до давления 11 МПа. Затем образец был разгружен, вновь нагружен до 11 МПа семь раз. Видно, что после седьмого цикла нагружения температура при одном и том же времени приблизительно на 30 градусов ниже, чем при первом нагружении.

Это показывает, что около $30 \%$ энергии, выделяющейся при трении, было затрачено на высокоэластическую деформацию покрытия.

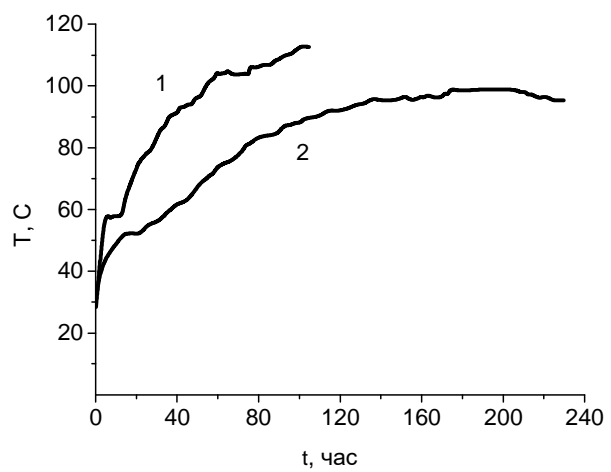

Рис. 58. Временная зависимость температуры в зоне трения втулки с полимерным покрытием о стальной вал при давлении P = 11 МПа: 1 первое нагружение, 2 - седьмое нагружение.

Рост ориентации молекул при высокоэластической деформации уменьшает силу трения скорость роста температуры в зоне трения. Одновременно растет прочность покрытия (уменьшается величина параметра $\gamma$ ) и уменьшается скорость его износа. Возможно, что увеличение ориентации при трении обуславливает большую износостойкость полимерного покрытия по сравнению с бронзой (несмотря на то, что энергия активации разрушения полимерного покрытия приблизительно в 2,5 раза меньше, чем у бронзы ( $\approx 2.4$ эВ)). 


\section{3. Деструкция полимеров и полимерных композитов при трении}

Как уже говорилось выше (см. п. 2.2.2) при разрывах химических связей свободные радикалы. Часть из них находится в возбужденном электронном состоянии. Энергия возбуждения часто выделяется в виде излучения в видимой области спектра - механолюминесценции (пример такого спектра показа на рис. 9).

Таким методом при трении ПЭ были зафиксированы спектры свободных радикалов, образовавшихся при разрывах химических связей в основном скелете молекул ПЭ, ПП, ПА6, ПФС и угольного волокна при трении [23 - 25].

Свободные радикалы весьма активны и вступают в химические реакции с окружающими молекулами и кислородом воздуха, что приводит к образованию различных химических соединений. Эти соединения можно зафиксировать методами фотолюминесценции и инфракрасной спектроскопии [26 - 33]. Например, на рис. 59 показан спектр фотолюминесценции ПА до трения и после изнашивания.

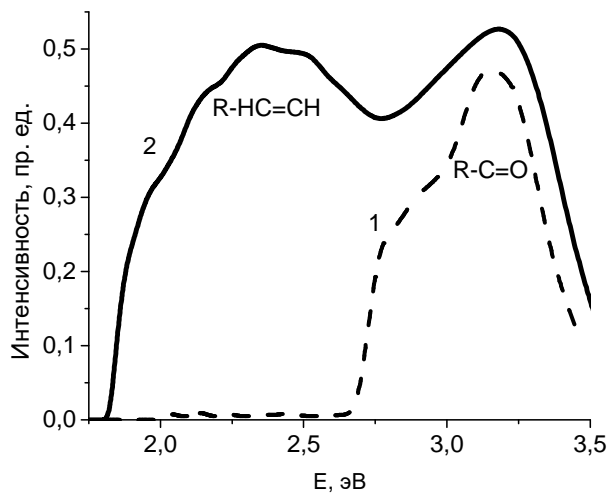

Рис. 59. Спектры фотолюминесценции поверхностного слоя ПА-6 толщиной 19 мкм, возбужденной излучением лазера, до трения (1) и после изнашивания (2).

На рис. 60 представлен ИК спектр поверхностного слоя ПЭ толщиной 1 мкм до после трения. 


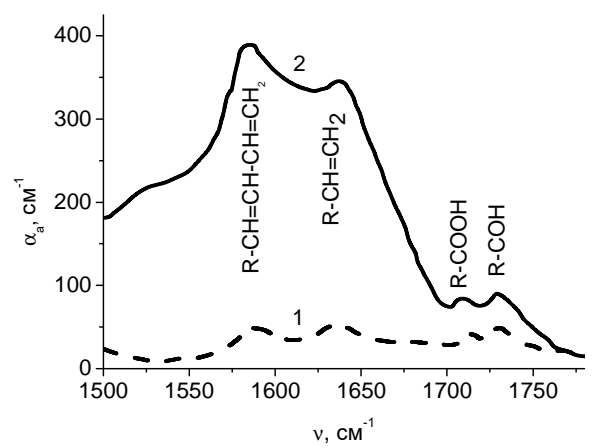

Рис. 60. ИК спектры коэффициента поглощения поверхностного слоя ПЭ толщиной 1 мкм до (1) и после изнашивания (2).

Величина коэффициента поглощения пропорциональна концентрации $\mathrm{C}_{\mathrm{r}}$ новых концов $\alpha_{\mathrm{ab}}=\kappa \mathrm{C}_{\mathrm{r}}$, где $\kappa_{\mathrm{a}}-$ молярный коэффициент поглощения. Это позволило найти концентрацию $\mathrm{C}_{\mathrm{r}}$ новых концов молекул $\mathrm{C}_{\mathrm{r}}$ (Таблица 11).

Таблица. 11. Частота максимума полос, соответствующих колебаниям концевых группировок, и концентрация таких группировок, образовавшихся в поверхностном слое ПЭ толщиной $\approx 1$ мкм после трения.

\begin{tabular}{|c|c|c|c|}
\hline $\begin{array}{l}\text { №, } \\
\text { п/п }\end{array}$ & $\begin{array}{l}\text { Частота } \\
\text { полосы, } \\
\mathrm{cm}^{-1}\end{array}$ & $\begin{array}{l}\text { Химическая } \\
\text { группировка }\end{array}$ & $\begin{array}{l}\mathrm{C}_{\mathrm{r}} \cdot 10^{2}, \\
\mathrm{HM}^{-3}\end{array}$ \\
\hline 1 & 1379 & $-\mathrm{CH}_{2}-\mathrm{CH}_{3}$ & 10 \\
\hline 1 & 1590 & $-\mathrm{CH}=\mathrm{CH}-\mathrm{CH}=\mathrm{CH}_{2}$ & 2,7 \\
\hline 2 & 1645 & $-\mathrm{CH}=\mathrm{CH}_{2}$ & 2,8 \\
\hline 3 & 1690 & $-\mathrm{CH}=\mathrm{CH}-\mathrm{HC}=\mathrm{O}$ & 2,5 \\
\hline 4 & 1710 & $-\mathrm{H}_{2} \mathrm{C}-\mathrm{COOH}$ & 0,9 \\
\hline 5 & 1735 & $-\mathrm{H}_{2} \mathrm{C}-\mathrm{COH}$ & 1,0 \\
\hline \multicolumn{3}{|c|}{ Сумма } & $\approx 20$ \\
\hline
\end{tabular}

Оценим число углерод - углеродных связей в «обрывках» молекулы ПЭ, образовавшихся в поверхностном слое толщиной $\approx 1$ мкм по- 
сле трения. Длина углерод - углеродной связи в ПЭ - 0,154 нм, а площадь поперечного сечения молекулы ПЭ - 0.18 нм² [90]. Отсюда объем, занимаемый частью молекулы, приходящейся на на одну связь, $0,154 * 0.18 \approx 2.8 * 10^{-3}$ нм$^{-3}$. Каждый «обрывок» имеет два конца. Отсюда число углерод-углеродных связей в «обрывке» молекулы ПЭ после трения $\approx 200 / 2.8 \approx 60$.

Приблизительно такое число углерод-углеродных связей входит в состав молекул парафиновых масел. По строению поверхностный слой напоминает деструктированное масло и обладает малым сопротивлением к сдвигу.

Это означает, что продукты деструкции полимера играют роль своеобразной смазки, что и объясняет успех использования полимеров и полимерных композитов в узлах трения.

\section{4. Определение допустимого давления в узле трения}

Теперь, не проводя дополнительных испытаний, мы можем оценить величину предельного давления в узле трения. Испытанию подвергались стальные втулки с покрытием толщиной 0,3 мм из ПА 6/6,6. Нагружение образцов производили ступенями - через 1,33 МПа. На рис.64 приведена зависимость температуры, измеренной термопарой, в конце каждой ступени нагружения, от величины приложенного давления.

Видно, что температура растет приблизительно пропорционально давлению:

$$
\mathrm{T} \approx \mathrm{T}_{\mathrm{g}}+\mathrm{QP}
$$

где Q - опытный коэффициент. 


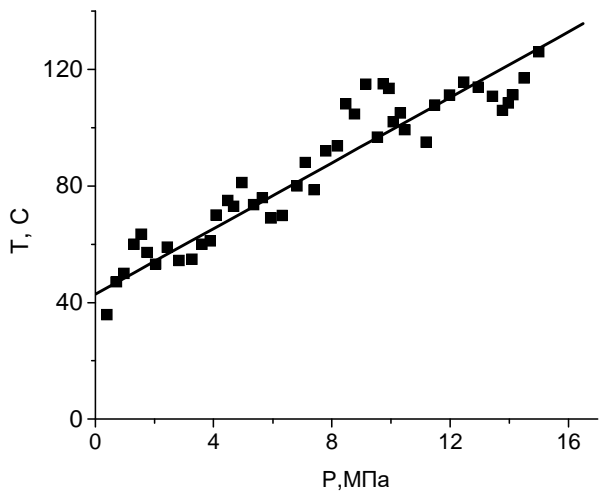

Рис. 61. Зависимость температуры от величины давления в конце каждой ступени нагружения.

Поскольку долговечность обратно пропорциональна скорости деформации $\dot{\varepsilon}$ а сила трения - давлению, то уравнение Журкова (1) можно переписать следующим образом:

$$
\mathrm{P}=\frac{\mathrm{U}_{0}}{\gamma}-\frac{\mathrm{kT}}{\gamma} \ln \frac{\dot{\varepsilon}_{0}}{\dot{\varepsilon}}
$$

Учтем, что при испытании полимерное покрытие ориентируется в направлении вращения, что приводит к уменьшению величины параметра $\gamma$. Зависимость величины $\gamma$ от степени ориентационной вытяжки $\lambda$ имеет вид [91]:

$$
\gamma=\frac{\gamma_{0}}{\lambda}
$$

где: $\gamma_{0}$ - параметр $\gamma$ для неориентированного образца.

Предельная степень вытяжки для ПА 6/6,6 равна $\approx 7$. Значение $\gamma_{0}=$ $15 \mathrm{нм}^{3}$, т.е. для предельно вытянутого образца $\gamma=\gamma_{0} / \lambda \approx 2,2 \mathrm{Hм}^{3}$. Предельная температура в зоне трения составляет 400 К. Подставив эти 
значения в (31) получим $\mathrm{P}=11$ МПа, что близко к экспериментальному значению $\mathrm{P} \approx 12$ МПа.

Этот результат позволяет предложить следующий способ оценки предельного давления. Подставив выражение (30) в (31), и учитывая, что скорость износа пропорциональна скорости вращения вала V, получим:

где $\mathrm{V}_{0}=10^{13} \mathrm{c}^{-1}$.

$$
\mathrm{P}=\frac{\mathrm{U}_{0} \mathrm{kT}_{\mathrm{g}} \ln \frac{\mathrm{V}_{0}}{\mathrm{~V}}}{\gamma+\mathrm{kq} \ln \frac{\mathrm{V}_{0}}{\mathrm{~V}}}
$$

Из графика на рис. 64 нашли, что для наших условий испытаний Q $=5,6$ град/МПа. Подставляя это значение в формулу (4.10) получаем тоже значение предельного давления $\mathrm{P} \approx 10 \mathrm{MПа.}$

\section{5. Динамика разрушения при трении волокнистого композита}

Представляло интерес исследовать динамику накопления разрывов полимерных молекул при трении волокнистых композитов [23 25]. Образцы имели вид пластинок с линейными размерами: 20х20х10 мм. Их выпиливали из композита с матрицей из ПФС, армированной слоями углеродной ткани. Среднее расстояние между слоями ткани составляло приблизительно 400 мкм. Схема установки показана на рис. 60. Диаметр вала составлял 4 см. Контактное давление - $\approx 0.1$ МПа. Частота вращения вала - 27 Гц. Возникающее излучение через световод направляли на поверхность фотокатода фотоэлектронного умножителя -= ФЭУ 136, электрические сигналы с которого поступали на один из входов аналогово-цифрового преобразователя АСК 3106 фирмы “АКТАКОМ”. Напряжение на его выходе, пропорциональное числу квантов, попавших на катод ФЭУ, через каждые 10 нс, записывалось в память компьютера. 


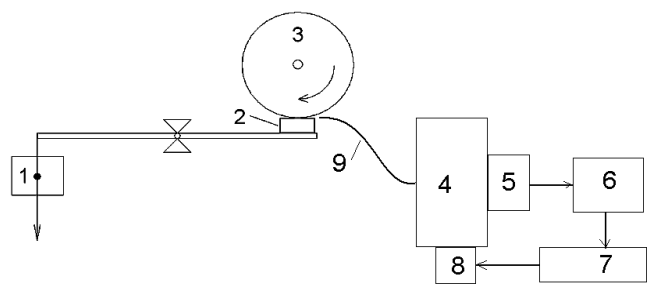

Рис. 62. Блок схема экспериментальной установки для изучения TL при сухом трении: 1- груз, 2- исследуемый образец, 3- стальной вал, 4монохроматор, 5- ФЭУ, 6 - ADC, 7- компьютер, 8 - шаговый двигатель. 9 - кварцевый световод.

Временная зависимость люминесценции композита, в котором волокна направлены перпендикулярно плоскости скольжения, показана на рис. 63.

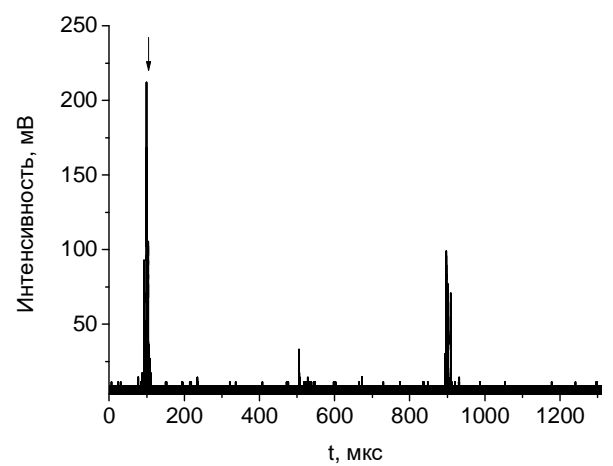

Рис. 63. Временные зависимости люминесценции композита, в котором волокна направлены перпендикулярно плоскости скольжения. Стрелкой показана серия вспышек, которая более подробно изображена на рис. 62.

При анализе, данных, показанных на рис. 63, нужно учесть, что интенсивность излучения свободных радикалов, образующихся при разрыве молекул ПФС на два порядка меньше, чем при разрыве угольных волокон (см. рис. 9). Это означает, что интенсивность 
вспышек излучения композита соответствует не трещинам в матрице, а разрывам угольных волокон.

Как видно, наблюдается две серии мощных вспышек, разделенным интервалом $\approx 800$ мкс. Т.к. скорость звука в матрице ПФС составляет 0,5 км/с, время пробега механического импульса от одного слоя армирующей углеродной ткани составляет - 800 мкс. Таким образом, вспышки появляются тогда, когда механические напряжения после разрушения одного слоя ткани, достигают второго слоя.

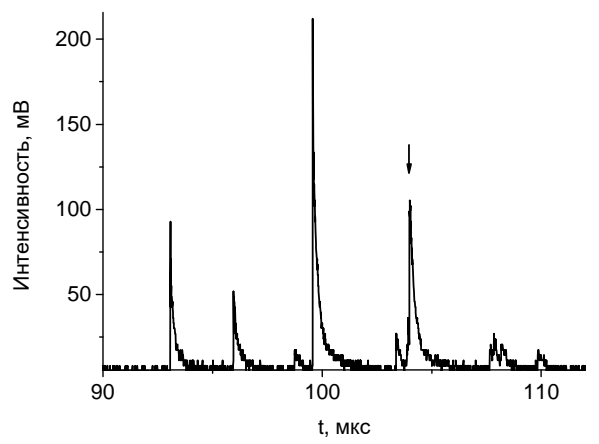

Рис. 64. Серия вспышек люминесценции, коррелированных во времени. Стрелкой показана вспышка, вид которой более подробно показан на рис. 63.

Эти серии мощных вспышек состоят несколько серий менее интенсивных вспышек, коррелированных во времени: следующая вспышка всегда появлялась через 3 - 4 мкс после предыдущей (рис. 62). Они состоят из 4 интенсивных и 5 слабых вспышек. Интенсивные вспышки возникают при разрыве 3-10 нитей в течение 10 мкс, а слабые - 1- 2 нитей. Промежуток времени между ними составлял $\approx 3$ мкс. Он, по-видимому, соответствует времени перераспределения напряжений в окрестности следующей серии нитей, после разрыва первой.

Более детальное рассмотрение вспышек позволяет проследить за последовательным разрывом волокон внутри нитей. Для примера, на рис. 63 показана в увеличенном масштабе вспышка, отмеченная на рис. 62 стрелкой. Видно, что она состоит из $\approx 30$, наложенных друг на друга вспышек, возникающих последовательно, друг за другом, через 
20 ns. Каждая нить содержит $\approx 30$ волокон. Поэтому каждая вспышка содержит $\approx 30$ наложенных друг на друга более мелких вспышек, возникающих при разрыве волокон, из которых состоит нить.

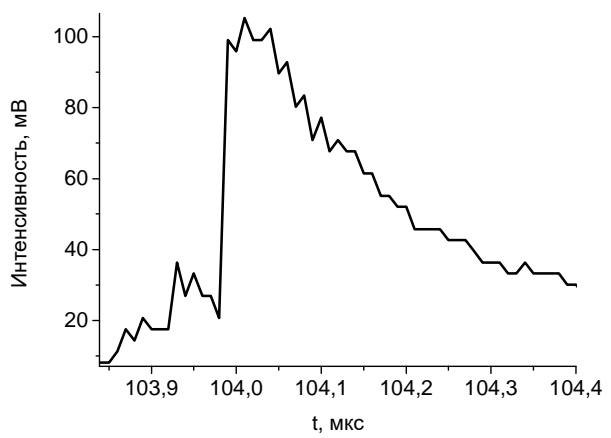

Рис. 65. «Одиночная» вспышка люминесценции.

\section{6. Зависимость коэффициента трения композита от свойств матрицы}

В данном разделе мы рассмотрим. как влияют свойства матрицы на коэффициент трения композитов.

Сначала измеряли коэффициенты сухого трения следующих матриц: ПТФЭ, ПЭ, ПП, ПА 6, ПА 6/10, ПЭТФ, ПФС (Таблица 12). С этой целью из них готовили стержни длиной 1 см и диаметром $\approx 4$ мм.

Таблица 12. Коэффициенты трения изотропных матриц.

\begin{tabular}{|l|l|l|l|l|}
\hline Полимер & $\begin{array}{l}\mathrm{P}, \\
\mathrm{MПа}\end{array}$ & $\mu_{\mathrm{o}}$ & $\mu_{\mathrm{s}}$ & $\mathrm{T}_{\mathrm{g}}, \mathrm{K}$ \\
\hline ПТФЭ & 55 & 0,15 & 0,07 & 150 \\
\hline ПЭ & 50 & 0,26 & 0,24 & 250 \\
\hline ПП & 56 & 0,062 & 0,05 & 270 \\
\hline ПА-6-10 & 55 & 0,10 & 0,09 & 320 \\
\hline ПА-6 & 57 & 0,12 & 0,12 & 340 \\
\hline ПЭТФ & 50 & 0,24 & 0,24 & 350 \\
\hline ПФС & 55 & 0,18 & 0,18 & 360 \\
\hline
\end{tabular}


Для измерения коэффициента трения боковой поверхности волокон (Таблица 13) слой из нитей наклеивали на пластинку из алюминия.

Таблица 13. Коэффициенты трения боковой поверхности волокон в направлении, параллельном их оси.

\begin{tabular}{|l|l|l|l|}
\hline Волокно & $\begin{array}{l}\text { Р, } \\
\text { МПа }\end{array}$ & $\mu_{\mathrm{o}}$ & $\mu_{\mathrm{s}}$ \\
\hline ПТФЭ & 12 & 0,1 & 0,05 \\
\hline ПА-6 & 14 & 0,16 & 0,15 \\
\hline ПАБИ & 60 & 0,27 & 0,27 \\
\hline углеродное & 47 & 0,20 & 0,19 \\
\hline
\end{tabular}

Чтобы оценить коэффициент трения торцов волокон ПАБИ, нити из них пропитывали матрицами при высоких температурах (методика описана в [92]) и готовили стержни, таких же размеров, как из матриц. Оба конца стержней шлифовали алмазным кругом. Затем один из концов стержней протирали не каландрированной фенелоновой бумагой. При протирке удавалось удалить частицы разрушенной матрицы, оставив нетронутыми концы нитей. В результате получали поверхность, из которой выходили торцы нитей длиной $\approx 20-50$ мкм и диаметром $\approx 30$ мкм (рис.66А).

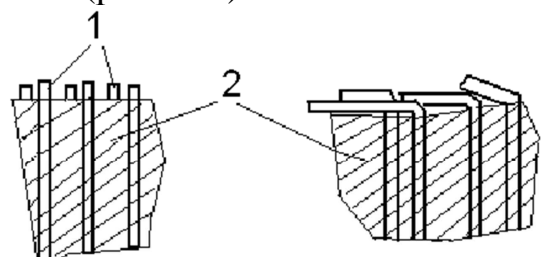

A

Б

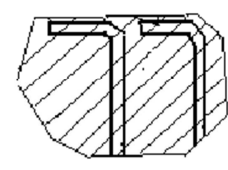

B

Рис. 66. Схема расположения торцов волокон ПАБИ (1) на поверхности матрицы (2) после трения: А - матрица жесткая (температура стеклования выше комнатной, по крайней мере, на 50 К); Б - пластичность матрицы не очень высока (значение $\mathrm{T}_{\mathrm{g}}$ меньше $300 \mathrm{~K}$ не более, чем на $50 \mathrm{~K}$ ), В - пластичность матрицы высока (разность между $\mathrm{T}_{\mathrm{g}}$ и 300 К больше $50 \mathrm{~K})$. 
Стержни устанавливали в держатели, укрепленные на алюминиевой пластинке, перпендикулярно к ее поверхности.

Коэффициенты стержней при комнатной температуре измеряли на построенной в лаборатории установке, которая схематически изображена на рис. 67. Алюминиевые пластинки (3) с образцами волокон или стержней (2), на которые помещали груз (4), перемещали со скоростью $\approx 0,2 \mathrm{~cm} / \mathrm{s}$ по шлифованной пластине из стали 45 (1). Усилие перемещения регистрировали тензодатчиком.

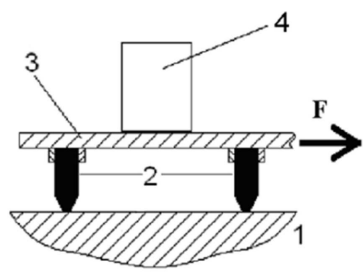

Рис. 67. Фрагмент установки для измерения коэффициента трения: 1 пластина из стали 45; 2 - образцы из матрицы или композита, укрепленные на алюминиевой пластинке (3), 4 - груз.

На рис. 68 показаны примеры зависимостей силы трения $\mathrm{F}$ матриц от пути $\mathrm{L}_{\text {тр. }}$ Такие же зависимости были получены для боковой поверхности волокон.

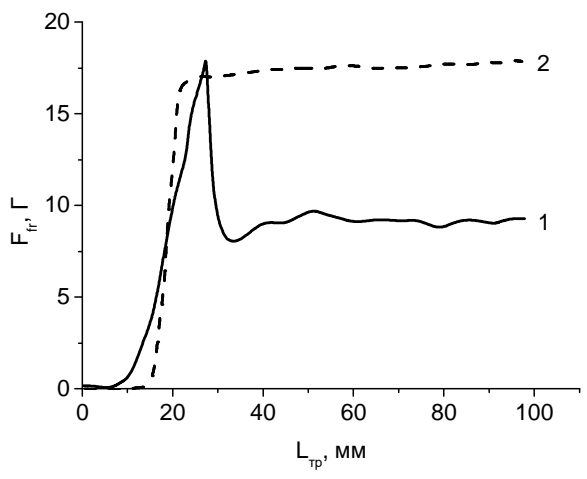

Рис. 68. Зависимости силы от пути трения различных матриц: 1 ПЭТФ ( $\mathrm{T}_{\mathrm{g}}<300$ К на $\left.140 \mathrm{~K}\right), \mathrm{P}=3$ МПа; 2 - ПА 6 ( $\mathrm{T}_{\mathrm{g}}>300 \mathrm{~K}$ на 60 К), P $=8 \mathrm{M}$ Па. 
Исследуемые образцы можно условно разделить на две группы. Для первой группы в начале пути сила трения возрастет, достигает значения $\mathrm{F}_{0}$, а затем уменьшается до квазистационарного значения $\mathrm{F}_{\mathrm{s}}$. T.е. для этих матриц коэффициент трения покоя $\mu_{0}$ больше, чем коэффициент трения скольжения $\mu_{\mathrm{s}}$. Вторую группу образуют матрицы и волокна, для которых $\mathrm{F}_{0} \approx \mathrm{F}_{\mathrm{s}}$, т.e. $\mu_{0} \approx \mu_{\mathrm{s}}$.

Известно, что усилие движения образца по контртелу, затрачивается на разрыв адгезионных связей между поверхностями трущихся тел. Возможны два случая. В первом скорость образования адгезионных связей больше скорости их взаимного перемещения. Тогда в начале пути коэффициент трения увеличивается до значения $\mu_{0}$. После их разрыва устанавливается равновесие между числом образующихся и распадающихся связей, и коэффициент трения уменьшается до $\mu_{\mathrm{s}}$. Во втором случае скорость образования адгезионных связей близка к скорости перемещения трущихся тел.

Оказалось, что для матриц и волокон первой группы температура стеклования $\mathrm{T}_{\mathrm{g}}$ ниже комнатной, а второй - выше (табл. 14) (Значения $\mathrm{T}_{\mathrm{g}}$ взяты из работ [97-98]).

Известно, что при температуре стеклования пластическая деформация полимеров под давлением резко возрастает. По этой причине возрастают площадь контакта матриц со сталью и адгезионное взаимодействие между ними, что и обуславливает увеличение коэффициента трения покоя. Однако пластическая деформация полимера развивается не мгновенно, а со скоростью, которая зависит от температуры и давления. Поэтому после начала движения площадь адгезионного контакта уменьшается, что и проявляется в уменьшении коэффициента трения до $\mu_{\mathrm{s}}$. Для матриц и волокон второй группы податливость и площадь контакта между полимером и металлом остаются практически неизменными и $\mu_{0} \approx \mu_{\mathrm{s}}$.

Измерение коэффициента трения торцов волокон ПАБИ представляет собой более трудную задачу. Оказалось, что, если $\mathrm{T}_{\mathrm{g}}<\mathrm{T}_{\mathrm{R}}$, то матрица пластически деформируется, выходящие из нее торцы нитей изгибаются и покрывают поверхность (рис. 66Б) или частично утапливаются в ней (рис. 66В). 
В противном случае матрица жесткая, и торцы нитей практически не изгибаются (рис. 64А). В этих условиях, зная концентрацию волокон - $\mathrm{C}_{\text {об̆ }}$ можно оценить величину коэффициента трения торцов волокон: $\mu_{\mathrm{e}} \approx \mu_{\mathrm{c}}$, где $\mu_{\mathrm{c}}-$ коэффициент трения композита. Так, например, для образцов с матрицами из ПА 6 и ПЭТФ (Т $>300 \mathrm{~K})$, концентрация волокон ПАБИ в которых $\approx 39$ и $\approx 32 \%$, нашли, что $\mu_{c} \approx 0,06$ и $\approx$ 0,07 , соответственно. Оценка коэффициента трения торцов волокон ПАБИ в этом случае дала $\mu_{\mathrm{e}} \approx 0,02$.

Анализ показал (таблица 14), что величина коэффициента трения композита, волокна в котором направлены перпендикулярно плоскости скольжения, зависит от температуры стеклования матрицы. Если $\mathrm{T}_{\mathrm{g}}>\mathrm{T}_{\mathrm{R}}$, то $\mu_{\mathrm{c}} \approx \mu_{\mathrm{e}} / \mathrm{C}_{\text {об }}$, где $\mathrm{C}_{\text {об }}-$ объемная концентрация волокон (№№ образцов 1-3), т.е. определяется коэффициентом трения торцов волокон и их концентрацией $\mathrm{C}_{\mathrm{f}}$.

Таблица 14. Коэффициенты трения однонаправленных композитов с волокнами из ПАБИ

\begin{tabular}{|l|l|l|l|l|l|}
\hline № & матрица & $\begin{array}{l}\text { Р, } \\
\text { МПа }\end{array}$ & $\mu_{0 \mathrm{c}}$ & $\mu_{\text {sc }}$ & $\begin{array}{l}\mathrm{C}_{\text {об, }} \\
\%\end{array}$ \\
\hline 1 & ПЭТФ & 230 & 0,07 & 0,07 & 32 \\
\hline 2 & ПА-6 & 12 & 0,11 & 0,06 & 39 \\
\hline 3 & ПА-6-10 & 145 & 0,13 & 0,13 & 36 \\
\hline 4 & ПЭ & 280 & 0,26 & 0,22 & 30 \\
\hline 5 & ПТФЭ & 46 & 0,10 & 0,05 & 35 \\
\hline
\end{tabular}

Если $\mathrm{T}_{\mathrm{g}}<\mathrm{T}_{\mathrm{R}}$, то $\mu_{\mathrm{c}}$ может иметь три значения в зависимости от величины пластической деформации матрицы. Если $\mathrm{T}_{\mathrm{g}}>\mathrm{T}_{\mathrm{R}}$ не больше, чем на $50^{\circ}$, то концы нитей при движении композита укладываются вдоль ее поверхности (Рис. 64Б). В этом случае коэффициенты трения покоя и скольжения композита близки к их значениям для боковой поверхности волокон (№4 в таблице 3). Если разница между $\mathrm{T}_{\mathrm{g}}$ и $\mathrm{T}_{\mathrm{R}}$ больше $\approx 50^{\circ}$, то при движении композита нити утапливаются в ее поверхностном слое (Рис. 64В) (№5 в таблице 18). Тогда коэффициен- 
ты трения покоя и скольжения композитов и матриц близки. Наконец, возможен вариант, когда нити частично утоплены в поверхностном слое матрицы. В этом случае $\mu_{\text {c }}$ имеет значение промежуточные между коэффициентами трения боковой поверхности волокон и матрицы.

Эти утверждения справедливы и для двумерного композита. Измерения показали, что коэффициент трения двумерного композита (температура стеклования матрицы - ПФС выше комнатной и составляет 360 К) с углеродными волокнами, ориентированными перпендикулярно к поверхности трения, составил 0,04 , а параллельно к ней в 4 раза больше - 0,16 .

Таким образом, величина коэффициентов трения покоя и скольжения волокнистого композита определяется пластичностью полимерной матрицы, направлением по отношению к плоскости скольжения и концентрацией волокон.

\section{Заключение}

1. Кинетика изнашивания, разогрева при трении при температуре ниже $\mathrm{T}_{\mathrm{b}}$ описываются уравнением Журкова.

2. При разрывах химических связей в процессе изнашивания образуются свободные радикалы. Они инициируют цепь химических реакций, которые приводят к образованию между металлом и полимером граничного слоя, обладающего низким коэффициентом трения и высокой износостойкостью. 


\section{5. Влияние окружающей атмосферы на кинетику разруше- ния}

\section{1. Влияние воды на кинетику разрушения под действием растягивающих напряжений}

Известно, что конструкционные материалы постоянно подвергаются воздействию воды, которая оказывает значительное влияние на их прочность и долговечность. Резко выраженная зависимость прочности стекла от длительности действия нагрузки и среде влажного воздуха впервые была обнаружена Л. Грене в 1899 г. [94]. Журков в начале 30-х годов обнаружил, что в вакууме прочность кварцевых волокон увеличивается в три раза [95].

Уменьшение прочности было зафиксировано для различных твердых тел - стекол и стекловолокон, природных и синтетических полимеров, металлических сплавов, строительных материалов, композитов и др. Например, энергия активации разрушения керамики в вакууме составляет 5,9 - 6,7 эВ, а в присутствии адсорбированной воды - 0,8 эВ [96]. С водой связаны многочисленные поломки в деталях из высокопрочных алюминиевых сплавов на космических кораблях «Апполон», в ракетах и др. [96].

В работах школы Ребиндера и других исследователей [97 101] широкое распространение получило представление об адсорбционном влиянии воды и других жидкостей на прочность твердых тел разной природы за счет понижения поверхностной энергии и «расклинивающего» воздействия на стенки трещины. В этих работах предполагается, что уменьшение прочности полимеров вызвано изменением поверхностной энергии, что приводит к уменьшению критического напряжения в вершине трещин. При таком подходе разрушение представляет собой критическое явление, которое наступает, когда напряжение в вершине наиболее опасной трещины достигает прочности материала. В этом случае, прочность не зависит от времени действия нагрузки, а зависимость от температуры обусловлена зависимостью поверхностной энергии от нее.

Иной подход, основанный на кинетической концепции прочности, был развит в работах Берштейна [102 - 104]. Автор исходил из ос- 
новного положения кинетической концепции, что в основе явления разрушения лежит процесс накопления разрывов химических связей под действием тепловых флуктуаций. Он провел детальные исследования кинетики разрушения и накопления разрывов химических связей как в нагруженных, так и в ненагруженных образцах кварца, ПА 6 и целлюлозы, вызванных взаимодействием этих материалов с водой. В результате было получено прямое доказательство, что процессы зарождения и развития разрушения в присутствии молекул воды представляют собой реакцию механически стимулироианного гидролиза.

Продемонстрируем полученные результаты на примере ПА 6, который может вступать в реакцию гидролиза при $\sigma=0$ :

$$
-\left(\mathrm{CH}_{2}\right)_{5} \mathrm{CONH}-\ldots .+\mathrm{H}_{2} \mathrm{O} \rightarrow \ldots . .-\left(\mathrm{CH}_{2}\right)_{5} \mathrm{COOH}+\mathrm{H}_{2} \mathrm{~N}-\left(\mathrm{CH}_{2}\right)_{5}-\text {. }
$$

В результате гидролиза молекула ПА 6 распадается на части, концы которых содержат химические группы R-COOH и $\mathrm{H}_{2} \mathrm{~N}-\mathrm{C}-\mathrm{R}$. Ha рис. 69 зависимости логарифма времени до разрушения ПА 6 от величины разрывного напряжения при разных температурах в вакууме, а на рис. 70 - во влажном воздухе.

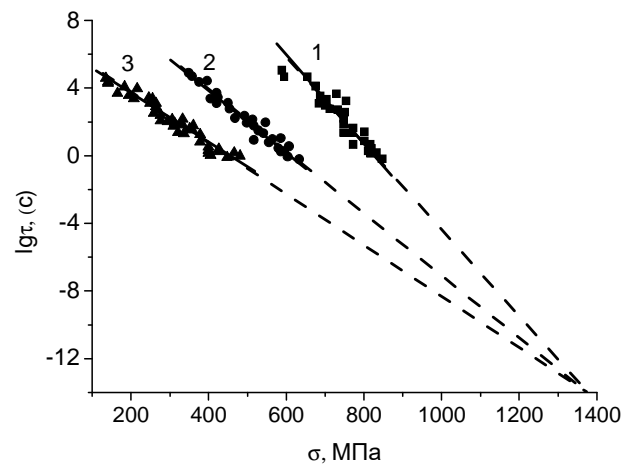

Рис. 69. Зависимости прочности ПА 6 от растягивающего напряжения в вакууме при разных температурах, Т, К: $1-293 ; 2-363 ; 3-433$ [102]. 


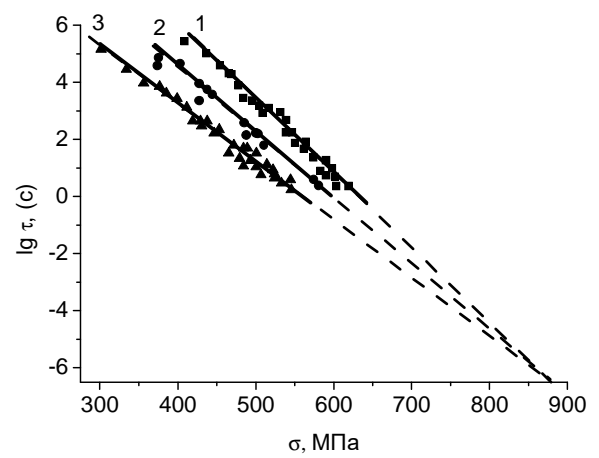

Рис. 70. Зависимости прочности ПА 6 от растягивающего напряжения во влажном воздухе (содержание воды 3-4\%) при разных температуpax T, K: 1 - 293, 2- 323, 3-363) [102].

Видно, что в согласии с кинетической концепцией прочности экспериментальные точки укладываются на веера прямых, которые сходятся в полюс при времени $\tau_{0} \approx 10^{-14} \mathrm{c}$ для испытаний в вакууме и $\tau_{0} \approx$ $10^{-6}$ для испытаний во влажном воздухе.

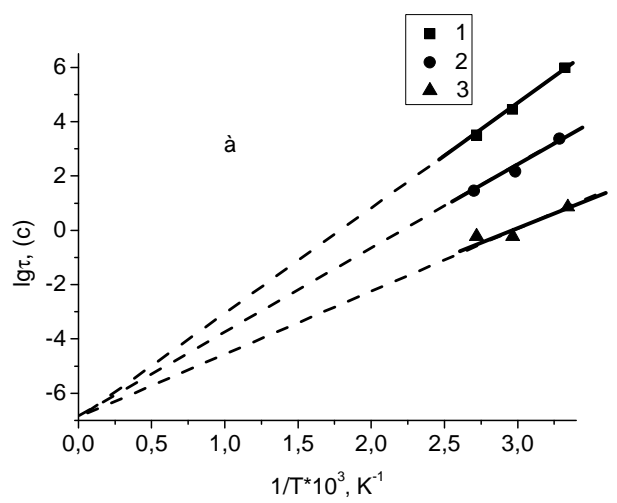

Рис. 71. Зависимости логарифма времени до разрушения от обратной температуры для испытаний во влажном воздухе (содержание воды (3-4) \%) при различных нагрузках [102], б, МПа: 1- 400, 2- 500, 3 600 . 


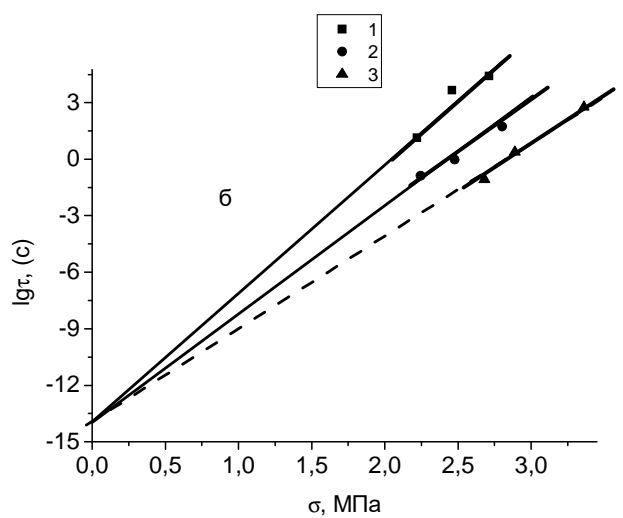

Рис. 72. Зависимости логарифма времени до разрушения от обратной температуры для испытаний [102] в вакууме при различных нагрузках,, МПа: 1- 500, 2 - 650. 3 - 800.

На рис. 71 и 72 приведены зависимости логарифма времени до разрушения при различных нагрузках от обратной температуры. И в этих координатах экспериментальные точки укладываются на веера прямых, которые сходятся в полюс при времени $\tau_{0} \approx 10^{-14}$ с для испытаний в вакууме и $\tau_{0} \approx 10^{-6}$ - во влажном воздухе.

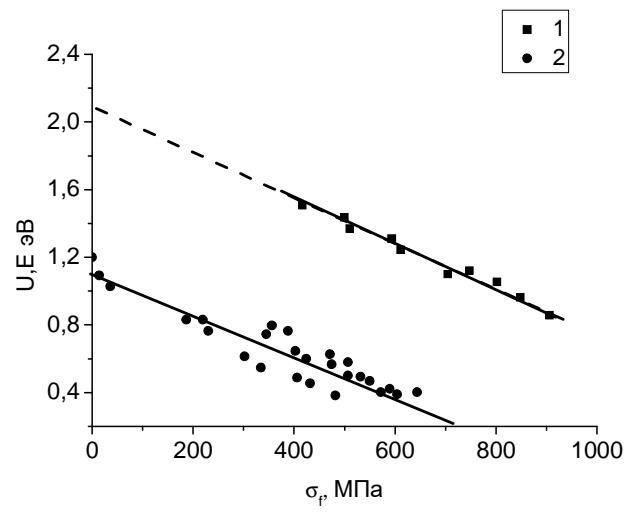

Рис. 73. Зависимость энергии активации разрушения $\mathrm{U}(1,2)$ и накопления разрывов химических связей $\mathrm{E}$ (3) от разрывного напряжения для испытаний в вакууме - 1 и во влажном воздухе 2 и 3) [102]. 
Из приведенных данных следует, что для испытаний в вакууме и во влажном воздухе зависимость долговечности от величины разрывной нагрузки описывается уравнением Журкова. Однако параметры $\mathrm{U}_{0}$ и $\tau_{0}$, входящие в это уравнение зависят от влажности: в вакууме $\mathrm{U}_{0}$ $\approx 2,2$ эВ и $\tau_{0} \approx 10^{-14} \mathrm{c}$, а во влажном воздухе - $\mathrm{U}_{0} \approx 1,2$ эВ и $\tau_{0} \approx 10^{-6} \mathrm{c}$.

При разрывах полимерных молекул образуются новые концы. Часть из них содержит СООН. Их можно зафиксировать, используя метод ИК - спектроскопии [104]. Для примера, на рис. 74 приведены дифференциальные ИК-спектры (полученные путем вычитания спектров после воздействия воды из спектров до ее воздействия). групп $\mathrm{COOH,} \mathrm{образовавшихся} \mathrm{в} \mathrm{ориентированном} \mathrm{ПА} \mathrm{вследствие} \mathrm{гидролиза}$ амидных связей.

Видно, что после гидролиза резко возрастает поглощение в области $1690-1770 \mathrm{~cm}^{-1}$. В этой области расположены 2 полосы - 1712 и $1740 \mathrm{~cm}^{-1}$, соответствующие валентным колебаниям $\mathrm{C}=\mathrm{O}$ связей в концевых группировках СООН. Рост интенсивности этих полос означает, что при гидролизе С-С связи в молекуле ПА 6 разрываются и образуются новые концы разорванных молекул.

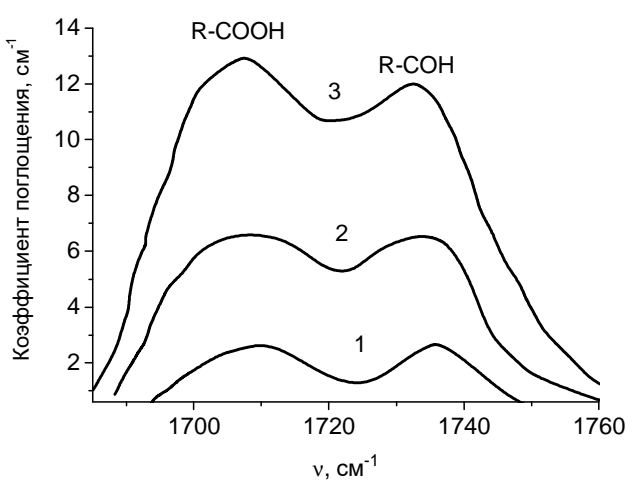

Рис. 74. Дифференциальные ИК спектры ненагруженного ПА 6 после реакции гидролиза при различных температурах Т и временах $\mathrm{t}$ выдержки образцов в среде влажного воздуха. T, C; t, час: 1 - 60, 70; 2 - 90, 10; 3 - 90 C, 100. [104]. 
Временные зависимости концентрации $\mathrm{C}_{\mathrm{r}}$ концевых группировок $\mathrm{COOH}$ для ненагруженных и нагруженных образцов ПА 6 показаны $\tau_{0}$ $\approx 10^{-13}$ на рис. 75 и 76 .

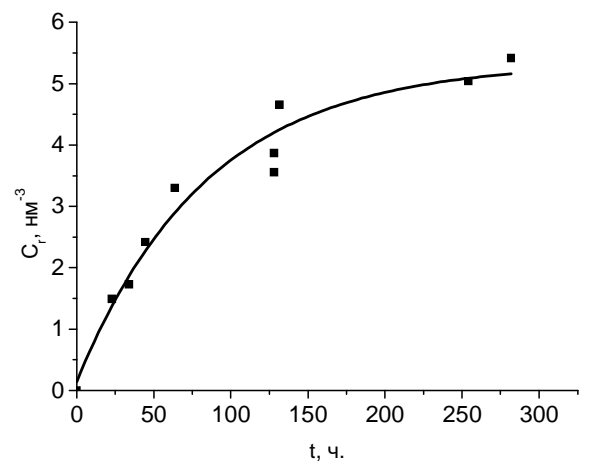

Рис. 75. Временная зависимость концентрации $\mathrm{C}_{\mathrm{r}}$ концевых группировок СООН для ненагруженных образцов ПА 6 [104].

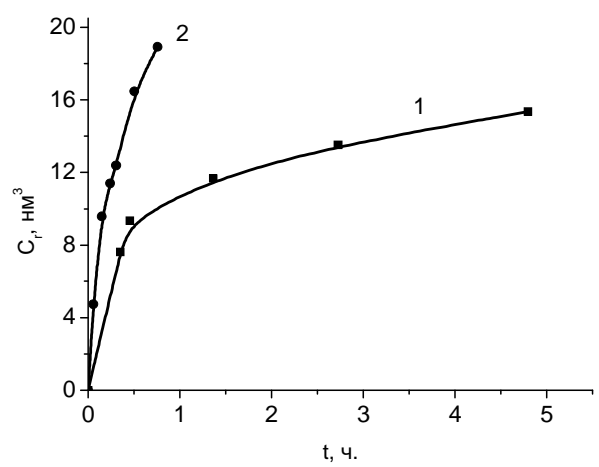

Рис. 76. Зависимости концентрации концевых группировок СООН от длительности гидролиза ПА 6 при 360 К, б, МПа: 1 - 200; 2 - 300 [102]. 
Оказалось, что они описываются уравнением:

$$
\mathrm{C}_{\mathrm{r}}(\mathrm{t})=\mathrm{C}_{*}\left(1-\mathrm{k}_{\mathrm{r}} \mathrm{t}\right)
$$

где $\mathrm{C}_{*}$ предельная концентрация разорванных химических связей, $\mathrm{k}_{\mathrm{r}}$ константа скорости накопления разрывов. Отметим, что таким же уравнением описывается кинетика накопления концов молекул, образовавшихся под нагрузкой и других полимеров, не подверженных гидролизу.

На рис. 77 представлены температурные зависимости логарифма константы скорости гидролиза полиамида при различных напряжениях. Из него следует, что зависимость константы накопления разрывов от температуры описывается уравнением

$$
\mathrm{k}_{\mathrm{g}}=\mathrm{k}_{0 \mathrm{~g}}\left[-\left(\mathrm{E}_{0 \mathrm{~g}}-\gamma \sigma\right) / \mathrm{kT}\right]
$$

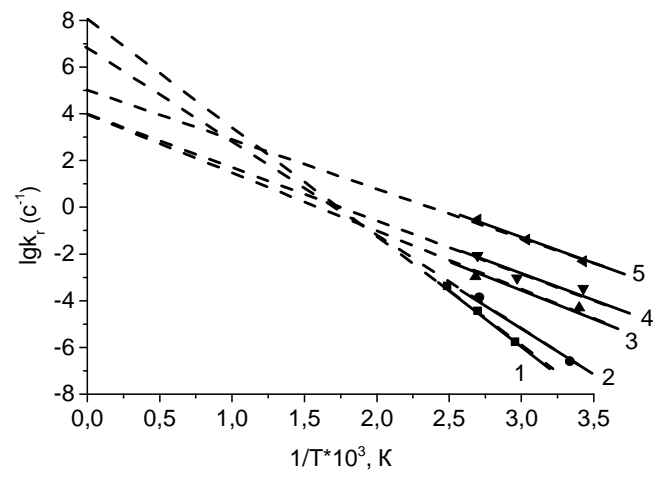

Рис. 77. Зависимости константы скорости гидролиза ПА 6 от обратной температуры при растягивающих напряжениях, $\sigma$, МПа: 1 - 0; 2 - 200; 3 - 300; 4 - 400; 5 - 500. [102].

На рис. 78 приведены зависимости энергии активации процесса гидролиза $\mathrm{E}_{\mathrm{g}}$, а на рис. 79 - предэкспоненциального сомножителя $\mathrm{k}_{\mathrm{og}}$ в уравнении (21) от величины среднего растягивающего напряжения. Из 
них видно (точки на оси ординат), что в отсутствие приложенной нагрузки $\mathrm{E}_{0 \mathrm{~g}}=(1 \pm 0,1)$ эВ, a $\mathrm{k}_{\mathrm{og}} \approx 10^{8} \mathrm{c}$.

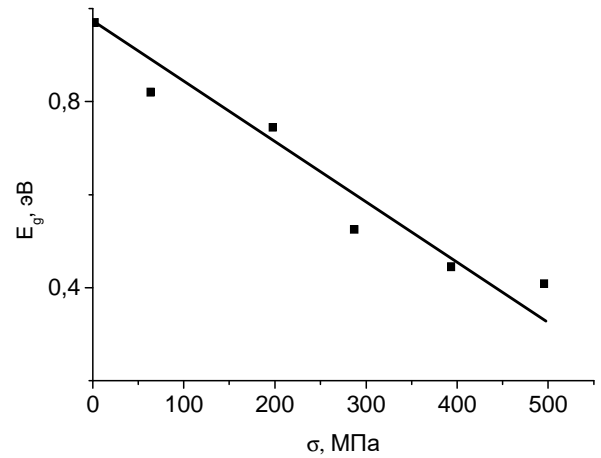

Рис. 78. Зависимости энергии активации $\mathrm{E}_{\mathrm{g}}$ в уравнении Аррениуса для гидролиза нагруженного ПА 6 от величины растягивающего напряжения [102].

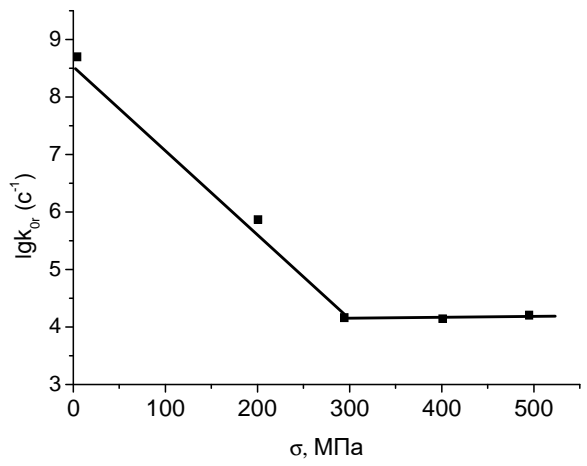

Рис. 79. Зависимости $\mathrm{k}_{0 \mathrm{~g}}(2)$ в уравнении Аррениуса для гидролиза нагруженного ПА 6 от величины растягивающего напряжения [102].

Механическая нагрузка оказывала двоякое влияние на кинетические параметры гидролиза ориентированного полиамида. Первый 
эффект - это снижение растягивающим напряжением энергии активации процесса гидролиза полиамида. Оно происходит по такому же линейному закону $\mathrm{E}_{\mathrm{g}}=\mathrm{E}_{0 \mathrm{~g}}-\gamma \sigma$, как и в случае термофлуктуационпого разрыва межатомных связей в отсутствие действия среды. Подчеркнем, что значение $\mathrm{E}_{\mathrm{og}}$ совпадает с величиной энергии активации гидролиза ненагруженных образцов.

Второй эффект - величина $\mathrm{k}_{0 \mathrm{~g}}=1 / \tau_{0}$ в отличие от полимеров, не подверженных гидролизу, существенно меньше $10^{13}$ с и зависит от величины нагрузки. А именно, нагрузка уменьшает величину $\mathrm{k}_{0 \mathrm{~g}}$ от $\approx 10^{9}$ с для ненагруженного образца до $10^{4}$ с для образца под нагрузкой 300 МПа. При более высоких значениях нагрузки величина $\mathrm{k}_{0 \mathrm{~g}}$ остается неизменной.

Зависимость $\mathrm{k}_{0 \mathrm{~g}}$ от нагрузки вызвана торможением подвижности полимерных молекул под нагрузкой (механическому стеклованию). По этой причине уменьшается скорость диффузии молекул воды к перенапряженным химическим связям, что проявляется в уменьшении параметра $\mathrm{k}_{0 \mathrm{~g}}$.

Следовательно, зависимость константы скорости разрывов химических связей можно описать с помощью уравнения Аррениуса для реакции:

$$
\mathrm{k}_{\mathrm{g}}=\mathrm{k}_{0 \mathrm{~g}} \exp \left[-\left(\mathrm{E}_{0 \mathrm{~g}}-\gamma \sigma\right) / \mathrm{kT}\right]
$$

где энергия активацииЕ $\mathrm{E}_{0 \mathrm{~g}}=0,9-1,1$ эВ - типична для реакций гидролиза, $\mathrm{a}_{0 \mathrm{~g}}=-10^{4}-10^{6} \mathrm{c}^{-1}$.

В таблице 15 приведены значения $\mathrm{U}_{0}$ для различных полимеров в отсутствии воды и при гидролизе. Из нее следует, что энергия активации разрушения полимеров в присутствии воды уменьшается в два три раза.

Выше было показано, что долговечность гидрофобных полимеров в присутствии воды существенно ниже, чем в сухом воздухе. Поскольку разрываются лишь возбужденные химические связи, то можно было ожидать, что вода должна повлиять на их концентрацию и деформацию. 
Таблица 15. Энергия активации разрушения полимеров в отсутствии воды и при гидролизе [102].

\begin{tabular}{|c|c|c|c|}
\hline \multirow[t]{2}{*}{ Полимеры } & \multirow{2}{*}{$\begin{array}{l}\text { Связи, спо- } \\
\text { собные } \\
\text { к гидролизу }\end{array}$} & \multicolumn{2}{|l|}{$\mathrm{U}_{0}$, эB } \\
\hline & & $\begin{array}{l}\text { В отсутствии } \\
\text { воды }\end{array}$ & $\begin{array}{l}\text { В присутствии } \\
\text { воды }\end{array}$ \\
\hline Полиамиды & \multirow[t]{2}{*}{$\mathrm{CONH}$} & $2,1-2,5$ & $0,7-1,1$ \\
\hline Полиимиды & & $2,5-3,4$ & 0,8 \\
\hline Полигетероарилены & \multirow[t]{3}{*}{$\equiv \mathrm{C}-\mathrm{O}-$} & - & $0,6-0,8$ \\
\hline Полиэфиры & & 2,5 & $0,8-0,9$ \\
\hline Целлюлоза & & $2,1-2,9$ & $1,3-1,5$ \\
\hline
\end{tabular}

Эти ожидания оправдались на опыте [105]. Для примера, на рис. 80 показана полоса приписанная колебаниям углеродного скелета молекулы ПА 6 длиной $\approx 1$ нм, в ИК-спектре влажного и сухого образца.

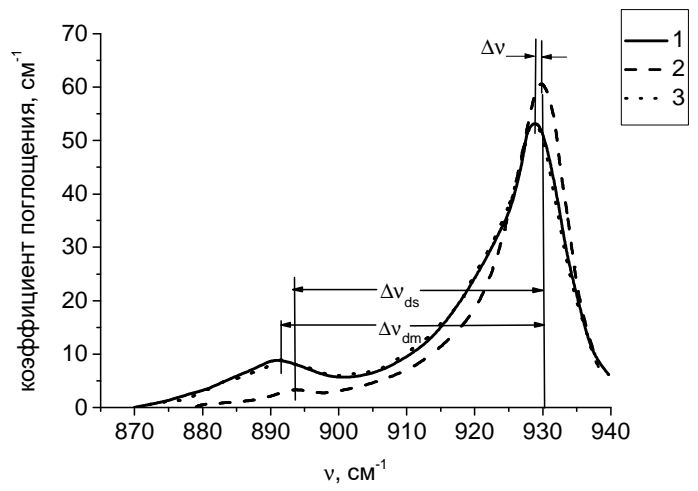

Рис. 80. Смещение и изменение формы полосы $929 \mathrm{~cm}^{-1}$ в ИК спектре ПА 6 под влиянием воды: 1 - поверхность образца высушена; 2 - поверхность образца увлажнена; 3 - поверхность образца после высушивания.

Видно, что под влиянием влаги основной, наиболее интенсивный максимум полосы смещается в сторону низких частот на величину $\Delta v$ $\approx 1 \mathrm{~cm}^{-1}$. Это показывает, что под влиянием воды скелеты основной массы молекулы ПА 6 растягивается. Другими словами, увлажнение 
эквивалентно приложению растягивающих напряжений. Величина напряжений равна $1 / 3,7 \approx 27$ МПа.

Ранее было установлено, что растягивающие напряжения вызывают увеличение деформации возбужденных химических связей и увеличение их деформации. Поэтому ожидалось, что концентрация возбужденных химических связей (оцениваемая по отношению интенсивности дополнительного максимума к основному) и величина средних перенапряжений на них во влажном образце должны расти. Результат получился обратным ожидаемому: увлажнение привело к уменьшению концентрации возбужденных связей в 6 раз - с 18 до $3 \%$, а перенапряжения на них уменьшились с $\Delta v_{\mathrm{dm}} / \alpha=38 / 3,7 \approx 10$ ГПа до = 38/3,7 = 9,3 ГПа.

Что же означают эти изменения? Интенсивность $\mathrm{I}_{\mathrm{d}}$ дополнительного максимума представляет собой результат конкуренции двух процессов - образования и разрыва возбужденных связей. Поэтому уменьшение концентрации таких связей означает, что скорость их разрыва превышает скорость их образования. Уменьшение перенапряжения возбужденных связей показывает, что в присутствии воды они разрываются при меньших удлинениях.

\section{2. Напряжения в граничных слоях с воздушной атмосферой и их влияние на кинетику разрушения}

Как уже упоминалось, ранее полагалось, что ведущая роль поверхности в разрушении обусловлена тем, что на ней, как правило, содержится большое число микротрещин, образованных под действием внешних механических воздействий. Однако в результате развития кинетической концепции прочности возникло еще одно представление о причинах, определяющих ведущую роль поверхности. А именно, на поверхности возможно увеличение вероятности возникновения разрушающих флуктуаций из-за изменения спектра атомных колебаний. Например, известно, что на поверхности и в граничных слоях твердых тел спектр колебаний атомов перестраивается: наряду с объемными, появляются поверхностные колебания. Изменения спектра проявляются на расстояниях от границы раздела, достигающих сотен мкм и могут приводить к изменению теплового расширения, появлению 
внутренних напряжений и изменению вероятности образования возбужденных химических связей.

Рассмотрим ИК - спектры поверхностных слоев и объема полимеров [106].

На рис. 81 приведена полоса $929 \mathrm{~cm}^{-1}$ в ИК-спектрах объема пленки ПА 6 толщиной 40 мкм и поверхностного слоя этой же пленки толщиной 1 мкм в сухой атмосфере. Видно, что в спектре поверхностного слоя основной максимум смещен в сторону низких частот на $\approx 1 \mathrm{~cm}^{-1}$. На длинноволновом крыле полосы наблюдается дополнительный максимум, интенсивность $D_{\mathrm{d}}$ и смещение $\Delta v_{\mathrm{d}}$ которого в спектре поверхностного слоя $\left(\mathrm{D}_{\mathrm{d}}=9,8, \Delta v_{\mathrm{d}} \approx 46 \mathrm{~cm}^{-1}\right)$ больше, чем в спектре пропускания $\left(\mathrm{D}_{\mathrm{d}}=4, \Delta v_{\mathrm{d}} \approx 40 \mathrm{~cm}^{-1}\right)$.

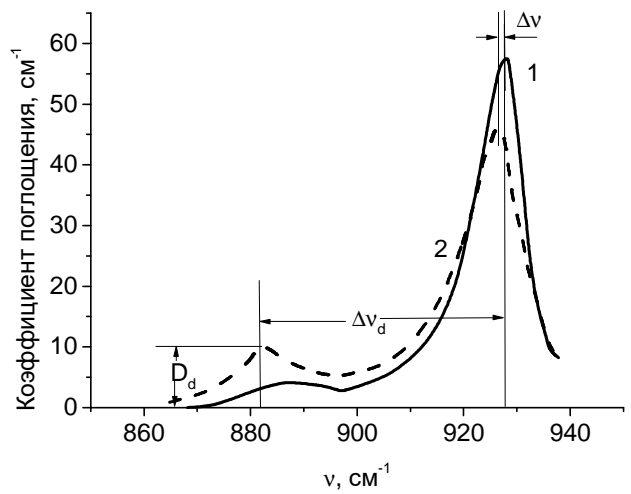

Рис. 81. ИК-спектры объема пленки ПА 6 толщиной 40 мкм (1) и поверхностного слоя и этой же пленки толщиной 1 мкм (2) в сухом воздухе.

На рис. 82 показаны ИК спектры пропускания пленки ПА 6 толщиной 16 мкм и образца, составленного из 16 пленок того же материала толщиной в 1 мкм. Видно, что в спектре составного образца основной максимум полосы $929 \mathrm{~cm}^{-1}$ смещен в сторону низких частот на $\approx 1,5 \mathrm{~cm}^{-1}$. Одновременно интенсивность $\mathrm{D}_{\mathrm{d}} \approx 8$ и величина смещения дополнительного максимума $\approx 42 \mathrm{~cm}^{-1}$ в спектре составного образца больше $\left(\mathrm{D}_{\mathrm{d}} \approx 10, \Delta v_{\mathrm{d}} \approx 45 \mathrm{~cm}^{-1}\right)$, чем в спектре сплошной пленки $\left(\mathrm{D}_{\mathrm{d}} \approx\right.$ $\left.3,5, \Delta v_{\mathrm{d}} \approx 40 \mathrm{~cm}^{-1}\right)$. 


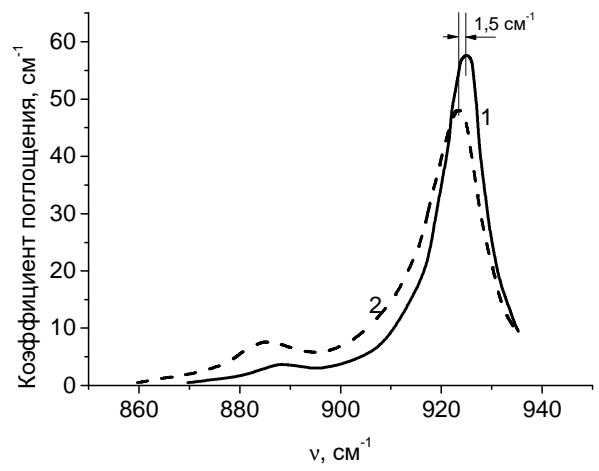

Рис. 82. ИК - спектры пропускания образцов ПА-6: сплошного толщиной 16 мкм (1) и составленного из 16 пленок толщиной в 1 мкм (2) в сухом воздухе.

На рис. 83 показаны рамановские спектры порошка и блочного образца полистирола (ПС), приготовленного из этого же порошка. В рамановском спектре порошка основной максимум полосы $1002 \mathrm{~cm}^{-1}$ смещен в низкочастотную сторону на $\approx 2 \mathrm{~cm}^{-1}$ и с этой же стороны увеличены смещение и интенсивность дополнительного максимума на длинноволновом крыле полосы. Наконец, на рис. 84 показаны рамановские спектры волокна ПЭТФ в условиях, когда луч лазера диаметром $\approx 3$ мкм проходит через центр волокна диаметром 100 мкм и слегка касается его поверхности. В рамановском спектре поверхностного слоя основной максимум полосы $1614 \mathrm{~cm}^{-1}$ смещен в длинноволновую сторону на $\approx 1 \mathrm{~cm}^{-1}$. Одновременно, в спектре поверхностного слоя волокна увеличены интенсивность и смещение дополнительного максимума на длинноволновом крыле полосы. 


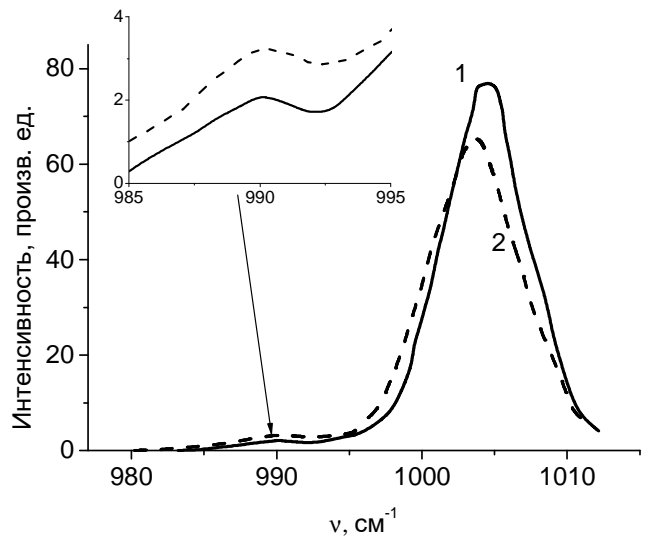

Рис. 83. Рамановские спектры блочного образца (1) ПС и порошка (2), из которого он приготовлен.

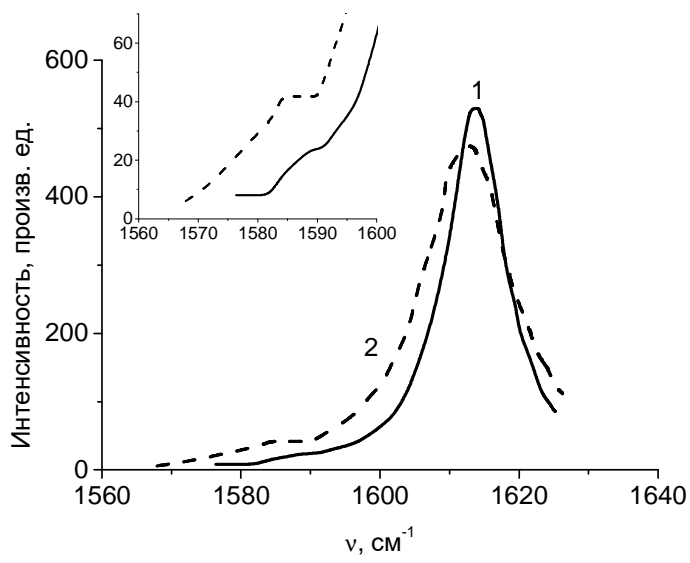

Рис. 84. Рамановские спектры волокна ПЭТФ: 1 - луч лазера диаметром $\approx 3$ мкм проходит через центр волокна диаметром 100 мкм; 2 - луч слегка касается его поверхности.

Такие же эффекты смещения в сторону низких частот основного максимума полос регулярности, а также роста интенсивности и величины смещения дополнительного максимума на их длинноволновом 
крыле в ИК- и рамановских спектрах наблюдались для большого числа других полимеров [106].

Смещение максимума полос в сторону низких частот показывает, что основная масса участков скелета макромолекул полимеров растянута.

Оценим величину эффективного напряжения, которое может вызвать эту деформацию. Для полосы $929 \mathrm{~cm}^{-1}$ коэффициент $\alpha$ в уравнении (10) равен $3,7 \mathrm{~cm}^{-1} /$ Па. Тогда смещение $1,5 \mathrm{~cm}^{-1}$ соответствует растягивающему напряжению $\sigma_{\mathrm{s}}=1,5 / 3,7=0,4$ ГПа.

Измерив смещение и интенсивность дополнительного максимума на длинноволновом крыле полос регулярности, нашли напряжение $\sigma_{\mathrm{d}}$, действующее на возбужденные химические связи, и концентрацию $\mathrm{C}_{\mathrm{d}}$ таких связей в объеме и поверхностном слое полимеров толщиной 1 мкм (таблица 16.).

Таблица 16. Напряжение $\sigma_{d}$, действующее на возбужденные химические связи и концентрация $\mathrm{C}_{\mathrm{d}}$ таких связей в объеме и поверхностном слое толщиной 1 мкм некоторых полимеров.

\begin{tabular}{|l|l|l|l|l|}
\hline Полимер & \multicolumn{2}{|l|}{$\begin{array}{l}\text { Поверхностный } \\
\text { слой }\end{array}$} & \multicolumn{2}{l|}{ Объем } \\
\cline { 2 - 5 } & $\sigma_{\mathrm{d}}$ & $\mathrm{C}_{\mathrm{d}}$ & $\sigma_{\mathrm{d}}$ & $\mathrm{C}_{\mathrm{d}}$ \\
\cline { 2 - 5 } & Га & $\%$ & ГПа & $\%$ \\
\hline ПЭ & 18 & 4 & 12 & 2 \\
\hline ПП & 18 & 4 & 12 & 2 \\
\hline ПЭТФ & 18 & 10 & 9 & 2 \\
\hline ПА-6 & 16,5 & 10 & 6 & 3 \\
\hline ПМ & 16,5 & 10 & 12 & 4 \\
\hline
\end{tabular}

Из таблицы следует, что растягивающее напряжение, действующее на возбужденные химические связи в поверхностном слое полимеров 1,5 - 2 раза больше, чем в объеме. Их концентрация в поверхностном слое также в $2-5$ раза выше, чем в объеме.

Выше уже говорилось о том, что в нагруженном теле возбужденные химические связи разрываются в первую очередь. Поэтому ско- 
рость их разрушения поверхностных слоев толщиной $\approx 1$ мкм больше на 1 - 3 порядка, чем более глубоких слоев полимеров [107 - 111].

\section{3. Влияние окружающей среды на трибологические свойства композитов}

Как показано в предыдущем разделе, молекулы окружающей композит среды, диффундируют в него и могут вступать в химическое взаимодействие с его молекулами. В результате изменяются все параметры уравнения Журкова $\mathrm{U}_{0}, \gamma$ и $\tau_{0}$, что приводит к изменению скорости разрушения. В свою очередь изменение скорости износа проявляется в изменении силы и коэффициента трения. Для примера, на рис. 85 показана зависимость логарифма скорости износа от нормального давления в пресной воде композита с матрицей из ПФО, наполненной углеродными волокнами, с контртелом из стали. Видно, что, как и на воздухе, скорость износа экспоненциально зависит от давления.

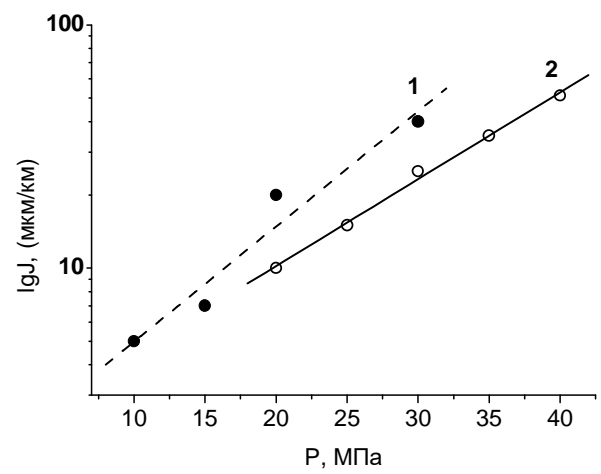

Рис.85. Зависимость интенсивности износа от давления на воздухе (1) и пресной воде (2) композита с матрицей из ПФО, наполненной 35 об.\% углеродных волокон при трении с контртелом из коррозионностойкой стали ОХІ8H10T. (Исследования проводили на машине торцевого трения МФТ-1 при скорости скольжения 0,5 м/с.) 
Этот результат показывает, что механизм износа в воде такой же, как и на воздухе. Он заключается в накоплении продуктов распада химических связей матрицы под действием термических флуктуаций.

В пресной воде интенсивность износа меньше, чем на воздухе. Оказалось, что она еще меньше (на два порядка - до $\approx 0,1$ мкм/км при нагрузках от 20 до $30 \mathrm{MПа)} \mathrm{в} \mathrm{морской} \mathrm{воде.}$

Износ всех композитов в вакууме больше, а углекислом газе меньше, чем в воздухе.

Этот результат может быть объяснен следующим образом. При трении, разрываются молекулы матрицы. Образуются свободные радикалы, которые в присутствии углекислого газа вызывают протекание химических реакций и образование промежуточного слоя в низким коэффициентом трения.

В таблице 17 и 18 приведены значения износа и силы трения в воздухе, вакууме и углекислом газе.

Таблица 17 . Влияние среды на износ и силу трения композита с матрицей из ПФО с различными наполнителями.

\begin{tabular}{|c|c|c|c|c|}
\hline \multirow[t]{2}{*}{ Наполнитель } & \multicolumn{2}{|c|}{$\begin{array}{l}\text { Вакуум, P } \\
0,001 \mathrm{H} / \mathrm{M}^{2}\end{array}$} & \multicolumn{2}{|c|}{$\begin{array}{l}\text { Углекислый газ, Р } \\
\text { } 100 \text { Н/м² }\end{array}$} \\
\hline & \begin{tabular}{|l|}
$\mathrm{J} \cdot \mathrm{IO}^{4}$ \\
$\mathrm{\Gamma} / \mathrm{KM}$ \\
\end{tabular} & $\mathrm{f}$ & $\mathrm{J} \cdot \mathrm{I} 0^{4}, \Gamma / \kappa \mathrm{M}$ & $\mathrm{f}$ \\
\hline Отрезки углеродных волокон & 6 & 0,23 & 4 & 0.16 \\
\hline $\begin{array}{l}\text { Отрезки углеродных волокон и } \\
\text { нитевидные кристаллы } \mathrm{TiO}_{2}\end{array}$ & 55 & 0,34 & 44 & 0,31 \\
\hline $\begin{array}{l}\text { Порошок ПТФЭ и нитевидные } \\
\text { кристаллы Ni }\end{array}$ & 4 & 0,15 & 2 & 0.18 \\
\hline $\begin{array}{l}\text { Порошок ПТФЭ и нитевидные } \\
\text { кристаллы ВN }\end{array}$ & 6 & 0,13 & 2 & 0,14 \\
\hline Порошки ПТФЭ и Сu & 4 & 0,16 & 2 & 0.21 \\
\hline Порошки ПТФЭ и Al & 10 & 0,18 & 5 & 0,20 \\
\hline
\end{tabular}


Таблица 18. Износ и коэффициент трения композитов с матрицей ПФО и полиимидов, наполненных отрезками углеродных волокон, в различных средах.

\begin{tabular}{|c|c|c|c|c|c|c|}
\hline \multirow[t]{2}{*}{$\begin{array}{l}\text { Матри- } \\
\text { ца }\end{array}$} & \multicolumn{2}{|c|}{$\begin{array}{l}\text { Воздух, } 760 \text { мм. } \\
\text { рт.ст. }\end{array}$} & \multicolumn{2}{|c|}{$\begin{array}{l}\text { Вакуум 5x10 } \\
\text { pт.ст }\end{array}$} & \multicolumn{2}{|c|}{$\begin{array}{l}\text { Уллекислый газ, } \\
10 \text { мм. рт. ст. }\end{array}$} \\
\hline & $\begin{array}{l}\text { износ, } \\
\text { мГ/км }\end{array}$ & $\begin{array}{l}\text { Коэффи- } \\
\text { циент } \\
\text { трения }\end{array}$ & $\begin{array}{l}\text { износ, } \\
\text { МГ/км }\end{array}$ & $\begin{array}{l}\text { Коэффи- } \\
\text { циент тре- } \\
\text { ния }\end{array}$ & $\begin{array}{l}\text { износ, } \\
\text { мГ/км }\end{array}$ & $\begin{array}{l}\text { Коэффи- } \\
\text { циент } \\
\text { трения }\end{array}$ \\
\hline ПФО & 0,3 & 0.12 & 0.5 & 0.19 & 0,2 & 0.08 \\
\hline ПАИС & 0,2 & 0,15 & 0,8 & 0.25 & - & - \\
\hline ПФХС & - & - & 2,3 & 0,28 & 0,6 & 0,19 \\
\hline ПАИС ${ }^{*}$ & 0,2 & 0,11 & 0.5 & 0,17 & - & - \\
\hline
\end{tabular}

Вода и кислород изменяют ход таких реакций и приводят к образованию более мелких фрагментов молекул. В результате величина параметра $\mathrm{J}_{\infty}$ и скорость износа уменьшаются.

\section{Заключение}

Окружающая атмосфера влияет на скорость износа двумя путями:

1. Она изменяет распределение напряжений по химическим связям в композите;

2. Изменяет механизм разрыва химических связей. 


\section{6. Влияние формы и концентрации частиц наполнителя на теплофизические свойства композитов}

\section{Введение}

Граничные слои оказывают существенное влияние не только на прочность и скорость изнашивания при трении, но и на теплофизические свойства композитов. Рассмотрим этот вопрос более подробно.

\subsection{1. Температуропроводность композитов}

Скорость изменения температуры в нестационарных условиях принято характеризовать коэффициентом температуропроводности $a$. Известно, что при введении наполнителей в полимеры величину $a$ можно изменять более чем на порядок [114 - 118].

Часть исследователей полагает, что механизм изменения температуропроводности можно описать также как и электропроводности - на основе теории протекания. Предполагается, что при критической концентрации наполнителя его частицы соединяются в непрерывную цепочку, по которой тепло перетекает от одной поверхности тела к противоположной. Такие представления хорошо описывают экспериментальные данные, когда температуропроводность наполнителя в $\approx 10^{8-10}$ раз больше, чем матрицы. Однако температуропроводность матрицы и наполнителей, как правило, отличаются не более чем в $10^{3}$ раз. Кроме того, между матрицей и наполнителем всегда существует высокое контактное тепловое сопротивление. По этим причинам такой способ описания плохо согласуется с экспериментом, в особенности при невысоких степенях наполнения.

Другая часть исследователей рассматривает композит как набор из параллельно или последовательно включенных элементов с коэффициентами температуропроводности матрицы и наполнителя. При таком описании приходится эмпирическим путем выбирать комбинацию соединения таких элементов друг с другом.

В этих подходах предполагается, что свойства матрицы остаются неизменными при формировании композита. Между тем в последние годы накопились данные, что теплофизические параметры матрицы 
существенно изменяются в граничных слоях с наполнителями. Толщина таких слоев может достигать 100 мкм, и они вносят существенный вклад в температуропроводность композита.

Измерения показали [119], что коэффициент температуропроводности композита $a_{c}$ растет с увеличением объемной концентрации $\mathrm{C}_{\text {об }}$ наполнителей (рис.86).

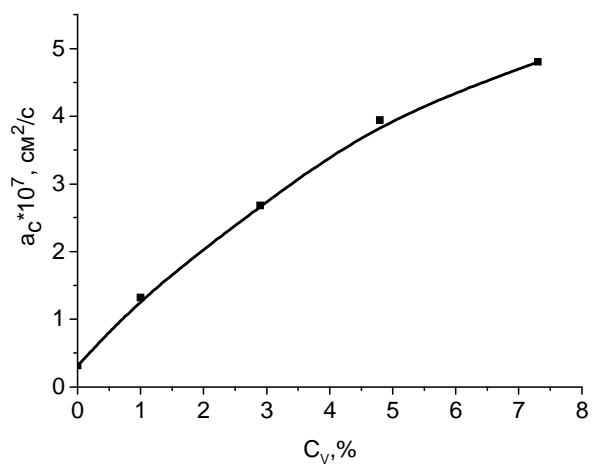

Рис. 86. Зависимость коэффициента температуропроводности композита $a_{c}$ с матрицей из ПФО от объемной концентрации $\mathrm{C}_{\text {об }}$ меди.

Однако его прирост $\Delta a_{c}=a_{c}-a_{m}$, где $a_{m}$ - коэффициент температуропроводности матрицы, неоднозначно связан с коэффициентом температуропроводности наполнителя $a_{f}$. Например, значения $\Delta a_{c}$ композитов, наполненных 5 об. \% меди и угольного волокна различаются на $\approx 20 \%\left(4 \cdot 10^{7}\right.$ и $3,3 \cdot 10^{7} \mathrm{~cm}^{2} / \mathrm{c}$, соответственно). В тоже время коэффициент температуропроводности меди равен $1,2 * 10^{5} \mathrm{~cm}^{2} / \mathrm{c}$, а угольного волокна $-5,5^{*} 10^{6} \mathrm{~cm}^{2} / \mathrm{c}$, т.е. различаются в $\approx 20$ раз (см. таблицу 19.).

Коэффициенты температуропроводности $\mathrm{Cu}-1,2 * 10^{5} \mathrm{~cm}^{2} / \mathrm{c}$ и $\mathrm{Al}-$ $1,3 * 10^{5} \mathrm{~cm}^{2} / \mathrm{c}$ близки, а $\Delta \mathrm{a}_{\mathrm{c}}$ композитов, наполненных 5 об. \% $\mathrm{Cu}$ и $\mathrm{Al}$, отличается в $\approx 2,5$ раза $\left(4 \cdot 10^{7}\right.$ и $\left.1,6 \cdot 10^{7} \mathrm{~cm}^{2} / \mathrm{c}\right)$.

Эти результаты противоречат представлениям о том, что изменение температуропроводности обусловлено только ростом концентрации наполнителей. 
Таблица 19. Размеры и коэффициенты температуропроводности частиц наполнителей.

\begin{tabular}{|c|c|c|c|c|}
\hline \multirow[t]{2}{*}{ Наполнитель } & \multirow[t]{2}{*}{ Вид частиц } & диаметр & длина & $a_{\mathrm{f}} \cdot 10^{7}$ \\
\hline & & МКM & MM & $\mathrm{cm}^{2} / \mathrm{c}$ \\
\hline $\mathrm{Cu}$ & \multirow{2}{*}{ Порошки } & 3 & - & 1200 \\
\hline $\mathrm{Al}$ & & 0,1 & - & 1300 \\
\hline $\mathrm{SiC}$ & \multirow{2}{*}{$\begin{array}{l}\text { Нитевидные } \\
\text { кристаллы }\end{array}$} & 3,5 & 7 & 600 \\
\hline $\mathrm{TiO}_{2}$ & & 2,5 & 0,35 & 400 \\
\hline Угольное & \multirow{3}{*}{$\begin{array}{l}\text { Отрезки } \\
\text { волокон }\end{array}$} & 7 & 3 & 55 \\
\hline ПАБИ & & 15 & 3 & 0,3 \\
\hline Стеклянное & & 5 & 3 & 7 \\
\hline
\end{tabular}

Результаты расчетов коэффициента температуропроводности модели из параллельно или последовательно соединенных элементов с коэффициентами температуропроводности матрицы и наполнителя не согласуются с данными измерений. Так для композита, наполненного порошком меди, при параллельном соединении элементов расчетное значение $a_{c}$ оказалось на порядок больше измеренного, а при последовательном соединении - практически не зависит от концентрации наполнителя. Очевидно, что, подобрав концентрации параллельно и последовательно соединенных элементов можно было добиться удовлетворительного описания результатов расчета и эксперимента для композита при определенной концентрации наполнителя. Однако при изменении концентрации или вида наполнителя приходится заново подбирать концентрации таких элементов.

Выражение для коэффициента температуропроводности $a$ имеет вид [110]:

$$
a=\mathrm{S} \Lambda
$$

где $\Lambda$ - длина свободного пробега квантов колебаний молекул - фононов, а $S$ - скорость звука.

Как уже упоминалось, в последнее время накопились факты, показывающие, что в композитах вокруг частиц наполнителей образуются граничные слои матрицы, молекулы в которых укладываются парал- 
лельно поверхности наполнителя. При этом основной скелет молекул «выпрямляется», что обеспечивает их плотную укладку.

Температура стеклования ПФО составляет $\approx 480$ К. Поэтому при комнатной температуре молекулярная подвижность отсутствует и «выпрямление» цепных молекул вызывает исчезновение колебаний, соответствующих их «изгибам» (гош - изомерам). В результате резко уменьшается рассеяние колебаний, и увеличиваются длина свободного пробега квантов колебаний молекул - фононов [120] и скорость звука. Все это должно приводить к росту температуропроводности граничных слоев матрицы и композита. Эти представления были положены в основу другого подхода к описанию концентрационных зависимостей коэффициента температуропроводности.

Оценим среднее расстояние L между центрами частиц наполнителя в единицах их диаметра $\mathrm{L} / \mathrm{d}_{\mathrm{f}}$.

Сначала будем полагать, что частицы порошков имеют вид шаров. В этом случае величину $L / d_{f}$ можно оценить как:

$$
\frac{\mathrm{L}}{\mathrm{d}_{\mathrm{f}}} \approx \frac{1}{\sqrt[3]{\mathrm{C}_{\mathrm{oб}}}}
$$

Так как отрезки волокон и нитевидные кристаллы в композите укладываются приблизительно параллельно друг другу, среднее расстояние между их осями можно оценить, как:

$$
\frac{\mathrm{L}}{\mathrm{d}_{\mathrm{f}}} \approx \frac{1}{\sqrt{\mathrm{C}_{\text {об }}}}
$$

Анализ экспериментальных данных показал, что $\ln \Delta a_{\mathrm{c}}$ уменьшается линейно от относительного расстояния $\mathrm{L} / \mathrm{d}_{\mathrm{f}}$ между частицами наполнителя (рис. 87): 


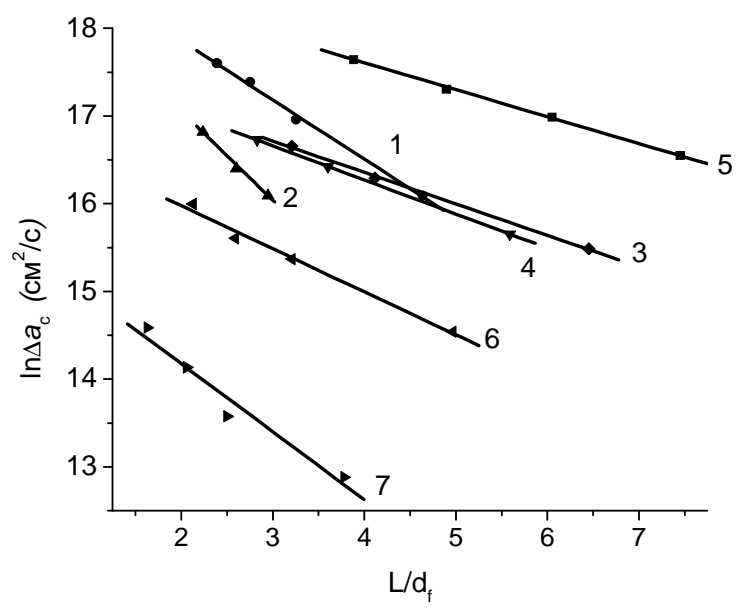

Рис. 87. Зависимость $\ln \Delta a_{c}$ композита с матрицей из ПФО от среднего расстояния между центрами частиц наполнителей: порошки - $\mathrm{Cu}$ (1) $\mathrm{Al}(2)$; нитевидные кристаллы - $\mathrm{SiC}(3)$ и $\mathrm{TiO}_{2}$ (4); отрезки волокон углеродные (5), стеклянные (6), ПАБИ (7).

$$
\ln \Delta \mathrm{a}_{\mathrm{c}} \approx \ln \Delta \mathrm{a}_{0}-\chi \frac{\mathrm{L}}{\mathrm{d}_{\mathrm{f}}}
$$

или

$$
\Delta \mathrm{a}_{\mathrm{c}} \approx \Delta \mathrm{a}_{0} \exp [-(\chi \mathrm{L} / \mathrm{d})],
$$

где $\Delta \mathrm{a}_{0}$ - значение прироста коэффициента температуропроводности композита при $\mathrm{L} \rightarrow 0$, a $\chi=\mathrm{d}\left(\Delta \mathrm{a}_{\mathrm{c}}\right) / \Delta \mathrm{a}_{\mathrm{c}}$ - относительное изменение его величины при единичном изменении $\mathrm{L} / \mathrm{d}_{\mathrm{f}}$.

Эти эмпирические выражения выполняются в диапазоне $\mathrm{L} / \mathrm{d}_{\mathrm{f}}=1,5$ - 7,5, или относительных расстояний между поверхностями частиц от 0,5 до 6,5. Очевидно, что они перестают быть справедливыми при 
$\mathrm{L} \rightarrow \mathrm{d}_{\mathrm{f}}$, когда образуются непрерывные теплопроводящие цепочки из частиц наполнителя и резко изменяется его коэффициент температуропроводности.

С другой стороны полученные результаты показывают, что граничный слой не имеет резкой границы. Оценим его толщину как расстояние, на котором величина $\Delta a_{c}$ уменьшается на порядок, по сравнению с эффективным предельным значением $\Delta \mathrm{a}_{0} \exp (-\chi)$.

Расчеты показали, что наибольшую толщину $\approx 60$ мкм этот слой имеет в композите, наполненном отрезками волокон ПАБИ, а наименьшую - $\approx 1$ мкм - в наполненном порошком Al. Композиты с другими наполнителями имеют промежуточные значения толщины граничных слоев.

Таким образом, изменение коэффициента температуропроводности композита при введении наполнителей вызвано образованием граничных слоев, температуропроводность которых больше, чем остальной матрицы.

Эмпирическое уравнение (35) позволяет прогнозировать изменение температуропроводности композита в зависимости от концентрации наполнителя.

\subsection{2. Теплоемкость композитов}

Если бы строение матрицы при введении наполнителя не изменялось, то теплоемкость композита $\mathrm{C}_{\mathrm{V}}$ являлась бы суммой теплоемкостей его составляющих и изменялась линейно от концентрации наполнителя. Однако оказалось [121], что на концентрационных зависимостях теплоемкости наблюдаются минимум при среднем расстоянии между поверхностями наполнителей $-\mathrm{L} / \mathrm{d}_{\mathrm{f}}-1 \approx 3$ (см. рис. 88).

Теплоемкость представляет собой количество энергии, которое затрачивается на возбуждение колебаний при изменении температуры на один градус. Поэтому изменение теплоемкости есть следствие изменения спектра молекулярных колебаний. В свою очередь спектр колебаний зависит от регулярности строения молекул матрицы и совершенства их укладки. Если молекулы полимера максимально выпрямлены, атомы в них уложены регулярно, и они не содержат изгибов (гош - изомеров) число их колебаний ограничено. 


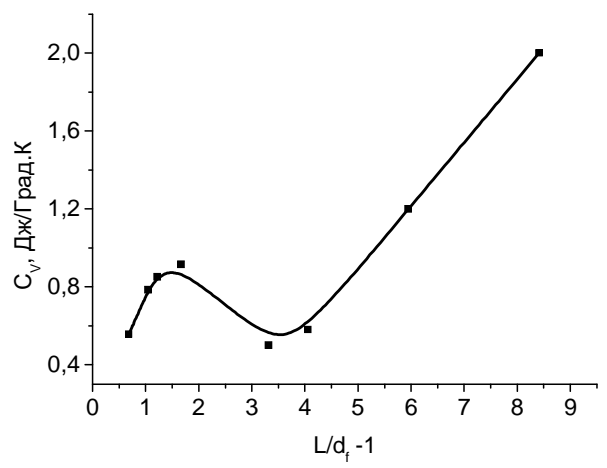

Рис. 88. Зависимости теплоемкости композита (матрица ПДФО, наполнитель отрезки стеклянных волокон) от среднего расстояния между их поверхностями волокон (в единицах диаметра).

Это колебания скелета молекулы, колебания боковых групп [38, 39] и скелета молекул. Любые нарушения регулярного строения молекул и их взаимной укладки ведут к появлению новых колебаний, локализованных на таких нарушениях. Отсюда следует, что уменьшение теплоемкости вызвано ростом регулярности строения полимерных молекул и их укладки.

Выясним теперь, причину появления минимума на зависимостях теплоемкости от среднего расстояния между частицами наполнителя.

В работе [35] исследовали кластеризацию различного вида объектов - трещин, нанодефектов, пятен коррозии, бактерий и т.д. при увеличении их концентрации. Установлено, что существует критическая концентрация рассмотренных объектов, при которой $\mathrm{L} / \mathrm{d}-1 \approx 3$ и составляющие начинают формировать кластеры. Кластеризация энергетически выгодна, т.к. она увеличивает конфигурационную энтропию системы и уменьшение теплоемкости.

Однако при малых расстояниях между частицами наполнителя (2 - 3 диаметра частиц наполнителя) кластеры начинают перекрываться. Наложение ведет к их разрушению. В результате энтропия начинает уменьшаться, а теплоемкость - увеличиваться. 


\section{2. Коэффициент теплового расширения композитов}

На всех концентрационных зависимостях коэффициента теплового расширения (КТР) $\beta$, независимо от вида и размера наполнителей (порошки или отрезки волокон), наблюдаются минимум, затем его значение увеличивается, достигает максимума и вновь уменьшается (рис. 89).

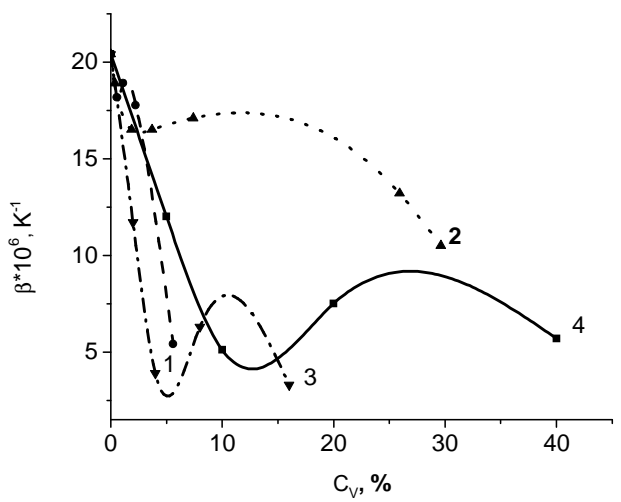

Рис. 89. Зависимость объемного значения КТР композита на основе ПДФО от объемной концентрации $\mathrm{C}_{\mathrm{V}}$ частиц наполнителя: 1 - $\mathrm{Cu}$ (порошок); 2 - $\mathrm{Al}$ (порошок), 3 -отрезки стеклянных волокон; 4 -отрезки углеродных волокон.

Рассчитаем $\beta$ композита, наполнителем в котором является порошок меди, по уравнению:

$$
\beta=\beta_{\mathrm{m}}\left(1-\mathrm{C}_{\mathrm{vol}}\right)+\beta_{\mathrm{f}} \tilde{\mathrm{N}}_{\mathrm{vol}}
$$

где $\beta_{\mathrm{m}}$ и $\beta_{\mathrm{f}} \mathrm{KTP}$ матрицы и наполнителя, соответственно, a $\mathrm{C}_{\mathrm{vol}}$ концентрация.

Из рис. 90 видно, что вычисленное по этому уравнению значение КТР значительно больше измеренного и уменьшается линейно от концентрации наполнителя. 


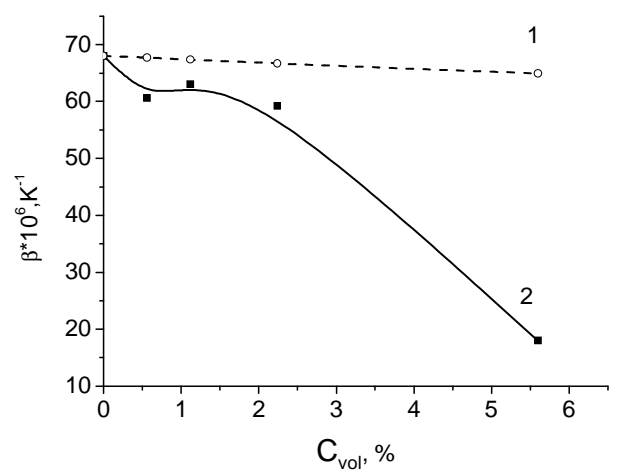

Рис. 90. Сравнение вычисленной (1) по уравнению (3.7) и экспериментальной (2) и зависимостей КТР композита от концентрации порошка меди.

Таким образом, уменьшение КТР композита не связано только с увеличением доли наполнителя с малым КТР, а имеет другую природу. По-видимому, оно обусловлено образованием граничных слоев матрицы вокруг частиц наполнителя.

Оценим толщину таких слоев. С этой целью построим зависимости КТР от среднего расстояния между поверхностями частиц наполнителя L. Будем полагать, что частицы порошков имеют вид шаров. B этом случае величину L можно оценить как:

$$
\mathrm{L}=\frac{\mathrm{d}}{\sqrt[3]{\mathrm{C}_{\mathrm{vol}}}}-\mathrm{d}
$$

На рис. 91 показаны зависимости КТР от L. Видно, что уже при концентрации $\mathrm{Cu} \approx 0,6 \%$ и $\mathrm{Al} \approx 0,4 \%$ КТР композита $\left(\approx 63 * 10^{6} \mathrm{~K}^{-1}\right)$ меньше вычисленного по уравнению $(3,7)\left(\approx 67 * 10^{6} \mathrm{~K}^{-1}\right)$. Среднее расстояние между поверхностями частиц Сu в этом случае составляет $\approx 5$ мкм, a $\mathrm{Al}-\approx 0,6$ мкм. Таким образом, в ПФО, наполненном порошком $\mathrm{Cu}$, толщина граничных слоев превышает 5 мкм, а порошком $\mathrm{Al}-0,6$ мКм. 

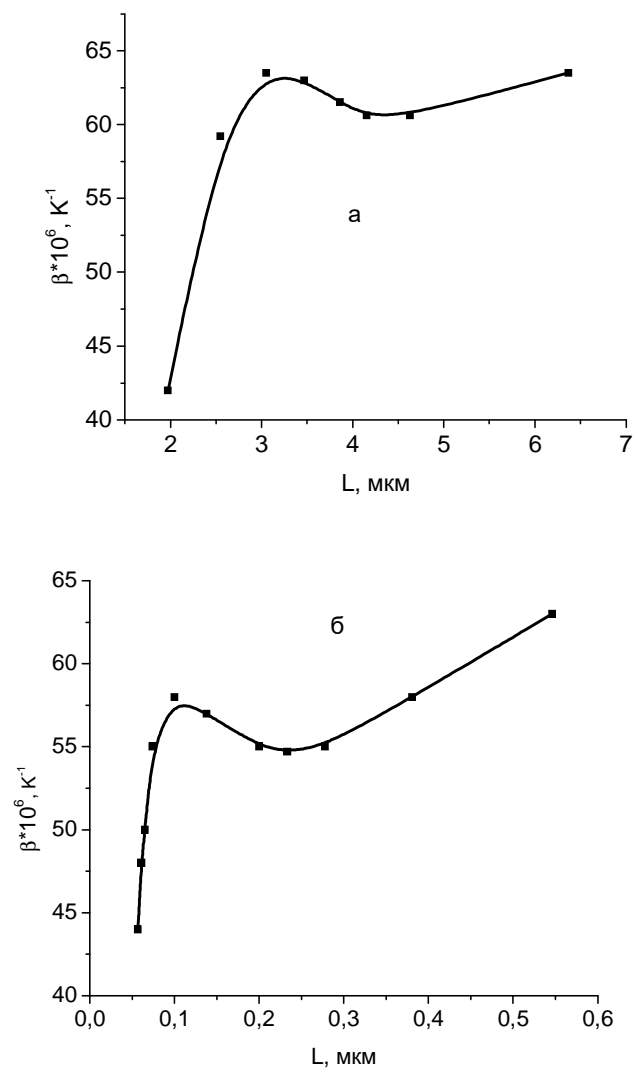

Рис. 91. Зависимости КТР композита от расстояния между поверхностями порошков меди (а) и алюминия (б).

Рассмотрим теперь случай, когда наполнителем служат отрезки волокон. Тогда среднее расстояние между их поверхностями L можно оценить, как:

$$
\mathrm{L} \approx \frac{\mathrm{d}}{\sqrt{\tilde{\mathrm{N}}_{\mathrm{vol}}}}-\mathrm{d}
$$


Зависимости $\beta=f(L)$ приведены на рис. 92.

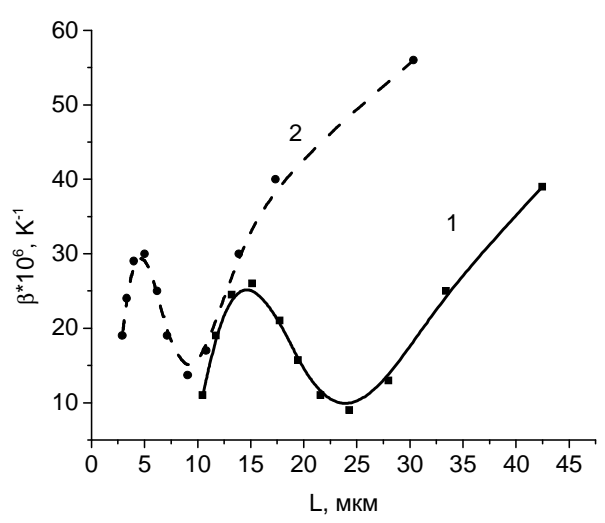

Рис. 92. Зависимости КТР композита от среднего расстояния между поверхностями угольных (1) и стеклянных (2) волокон.

Из рисунков 88 и 89 следует, что толщина граничных слоев в этом случае превышает 30 - 50 мкм.

Величина коэффициента теплового расширения $\beta$ пропорциональна теплоемкости $\mathrm{C}_{\mathrm{V}}$ [133] и обратно пропорциональна модулю упругости $\mathrm{E}_{\mathrm{p}}$ :

$$
\beta=\frac{\tilde{N}_{\mathrm{V}}}{\mathrm{E}_{\mathrm{p}} \mathrm{V}_{\mathrm{r}}}
$$

где $\mathrm{V}_{\mathrm{r}}$ - объем повторяющегося звена молекулы матрицы. Поэтому наблюдаемые концентрационные зависимости КТР представляют собой результат конкуренции двух концентрационных зависимостей модуля упругости и теплоемкости. 


\section{Заключение}

Взаимодействие между матрицей и наполнителем приводит к образованию между ними «граничных слоев», механические и теплофизические свойства которых отличны от свойств матрицы и наполнителя. Толщина таких слоев достигает сотен микрон и уже при малых концентрациях наполнителя они оказывают существенные влияние на механические и теплофизические свойства композитов. 


\section{Список использованных источников}

1. Журков С.Н. Кинетическая концепция прочности твердых тел. // Вестник АН СССР. 1957. Вып.11. С. 78 - 85.

2. Регель В.Р., Слуцкер А.И., Томашевский Э.Е. Кинетическая природа прочности твердых тел. М.: Наука 1974. 560 с.

3. Петров В.А., Башкарев А.Я., Веттегрень В.И. Физические основы прогнозирования долговечности конструкционных материалов. СПб.: Политехника. 1993 475c.

4. Arrhenius S. Über die Reaktionsgeschwindigkeit bei der Inversion von Rohrzucker durch Säuren. // Zeitschrift Physik. Chemie. (Leipzig). 1889. B. 4. S. 96-116.

5. Bailey J. Attempt to correlate some tensile strength measurement on glass // Glass industry. 1939. V. 20. N 1. P. 20-35.

6. Zhurkov S.N., Vettegren V.I., Novak I.I. Infrared Spectroscopic study in chemical bonds in stressed polymers. / Fracture 1969. Proc. Int. Conf. Fracture. L.: Chapman and Hall. 1969. P. 545-569,

7. V. I. Vettegren, I. I. Novak, K. J. Friedland. Overstressed interatomic bonds in stressed polymer. // Intern. J. Fracture. 1975. Vol. 11. No. 5. P. 789 $-801$.

8. В.И. Веттегрень, И. И. Новак Определение истинных напряжений на межатомных связях в нагруженных полимерах методом инфракрасной спектроскопии.// Физика твердого тела. 1973 Т. 15. Вып. 5. С. 1417 - 1422.

9. Vettegren V.I., Novak I.I. Determination of atomic stress distribution in stressed polymers by infrared spectroscopy. // J. Polymer Sci. Polymer Phys. 1973. Vol. 11. № 11. P. 2135 - 2142.

10.В.И. Веттегрень, А.Д. Габараева, Н.Л. Заалишвили. Изучение возбужденных химических связей в молекулах полиэтилена при помощи ИК - спектроскопии. // Высоком. Соед. (А). 2001, Т. 43. № 6, С. 988 995.

11.Siesler H.W., Holland-Mortz N. Infrared and Raman Spectroscopy of Polymers. N.Y.: Marcell Dekker. 1980.

12.Voroboboev V.M., Rasumovskaja I.V., Vettegren V.I. Deformation of interatomic bonds in polymers. // Polymer, 1978, Vol. 19, No. 11. P. 19671272.

13.Bronnikov S.V., Vettegren V.I., Frenkel S.Y. Kinetics of Deformation 
and Relaxation in Highly Oriented Polymers. // Adv. in Polymer Sci. 1996. Vol. 125, P. 103 - 146.

14.В.И. Веттегрень, Н.Р. Прокопчук, Л.Н. Коржавин, С.Я. Френкель, М.М. Котон. Прочность макромолекул полигетероариленов, содержащих имидный цикл в основной цепи. // Доклады А Н CССР. 1976. Т. 230. № 6. С. 1343-1346.

15.Веттегрень В.И., Кусов А.А. О природе перенапряженных межатомных связей в полимерах. // Физика твердого тела. 1982. Т. 24. Вып. 6. С. 1598-1605.

16.Абдульманов Р.Р., Веттегрень В.И., Воробьев В.М. Фононная температура перенапряженных межатомных связей в полимерах. // Высокомол. соед.. (А). 1984. Т. 26. С. 1830 - 1835.

17.Веттегрень В.И., Абдульманов Р.Р. Эволюция разрушающих флуктуаций плотности в полимерах. // Физика твердого тела. 1984. Т. 26. Вып. 11. С. 3266 - 3273.

18.Веттегрень В.И. Определение энергии активации и времени ожидания дилатонов в полимерах. // Физика твердого тела. 1986. Т. 28. С. $3417-3422$.

19.П. Ю. Бутягин, А. М. Дубинская, В. А. Радциг. Спектры ЭПР, конформация и химические свойства свободных радикалов в твердых полимерах. // Успехи химии. 1969. Т. 38. С. 593 - 623.

20.П. Ю. Бутягин. Кинетика и природа механохимических реакций // Успехи химии. 1971. Т. 40. С. 1935 - 1942.

21.П. Ю. Бутягин. Химическая физика твердого тела. М.: МГУ. 2006. $272 \mathrm{c}$.

22.H.H. Kausch. Polymer Fracture. Berlin: Springer. 1987. 456 p.

23.В.И. Веттегрень, А.И. Ляшков, А.В. Савицкий, И.П. Щербаков, К.Д. Васильев. Динамика микротрещин в полимерном композите при трении. // Журнал технической физики, 2012, Т. 82. Вып. 10. С. 124127.

24.И. Веттегрень, А.И. Ляшков, И.П. Щербаков. Влияние ориентации волокон на образование микротрещин в волокнистом полимерном композите при трении. // Журнал технической физики, 2010. Т. 80. Вып. 12. С. 115- 117.

25.В.И. Веттегрень, А.Я. Башкарев, А.И. Ляшков, Р.И. Мамалимов, А.В. Савицкий, И.П. Щербаков. Исследование образования микро- 
трещин в волокнистом композите при ударе и трении. // Проблемы материаловедения. 2012. Т. 57. С. 1445 - 1448.

26.С.Н. Журков, И.И. Новак, В.И. Веттегрень. Изучение механохимических превращений методом инфракрасной спектроскопии. // Доклады АН СССР. 1964. Т. 157. С. 1431-1433.

27.Велиев С.И., Веттегрень В.И., Новак И.И. Изучение разрушения полимеров под нагрузкой методом инфракрасной спектроскопии. // Механика полимеров, 1970. № 3. С. 433 - 436.

28. Велиев С.И., Корсуков В.Е., Веттегрень В.И., Шалаева Л.Ф., Новак И.И. Механохимические превращения в полимерах при ориентационной вытяжке. // Механика полимеров. 1971. № 3. С. 387 - 390.

29. В.Е. Корсуков, В.И. Веттегрень, И.И. Новак, Л.П. Зайцева. Кинетика деструкции полимеров в механически напряженном состоянии. // Высокомол. Соед.. (А) 1974. Т. 16. С. 1538 - 1542.

30.Велиев С.И., Санфирова Т.П., Веттегрень В.И. Долговечность полиолефинов в вакууме и на воздухе. // Высокомол. Соед. (Б) 1976. Т. 17. № 3. С. 183 - 185 .

31.В.И. Дырда, В.И. Веттегрень, В.П. Надутый. Исследование молекулярного механизма разрушения резин методом инфракрасной спектроскопии.// Каучук и резина. 1974. №10. С. 30 - 32.

32.Корсуков В.Е., Веттегрень В.И., Новак И.И., Зайцева Л.П. Кинетика деструкции полимеров в механически напряженном состоянии. // Высокомол. соед. (А). 1974. Т. 16. №7. С. 1538-1542.

33.В.И. Веттегрень, А.В. Савицкий, И.П. Щербаков. Фотолюминесценция продуктов деструкции полимеров при трении. // Письма в Журнал технической физики. 2008. Т. 34. Вып. 14. С. 88 -94.

34.Тамуж В.П., Куксенко В.С. Микромеханика разрушения полимерных материалов. Рига: Зинатне. 1978. 274 с.

35. Kilian H.G., Koepf M., Vettegren V.I. Model of reversible aggregation: universal feature of fluctuation ensembles. // Progress Colloid and Polymer Sci. 2001. Vol. 117. P. 172-181.

36. V.I. Vettegren, A.Ja. Bashkarev, V.N. Svetlov, G.I. Morozov. Hierarchy of Nano- and Microdefects at Surface of Loaded Metals. // Russian J. Phys. Chemistry. 2003., Vol. 77. Suppl.1. S. 163 - 166.

37.В.И. Веттегрень, А.Я. Башкарев, Р.И. Мамалимов, Р.К. Мамедов, И.П. Щербаков. Динамика вспышек люминесценции кварца и полиме- 
тилметакрилата при сухом трении. // Письма в Журнал технической физики. 2008. Т. 34. Вып. 10. С. 15 - 19.

38.J. Dechant, R. Danz, W. Kimmer, R. Schmolke. Ultrarotspektroskopische Untersuchungen an polymeren. Berlin: Akademie. 1972. $471 \mathrm{~s}$.

39.Painter P.C., Coleman M., Koenig J.L. The theory of vibrational spectroscopy and its application to the polymeric materials. NY: J.Wiley: 1986. $580 \mathrm{p}$.

40.Салганик Р.Л., Слуцкер А.И., Айдаров Х. Квантовые особенности кинетики разрушения твердых тел. // Доклады АН СССР. 1984. Т. 274. Вып. 6. С. 1362 - 1365.

41.Bronnikov S.V., Vettegren V.I., Frenkel S. Y. Description of the thermal and mechanical properties of the drawn polymers over a wide temperature range. // Polymer Eng. and Sci. 1992. V. 32, No. 17. P. 1204 - 1208.

42.Bronnikov S.V., Vettegren V.I., Frenkel S. Y. Description of the thermal and mechanical properties of the drawn polymers over a wide temperature range. // Polymer Eng. and Sci. 1992. Vol. 32, No. 17. P. 1204 - 1208.

43.Веттегрень В.И., Бронников С.В., Иброгимов И.И. // Влияние статистики молекулярных колебаний на кинетику разрушения ориентированных полимеров. // Высокомолекул. Соед. (А). 1994, Т. 36. С. $1331-1339$.

44.В.И. Веттегрень, В.Б. Кулик, С.В. Бронников. Температурная зависимость прочности полимеров и металлов в области высоких температур. // Письма в Журнал технической физики. 2005. Т.31. Вып. 22. С. $47-55$.

45.В.А. Сытов, В.В. Сытов, В.И. Веттегрень. Температурная зависимость прочности клеевых соединений стали 3 на основе эпоксикаучуковых клеев. // Известия Санкт-Петербургского государственного технологического института (технического университета). 2013. Т. 47. № 21. С. $102-105$.

46.В.И. Веттегрень, В.Б. Кулик, А.Я. Башкарев, А.А. Лебедев, В.А. Сытов. Температурная зависимость прочности адгезионной связи эпоксикаучуковых клеев и полиамидов в высокоэластическом состоянии со сталями. // Письма в Журнал технической физики. 2004. Т. 30. Вып. 20. С. 42-48.

47. Transitions and Relaxations in Polymers. In Journal Polymer Science. P. C. №14. American Chemical Symposium held Atlantic City, New Jersey, 
September 13-14, 1965. Interscience Publishers a Division of J. Willey \& Sons, Inc. 1966.380 p.

48. Berstein V.A., Egorov V.M. Differential Scanning Calorimetry of Polymers. NY: Ellis Horwood. 1994. 253 p.

49.В.И. Веттегрень, А.Я. Башкарев, А.В. Бараусов, А.Д. Габараева, В.А. Пикулин, А.В. Савицкий. Температурная зависимость прочности углеродного волокна и трехмерно армированного углерод - углеродного композита. // Журнал технической физики. 2008. Т. 78. Вып. 1. С. 63-67.

50.Вяткин С.Е. Деев А.Н., Нагорный В.Г. Ядерный графит. М.: Атомиздат. $1967.260 \mathrm{c}$

51.Семенович Г.М. Структура и свойства поверхностных слоев полимеров. Киев: Наукова Думка. 1972. 258 с.

52.Липатов Ю.С. Коллоидная химия полимеров. Киев: Наук. Думка. 1984. $344 \mathrm{c}$.

53.Gabaraeva A.D., Regel V.R., Filipov N.N., Leksovskij A.M. Faserforschung und Textiltechnik. 1978. B.29. N 1. S. 13 - 21.

54.Gi Xue, Jian Dong, Junfeng Zhang. Surface-Enhanced Raman Scattering Study of Polymer on Metal. 2. Molecular Chain Orientation of Polybenzimidazole and Poly(L-histidine) and Its Transition. // Macromolecules. 1991. Vol. 24. P. 4195-4198.

55.Firas Awaja, Michael Gilbert, Georgina Kelly, Bronwyn Fox, Paul J. Pigram. Adhesion of polymers. // Progress in Polymer Sci. 2009. Vol. 34. P. $948-968$.

56. Nakazava V. Mechanism of adhesion of epoxy resin to steel surface. // Nippon steel tech. rep. 1994. No. 63. P. 16-22.

57.Старостина И.А. Стоянов О.В. Кислотно-основные взаимодействия и адгезия в металл-полимерных системах. Казань: КГТУ. 2010. 195 с.

58.Ian Hamerton, Brendan J. Howlin, Peter Jepson. Metals and coordination compounds as modifiers for epoxy resins. // Coordination Chem. Rev. 2002. Vol. 224. P. 67-85.

59. Crabtree R,H. The Organometallic Chemistry of the Transition Metals. Fourth Ed. Yale New Haven: Wiley \& Sons. 2005. 546 p.

60.Скорчеллети В.В. Теоретическая электрохимия. Л.: Госхимиздат. 1959. $608 \mathrm{c}$.

61.Кукушкин Ю.Н. Реакционная способность координационных со- 
единений. Л.: Химия, 1987. 288 с.

62.В.И. Веттегрень, Р.И. Мамалимов, А.В. Савицкий, И.П. Щербаков, Сытов В.В., Сытов В.А.. Природа адгезионной связи между эпоксидным клеем и сталью. Журнал технической физики. 2014. Т. 84. Вып. 3. C. 133-136.

63.В.И. Веттегрень, А.Я. Башкарев, Р.И. Мамалимов, В.В. Сытов. Напряженное состояние и износостойкость полимерных покрытий. Физики твердого тела. 2015. Т.57. Вып.7. С. 1365 - 1370.

64.Supriti Sen, Sandipan Sarkar, Basab Chattopadhyay, Anuradha Moirangthem, Anupm Basu, Koushik Dhara, Pabitra Chattopadhyay Supporting Information. A Ratiometric Fluorescent Chemosensor for Iron: Discrimination of $\mathrm{Fe}^{2+}$ and $\mathrm{Fe}^{3+}$ and Living Cell Application. // Electronic Supplementary Material (ESI) for Analyst. 2012.

65.Huang Jinlong, Wang Bo, Ye Jianguo, Liu Bin, Qiu Huayu, Yin Shouchun A Highly Copper-Selective Ratiometric Fluorescent Sensor Based on BODIPY. // Chin. J. Chem. 2012. Vol. 30. P. 1857-1861. 66. Turro N.J. Molecular Photochemistry. NY: W.A. Benjamin, Inc. 1965. $328 \mathrm{p}$.

67.Nikolic, G.; Zlatkovic, S.; Cakic, M.; Cakic, S.; Lacnjevac, C; Rajic, Z. Fast Fourier Transform IR Characterization of Epoxy GY Systems Crosslinked with Aliphatic and Cycloaliphatic EH Polyamine Adducts// Sensors. 2010. Vol. 10, N 1, P. 684-696.

68.Jakes, J.; Krimm, S. Normal Coordinate Analyses of Molecules with the Amide Group" // Spectrochem. Acta 1971. Vol. 27. P. 19 - 34.

69.Ипатова И.П., Марадудин А.А. Валлис Р.Ф. К температурной зависимости ширины пика поглощения фундаментальных колебаний решетки ионных кристаллов. // Физика твердого тела. 1966. Т. 8. С. 1964 - 1970.

70.Chike K.E., Murick M.L. Lyon R.E., Angel S.M. Raman and near Infrared studies of an epoxy resin. // Appl. Spectroscopy. 1993. V 47. N. 10. P. 1631-1635.

71.В.И. Веттегрень, А.И. Слуцкер, Л.С. Титенков, В.Б. Кулик, В.Л. Гиляров. Возможности прямой оценки характеристик нулевой динамики в кристаллах полиэтилена. // Физика твердого тела. 2007, Т. 49, вып.2, С. 227 - 233. 
72.В. И. Веттегрень, В. Б. Кулик. Квантовая вибрационная динамика и деформация скелета полимерных молекул. // Высокомолекулярные соединения. (А). 2009. Т.51. №8. С. 1411 - 1420.

73.В.И. Веттегрень, А.И. Слуцкер, В.Л. Гиляров, В. Б. Кулик, Л.С. Титенков. Термическое расширение скелета цепных молекул в кристаллах полимеров. Физика твердого тела. 2003. Т. 45. Вып. 8. С. 15281534.

74. Socrates G. Infrared and Raman Characteristic Group frequencies. Tables and Charts. 3 Ed. Chichester: J. Wiley. 349 p.

75.K. Nakamoto. Infrared and Raman Spectra of Inorganic and Coordination Compounds. 4 Ed. , NY: J. Wiley. 350 p.

76.В.И. Веттегрень, С.А. Иваньков, Р.И. Мамалимов. Деформация химических связей в молекулах покрытия из полиамида 6 на поверхности стали. // Журнал технической физики. 2011. Т. 81. Вып. 10. С. 107113.

77.Веттегрень В.И., Башкарев А.Я., Лебедев А.А. Исследование внутренних напряжений в полимерном покрытии на поверхности металла при помощи ИК-спектроскопии // Механика композитных материалов. - 1990. - №6. - С. 978-983.

78. Чесноков Н.М. Количественная оценка внутренних напряжений в полимерных покрытиях металлопластмассовых цилиндров // Тр. ин-та / ЛПИ. - 1969. - С. $56-69$.

79.А. В. Стукач. Исследование термических напряжений в поверхностном слое полиамида при нагреве детали. Металлообработка. 2008. N 2. C. 24-27.

80.В.И. Веттегрень, А.Я. Башкарев, М.А. Суслов. Влияние формы частиц наполнителя на прочность полимерного композита. // Письма в Журнал технической физики. 2007. Т. 33. Вып. 20. С. 37-43.

81.Лурье А.И. Теория упругости. М: Наука. 1970. 939 с.

82.Крагельский И.В., Добычин М.Н., Комбалов В.С. Основы расчетов на трение и износ. М: Машиностроение. 1977. 826 с.

83.Белый В.А., Свириденок А.И., Петроковец М.И., Савкин В.Г.. Трение полимеров. М.: Наука, 1972. 202 с.

84.Башкарев А.Я. Андреев А.В. Применение полиамидных покрытий на плунжерных парах гидропривода. // Вестник машиностроения. 1980. №10. С. 26-29. 
85.В.И. Веттегрень, А.Я. Башкарев, М.А. Суслов. Кинетика трения и износа полимерных композиционных материалов. // Физика твердого тела. 2005. Т. 47. Вып. 9. С. 1619-1624.

86.Веттегрень В.И., Башкарев А.Я., Лебедев А.А. Определение "контактной" температуры в зоне трения антифрикционного полимерного покрытия по стали. // Письма в журнал технической физики. 2006, Т. 32, вып. 8. С. $78-82$.

87.А.Я. Башкарев, В.И. Веттегрень, А.А. Лебедев, А.В. Бараусов. Исследование механизма износа антифрикционного полиамидного покрытия в модели узла трения транспортных машин. // Научнотехнические ведомости СПб ГТУ. 2006. Т. 44. №2, С. 113 - 118.

88.А.С. Охотин, Р.П. Боровикова, Т.В. Нечаева, А.С. Пушкарский Теплопроводность твердых тел. М.: Энергоиздат. - 1984. - 320 с.

89.Bunn C.W. The crystal structure of long-chain normal paraffin hydrocarbons. The "shape" of the $\mathrm{CH}_{2}$ group. // Trans. Faraday Soc., 1939. V. 35. Р $482-491$.

90.Савицкий А.В., Носов М.П. Изменение прочности полиамидных волокон путем ориентационного вытягивания. // Химические волокна. 1978. №. 4. С. 13 - 15.

91.Савицкий А.В., Ляшков А.И. Устройство для пропитки ленточного волокнистого материала. // Патент РФ № 2054355, 24.08.1990.

92. Видерхорн С.// Чувствительность механических свойств к действию среды. М.: Мир, 1969. С. 309 - 327.

93.Журков С.Н. Эффект повышения прочности тонких нитей,// ЖТФ. 1934. Т. 4, № 9. С. 1640 -1652.

94.Спейдель М.О., Хитт М.В. // Достижения науки о коррозиии технология защиты от нее: Коррозионное растрескивание металлов. М.: Металлургия, 1985. С. 149 - 312.

95. Ребиндер П.А., Шрейнер Л.А., Жигач К.Ф. Понизители твердости в бурении. М.: Изд-во АН СССР, 1944.

96.Ребиндер П.А., Щукин ЕД. Поверхностные явления в твердых телах в процессах их деформации и разрушения // УФН. 1972. Т. 108, № 1 . C. 1 - 42 .

97. Асланова М.С. Влияние адсорбционно-активной среды на прочность стеклянных волокон // Доклады АН СССР. 1954. Т. 95, № 6. С. $1215-1218$. 
98. Бартенев Г.М. Сверхпрочные и высокопрочные неорганические стекла. М.: Стройиздат, 1974.

99. Лихтман В.И., Щукин Е. Д., Ребиндер П. А. Физикохимическая механика металлов. М.: Изд-во АН СССР, 1962.

100. Горюнов Ю.В., Перцов Н.В., Сумм Б.Д. Эффект Ребиндера. М., 1966. $92 \mathrm{c.}$

101. Берштейн В. А. Механогидролитические процессы и прочность твердых тел. Л.: Наука, 1987. 318 с.

102. Берштейн В.А., Егорова Л.М., Соловьев В.В. О разрушении полимеров по гидролитическому механизму // Мех. полимеров. 1977, № 5. С. $854-860$.

103. Берштейн В. А., Егорова Л. М., Соловьев В. В. 0 разрушении полимеров по гидролитическому механизму // Физика твердого тела. 1977. Т. 19. Вып. 3. С. 791-794. $168-171$.

104. В.И. Веттегрень, И.И. Новак, В.Б. Кулик. Тепловые и флуктуационные деформации химических связей в поверхностных и граничных слоях полимеров. // Физика твердого тела. 2005. Т. 47. Вып. 5. С. $893-898$.

105. V.I. Vettegren, A.E. Tshmel. The role of surface in atomic mechanism fracture of polymers// Europ. Polymer J. 1976. Vol. 12. P. 853 - 858 . 106. A.E. Tshmel, V.I. Vettegren,.V.M. Zolotarev. Investigation of the Molecular Structure of Polymer Surfaces by ATR Spectroscopy // J. Macromol. Sci.-Phys., 1982. Vol. B21. No 2. P. 243 - 256.

107. В.И. Веттегрень, И.И. Новак, Чмель А. Изменение концентрации продуктов деструкции на поверхности полимерных пленок. // Высокомол. Соед. (А). 1973. Т. 15. №8. С. 1909 - 1915.

108. В.И. Веттегрень, И.И. Новак, Чмель А. Разрывы межатомных связей на поверхности нагруженных полимеров. // Высокомол. Соед. (Б). 1975. Т. 17. №9. С. 665-668.

109. Zhang H., Ge X., Ye H. Effectiveness of the heat conduction reinforcement of particle filled composites. // Modelling Simul. Mater. Sci. Eng. 2005. Vol. 13. P. 401-412.

110. Kumlutas D., Tavman I.H. A Numerical and Experimental Study on Thermal Conductivity of Particle Filled Polymer Composites. // J. Thermoplastic Composite Materials 2006. Vol. 19. P. 441 - 445.

111. Mamunya Ye.P., Davydenko V.V., Pissis P., Lebedev E.V. Electrical 
and thermal conductivity of polymers filled with metal powders. // European Polymer J. 2002. Vol. 38. P. 1887 - 1897.

112. Sofian N. M., Neagu M. R., Neagu E. Metal Powder-Filled Polyethylene Composites. V. Thermal Properties. // J. Thermoplastic Composite Materials. 2001. Vol. 14. P. 20 -33.

113. Tekce H. S., Kumlutas D., Tavman I.H. Effect of Particle Shape on Thermal Conductivity of Copper Reinforced Polymer Composites. // J. Reinforced Plastics and Composites. 2007. Vol. 26. P. 113 - 121.

114. В.И. Веттегрень, А.Я. Башкарев, М.А. Суслов. Температуропроводность антифрикционных полимерных композитов. // Письма в Журнал технической физики. 2007. Т. 33. Вып. 20. С. 37 - 43.

115. Годовский Ю.К. Теплофизика полимеров. М.: Химия. 1982. 280 c.

116. В.И. Веттегрень, А.Я. Башкарев, М.А. Суслов. Влияние формы и концентрации частиц наполнителя на тепловое расширение полимерных композитов. // Журнал технической физики. 2007. Т. 77. Вып. 10. C. $135-138$. 